\title{
A decade of the Super Dual Auroral Radar Network (SuperDARN): scientific achievements, new techniques and future directions
}

\author{
G. Chisham - M. Lester $\cdot$ S. E. Milan - M. P. Freeman $\cdot$ W. A. Bristow \\ A. Grocott · K. A. McWilliams · J. M. Ruohoniemi · T. K. Yeoman • \\ P. L. Dyson · R. A. Greenwald · T. Kikuchi · M. Pinnock · J. P. S. Rash • \\ N. Sato · G. J. Sofko · J.-P. Villain · A. D. M. Walker
}

Received: 2 January 2007 / Accepted: 10 April 2007/Published online: 30 May 2007

(C) Springer Science+Business Media B.V. 2007

\begin{abstract}
The Super Dual Auroral Radar Network (SuperDARN) has been operating as an international co-operative organization for over 10 years. The network has now grown so that the fields of view of its 18 radars cover the majority of the northern and southern hemisphere polar ionospheres. SuperDARN has been successful in addressing a wide range of scientific questions concerning processes in the magnetosphere, ionosphere,
\end{abstract}

G. Chisham $(\bowtie) \cdot$ M. P. Freeman · M. Pinnock · J.-P.Villain

British Antarctic Survey, Natural Environment Research Council, High Cross,

Madingley Road, Cambridge CB3 OET, UK

e-mail: gchi@bas.ac.uk

M. Lester · S. E. Milan · A. Grocott · T. K. Yeoman

Department of Physics and Astronomy, University of Leicester, Leicester LE1 7RH, UK

W. A. Bristow

UAF Geophysical Institute, 903 Koyukuk Drive, Fairbanks, AK 99775, USA

K. A. McWilliams · G. J. Sofko

University of Saskatchewan, 116 Science Place, Saskatoon, SK, Canada S7N 5E2

J. M. Ruohoniemi · R. A. Greenwald

Applied Physics Laboratory, Johns Hopkins University, Laurel, MD20723, USA

P. L. Dyson

Department of Physics, La Trobe University, Victoria 3086, Australia

T. Kikuchi

Solar-Terrestrial Environment Laboratory, Nagoya University, Nagoya, Japan

J. P. S. Rash · A. D. M. Walker

School of Physics, University of KwaZulu-Natal, Durban 4041, South Africa

N. Sato

National Institute of Polar Research, Tokyo, Japan

J.-P.Villain

LPCE/CNRS, 3A, Avenue de la recherche Scientifique, Orleans 45071, France 
thermosphere, and mesosphere, as well as general plasma physics questions. We commence this paper with a historical introduction to SuperDARN. Following this, we review the science performed by SuperDARN over the last 10 years covering the areas of ionospheric convection, field-aligned currents, magnetic reconnection, substorms, MHD waves, the neutral atmosphere, and E-region ionospheric irregularities. In addition, we provide an up-to-date description of the current network, as well as the analysis techniques available for use with the data from the radars. We conclude the paper with a discussion of the future of SuperDARN, its expansion, and new science opportunities.

Keywords SuperDARN · Magnetosphere $\cdot$ Ionosphere $\cdot$ HF radar · Ionospheric convection · Magnetic reconnection - Substorms · Magnetic field-aligned currents · ULF waves · Gravity waves · Mesospheric winds · Ionospheric irregularities

\section{Introduction}

The Super Dual Auroral Radar Network (SuperDARN) (Greenwald et al. 1995a) has been in operation for over 10 years and is proving to be one of the most successful tools for studying dynamical processes in the Earth's magnetosphere, ionosphere, and neutral atmosphere. SuperDARN comprises similar ground-based coherent-scatter radars that operate in the high-frequency (HF) band and whose fields-of-view combine to cover extensive regions of both the northern and southern hemisphere polar ionospheres. The network was designed primarily for the measurement and study of plasma convection in the ionosphere but has proved successful for studying a wider range of magnetospheric and ionospheric phenomena. To date, $\sim 250$ publications in the Institute for Scientific Information (ISI) database refer to SuperDARN in the title or abstract and there are many others that make use of SuperDARN data. These publications have accrued over 2000 citations resulting in an average citation rate of $\sim 8$.

The origin of SuperDARN followed a number of years of experimentation with coherent-scatter radars. The first extensive use of coherent-scatter radars to study ionospheric convection at polar latitudes took place in the 1970s and 1980s with the development of the Scandinavian Twin Auroral Radar Experiment (STARE) (Greenwald et al. 1978). STARE comprised two radars that each transmitted radio signals in the very high frequency (VHF) range (at $400 \mathrm{MHz}$ ), simultaneously along 8 beams. The transmitted signals were backscattered from magnetic field-aligned irregularities in $E$-region electron density at locations where the transmitted radio wave was orthogonal to the magnetic field. From the backscattered signal the range, power and line-of-sight Doppler velocity of the $E$-region ionospheric irregularities were measured. Using two radars allowed the determination of both horizontal components of the irregularity drift velocity at $\sim 20 \mathrm{~km}$ resolution over a common viewing area of $\sim 400 \times 400 \mathrm{~km}$ in northern Scandinavia. The STARE system was used for studies of the two-dimensional structure and dynamics of ionospheric plasma convection (Nielsen and Greenwald 1979; Opgenoorth et al. 1983) and the study of ULF waves (Walker et al. 1979). However, the straight line propagation of VHF radio waves and the requirement that the wavevector be perpendicular to the magnetic field prohibited the use of these radars at higher latitudes, where the magnetic field becomes increasingly vertical, and limited the backscatter origin to E-region altitudes. 
Furthermore, the difference between ion and electron motion at E-region altitudes makes possible a range of irregularity wave modes with phase velocities that differ from the $\mathbf{E} \times \mathbf{B}$ drift velocity that STARE was designed to measure (Chen et al. 1995). For example, the E-region irregularities detected by STARE were often due to the two-stream drift instability. The motion of these irregularities is constrained to move at the ion acoustic velocity, which depends on the plasma temperature (Nielsen and Schlegel 1985).

At F-region altitudes, on the other hand, the virtual equivalence of the ion and electron drifts perpendicular to the magnetic field ensures that the drift of irregularities is at the $\mathbf{E} \times \mathbf{B}$ velocity. Hence, to make an accurate measurement of ionospheric plasma convection requires measuring the motion of irregularities in the ionospheric F-region. This can be achieved by using HF radars which utilize the refraction of HF radio waves by the ionosphere to achieve orthogonality of the transmitted waves with the Earth's magnetic field in the high-latitude E- and F-region ionospheres. Here, the transmitted signals are coherently backscattered from field-aligned decametre-scale ionospheric irregularities.

In October 1983, an electronically steerable, narrow beam, phased-array HF radar commenced operations at Goose Bay, Labrador (Greenwald et al. 1985). The radar is still operational today and comprises a main array of $16 \log$-periodic antennae which transmit and receive radio signals in the $\mathrm{HF}$ frequency range from $8 \mathrm{MHz}$ to $20 \mathrm{MHz}$. The standard 16-beam scan employed by the radar creates a field of view that extends $\sim 52^{\circ}$ in azimuth, and from $\sim 200 \mathrm{~km}$ to more than $3,000 \mathrm{~km}$ in range. The range resolution of the measurements is determined by the transmitted pulse length, which is $300 \mu$ s (equivalent to $45 \mathrm{~km}$ range) in the common modes of operation. The temporal resolution of complete scans of the field of view is either 1 or $2 \mathrm{~min}$ in these common modes. The backscattered signals are sampled and processed to produce multi-lag complex autocorrelation functions (ACFs) as a function of range. The ACFs are fitted by standard functions to estimate the backscattered power, the line-of-sight Doppler velocity of the irregularities, and the width of the Doppler power spectrum for each range where there are significant returns (e.g., Hanuise et al. 1993b; Baker et al. 1995). Goose Bay was, in essence, the first SuperDARN radar and every other subsequent SuperDARN radar has followed this original design and mode of operation.

The development of the Goose Bay radar made possible correlative experiments with the incoherent scatter radar at Sondrestrom, Greenland, that confirmed the equivalence of the F-region irregularity and $\mathbf{E} \times \mathbf{B}$ convection drift velocities (Ruohoniemi et al. 1987). The Goose Bay radar was also successful in providing the first HF radar studies of magnetospheric ULF waves (Ruohoniemi et al. 1991; Samson et al. 1991; Walker et al. 1992) and atmospheric gravity waves (Samson et al. 1990; Bristow et al. 1994). Subsequently, another, almost identical, radar was built at Halley, Antarctica with a geomagnetically conjugate field of view. The Halley radar commenced operation in January 1988, and the joint project was named the Polar Anglo-American Conjugate Experiment (PACE), providing simultaneous conjugate observations of ionospheric and magnetospheric phenomena. PACE was particularly successful in studies of the cusp, identifying signatures of the cusp in HF backscatter (Baker et al. 1995), illustrating the differences in transitions in the cusp-region convection pattern in the two hemispheres in response to changes in the direction of the $y$-component of the interplanetary magnetic field (IMF) (Greenwald et al. 1990), and identifying the first spatial signatures of the footprints of flux transfer events (FTE) in the ionospheric cusp (Pinnock et al. 1991, 1993). It was also used to study interhemispheric asymmetries in the location of the Harang discontinuity in the nightside ionosphere (Dudeney et al. 1991). 
It was soon apparent that the primary limitation of PACE was that only one velocity component was available from the spatial volume probed by each radar. Techniques had been developed to process the line-of-sight velocity data into two-dimensional ionospheric convection maps. The most common technique was called L-shell fitting — a sophisticated implementation of the beam-swinging technique used by incoherent scatter radars. It estimated the full velocity vector by testing for a sinusoidal variation of the line-of-sight velocity with look angle, assuming constancy of the velocity at constant magnetic latitude (Hanuise et al. 1985; Ruohoniemi et al. 1988). At times the solution could be extended to neighbouring regions with no data coverage by applying the condition that the overall flow be divergence-free, i.e., $\nabla \cdot \mathbf{v}=0$, which is valid as the ionospheric plasma is approximately incompressible (Ruohoniemi et al. 1989). However, it was later shown that curvature in the true convection flow could cause serious errors in the L-shell fitting velocity vector determination, even when the sinusoidal variation test was satisfied (Freeman et al, 1991).

Consequently, it was recognized that definitive determination of the full two-dimensional velocity vector requires measurements within a common backscattering volume from at least two radars with different look directions. A further HF radar in Schefferville, Quebec, had become operational in October 1989 and provided this bistatic capability in combination with Goose Bay. The first instantaneous mapping of two-dimensional flows using these two HF radars was reported by Hanuise et al. (1993a) but the small spatial separation between the radars limited the bistatic velocity determinations to nearer ranges. However, the observations demonstrated the viability of bi-directional common volume observations at HF frequencies.

This work led to the concept of SuperDARN; a network of HF radars operating in pairs with common viewing areas so that the Doppler information contained in the backscattered signals could be combined to yield maps of high-latitude ionospheric convection (Greenwald et al. 1995a). Since 1993, 16 more radars have been built (see Table 1), making SuperDARN a truly international operation. SuperDARN now comprises 4 such pairs from the 11 radars in the northern hemisphere, and 5 pairs from the 7 radars in the southern hemisphere. The fieldsof-view of the present SuperDARN radars (in 2006) are presented in Fig. 1. SuperDARN has provided a very successful model for creating and operating a large scientific instrument infrastructure. In the last 10 or so years, the SuperDARN community has been largely selforganizing, sharing hardware and software resources between different groups, and providing financial and in-kind contributions from international partners towards the building costs of new radars by others. This has resulted in a co-operative organization that is bureaucratically light and that provides science that is good value for money.

The original science planning for SuperDARN demonstrated that such a network would be particularly suited to studies of large-scale dynamical processes in the magnetosphereionosphere system, such as the evolution of the global configuration of the convection electric field under changing IMF conditions and the development and global extent of large-scale MHD waves in the magnetosphere-ionosphere cavity. The principal research objectives identified by Greenwald et al. (1995a), the seminal SuperDARN paper, were (with section references in the present paper in brackets):

- Structure of global convection-to provide a global-scale view of the configuration of plasma convection in the high-latitude ionosphere (see Sect. 2.2).

- Dynamics of global convection-to provide a global-scale view of the dynamics of plasma convection in the high-latitude ionosphere. (Previous studies of high-latitude convection had largely been statistical and time-averaged) (see Sect. 2.3). 
Table 1 Details of all the current SuperDARN radars

\begin{tabular}{|c|c|c|c|c|c|}
\hline \multicolumn{6}{|l|}{ Current SuperDARN Radars } \\
\hline \multirow[t]{2}{*}{ Radar name } & \multicolumn{2}{|c|}{ Code } & \multirow[t]{2}{*}{ Commenced operation } & \multicolumn{2}{|c|}{ Geographic co-ordinates } \\
\hline & Old & New & & Latitude & Longitude \\
\hline \multicolumn{6}{|l|}{ Northern hemisphere } \\
\hline Goose Bay & $\mathrm{g}$ & gbr & Oct 1983 & $53.32^{\circ} \mathrm{N}$ & $60.46^{\circ} \mathrm{W}$ \\
\hline Kapuskasing & $\mathrm{k}$ & kap & Sep 1993 & $49.39^{\circ} \mathrm{N}$ & $82.32^{\circ} \mathrm{W}$ \\
\hline Saskatoon & $\mathrm{t}$ & sas & Sep 1993 & $52.16^{\circ} \mathrm{N}$ & $106.53^{\circ} \mathrm{W}$ \\
\hline Iceland West (Stokkseyri) & $\mathrm{w}$ & sto & Aug 1994 & $63.86^{\circ} \mathrm{N}$ & $22.02^{\circ} \mathrm{W}$ \\
\hline CUTLASS Finland (Hankasalmi) & $\mathrm{f}$ & han & Jun 1995 & $62.32^{\circ} \mathrm{N}$ & $26.61^{\circ} \mathrm{E}$ \\
\hline CUTLASS Iceland East (Pykkvibaer) & $\mathrm{e}$ & pyk & Nov 1995 & $63.86^{\circ} \mathrm{N}$ & $19.20^{\circ} \mathrm{W}$ \\
\hline Kodiak & $\mathrm{a}$ & kod & Jan 2000 & $57.60^{\circ} \mathrm{N}$ & $152.20^{\circ} \mathrm{W}$ \\
\hline Prince George & $\mathrm{b}$ & pgr & Mar 2000 & $53.98^{\circ} \mathrm{N}$ & $122.59^{\circ} \mathrm{W}$ \\
\hline King Salmon & $\mathrm{c}$ & $\mathrm{ksr}$ & Oct 2001 & $58.68^{\circ} \mathrm{N}$ & $156.65^{\circ} \mathrm{W}$ \\
\hline Wallops Island & $\mathrm{i}$ & wal & Jun 2005 & $37.93^{\circ} \mathrm{N}$ & $75.47^{\circ} \mathrm{W}$ \\
\hline Rankin Inlet & - & rkn & May 2006 & $62.82^{\circ} \mathrm{N}$ & $93.11^{\circ} \mathrm{W}$ \\
\hline \multicolumn{6}{|l|}{ Southern hemisphere } \\
\hline Halley (SHARE) & $\mathrm{h}$ & hal & Jan 1988 & $72.52^{\circ} \mathrm{S}$ & $26.63^{\circ} \mathrm{W}$ \\
\hline Syowa South & $\mathrm{j}$ & sys & Feb 1995 & $69.00^{\circ} \mathrm{S}$ & $39.58^{\circ} \mathrm{E}$ \\
\hline Sanae (SHARE) & $\mathrm{d}$ & san & Feb 1997 & $71.68^{\circ} \mathrm{S}$ & $2.85^{\circ} \mathrm{W}$ \\
\hline Syowa East & $\mathrm{n}$ & sye & Feb 1997 & $69.01^{\circ} \mathrm{S}$ & $39.61^{\circ} \mathrm{E}$ \\
\hline Kerguelen & $\mathrm{p}$ & ker & Jun 2000 & $49.35^{\circ} \mathrm{S}$ & $70.26^{\circ} \mathrm{E}$ \\
\hline TIGER Tasmania & $\mathrm{r}$ & tig & Jan 2001 & $43.38^{\circ} \mathrm{S}$ & $147.23^{\circ} \mathrm{E}$ \\
\hline TIGER Unwin & $\mathrm{u}$ & unw & Nov 2004 & $46.51^{\circ} \mathrm{S}$ & $168.38^{\circ} \mathrm{E}$ \\
\hline
\end{tabular}

- MHD waves - to measure the energy influx from MHD waves on a larger spatial scale than previously possible (see Sect. 6).

- Substorms - to test various theories of polar cap expansion and contraction under changing IMF conditions and observe the large-scale response of the nightside convection pattern to substorms (see Sect. 5).

- Gravity waves (see Sect. 7.1).

- High-latitude plasma structures.

- Ionospheric irregularities (see Sect. 8).

In this paper we review how SuperDARN has been used to address these objectives. In addition, SuperDARN has also contributed to other areas of magnetospheric and ionospheric science not originally anticipated. These include the structure and dynamics of meso-scale convection (Sect. 2.4), the study of field-aligned currents (FAC) (Sect. 3), the remote sensing of magnetic reconnection (Sect. 4), and mesospheric phenomena (Sects. 7.2, 7.3). We also discuss the data analysis techniques that have been developed over the last 10 years which have facilitated these advances and which have made SuperDARN data more accessible to the scientific community. We conclude by discussing the future of SuperDARN, the expansion of the network and new scientific objectives which can be addressed in the next decade of operations. The emphasis in this paper is on studies in which SuperDARN has been the major instrument used to deliver the science. However, it 

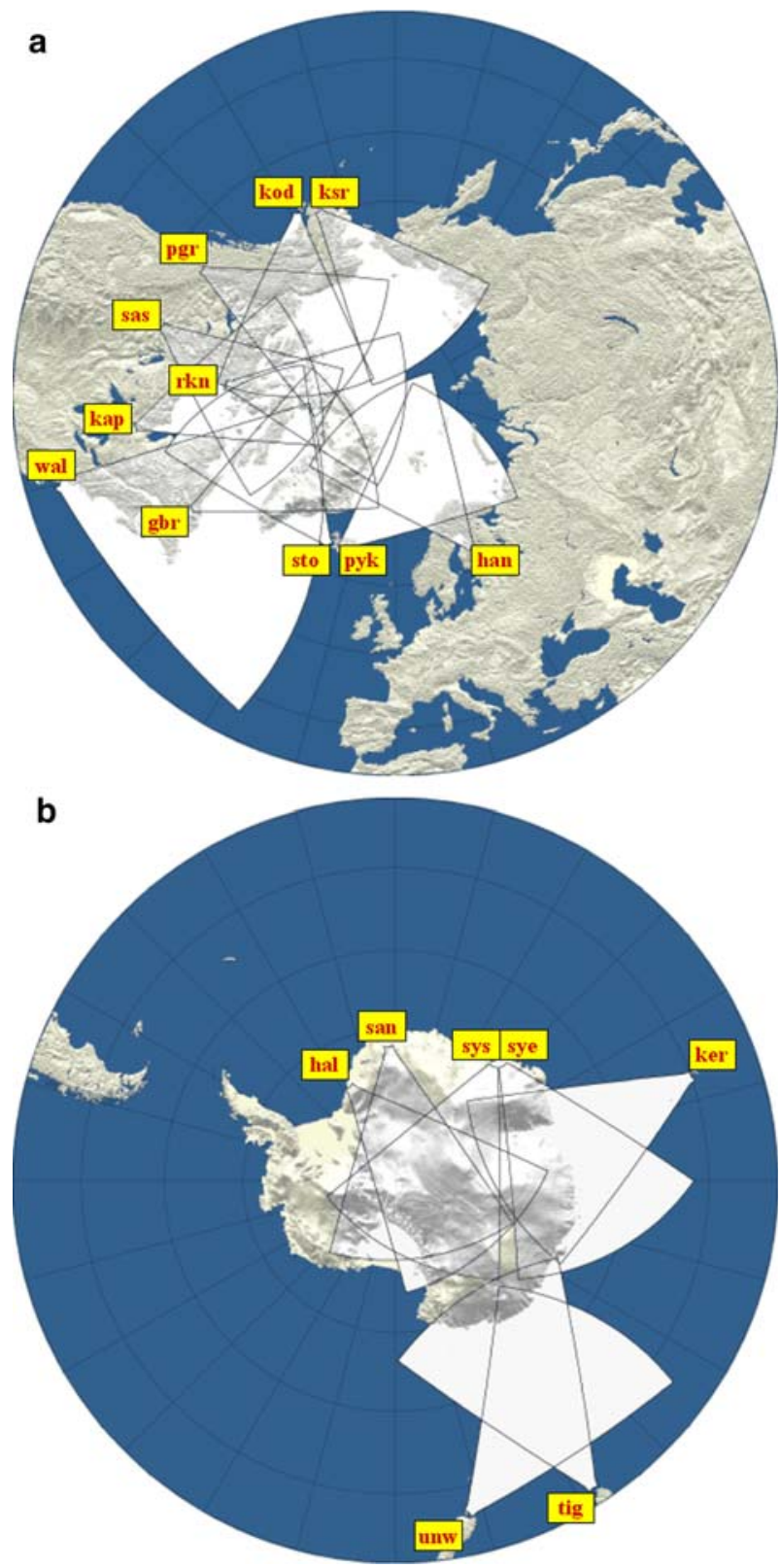

Fig. 1 Fields of view of the SuperDARN radars in the northern (a) and southern (b) hemispheres. The code name of each radar is highlighted in red close to the radar location. The full names and locations of all the radars can be found in Table 1

should be noted that there are a large number of significant satellite, data assimilation, and modelling-centric studies in which SuperDARN data have played an important supporting role (e.g., Lu et al. 2001; Maynard et al. 2003; Trattner et al. 2003; Farrugia et al. 2004; Trattner et al. 2005; Palmroth et al. 2005), which are not discussed here. 


\section{Ionospheric convection}

\subsection{Measuring global convection}

When SuperDARN was first conceived its principal research objective was to measure the global configuration and dynamics of plasma convection in the high-latitude ionosphere, an important diagnostic of energy transfer from the solar wind into the magnetosphere and ionosphere. Before the advent of SuperDARN, global studies of high-latitude convection had been largely statistical (Kamide et al. 1982; Friis-Christensen et al. 1985; Heppner and Maynard 1987; Rich and Hairston 1994, Papitashvili et al. 1994; Weimer 1995), due to the limited spatial extent of the contributing data sets, with studies of the dynamics of convection being limited to the small $(\sim 10 \mathrm{~km})$ or meso-scale $(\sim 100 \mathrm{~km})$. SuperDARN allowed the measurement of convection on a more global scale. The use of HF frequencies meant that the SuperDARN radars measured the Doppler velocity of F-region irregularity backscatter targets moving with the ambient plasma at the $\mathbf{E} \times \mathbf{B}$ convection velocity (Ossakow and Chataverdi 1979; Tsunoda 1988). The equivalence of these velocities was first shown for HF radar backscatter by Villain et al. (1985) and later by Ruohoniemi et al. (1987) using Goose Bay data. Further larger-scale statistical studies using other SuperDARN radars confirmed this relationship (Davies et al. 1999, 2000; Milan et al. 1999a; Xu et al. 2001; Drayton et al. 2005).

In order to provide a global-scale view of ionospheric convection it was necessary to devise a method to combine SuperDARN data from different radars. Early on, it was agreed that the most accurate results would be obtained by vectorially merging line-of-sight velocity measurements within the common fields-of-view of pairs of radars. This led to the development of the "Merge" algorithm (Cerisier and Senior 1994), which still remains the definitive method for measuring the convection velocity. Data from an early bistatic pair of SuperDARN radars at Kapuskasing and Saskatoon were combined using Merge to map, for the first time, a reverse dayside convection cell under northward IMF conditions (Greenwald et al. 1995b). As more radars were added to the network, the spatial coverage afforded by bistatic SuperDARN measurements increased from meso- ( hundreds of $\mathrm{km}$ ) to global ( $\sim$ thousands of $\mathrm{km}$ ) scales. The drawback of the Merge algorithm was that it could not make use of line-of-sight velocity measurements in regions where backscatter from only one radar was present, which usually constituted the bulk of the dataset. Efforts were made to adapt the old single-station techniques (like L-shell fitting) to augment the vector solutions but these were eventually abandoned in favour of a new approach.

The new approach was to find a functional form for the distribution of electrostatic potential in the ionosphere, $\Phi$, that 'best-fit' all the line-of-sight velocity measurements available at the time of interest. The convection velocity $\mathbf{v}$ is related to $\Phi$ through the relationships

$$
\mathbf{E}=-\nabla \Phi
$$

and

$$
\mathbf{v}=\frac{\mathbf{E} \times \mathbf{B}}{B^{2}}
$$

The algorithm for the implementation of this method is described by Ruohoniemi and Baker (1998). The first step is to map the line-of-sight velocity measurements onto a global 
grid of nearly equal-area grid cells measuring $1^{\circ}$ in geomagnetic latitude. While not strictly necessary, this aids in the visualization of the SuperDARN velocity products, provides benefits in terms of processing efficiency, and renders estimates of the velocity variability that can be applied as uncertainties in the fitting. An example of these gridded line-of-sight velocity data, using data from 8 of the northern hemisphere SuperDARN radars, is shown in Fig. 2a. At a glance one can appreciate the extent and general character of the velocity information. (It is also possible to perform a Merge-type vectorial analysis where gridded velocity measurements from different radars overlap).

In the next step of the analysis the gridded velocity data are fitted to an expansion of $\Phi$ in terms of spherical harmonic functions

$$
\Phi(\theta, \phi)=\sum_{l=0}^{L} \sum_{m=0}^{\operatorname{Min}(l, M)}\left(A_{l m} \cos m \phi+B_{l m} \sin m \phi\right) P_{l}^{m}(\cos \theta)
$$

where the $P_{l}^{m}$ are the associated Legendre functions. $L$ and $M$ express the order and degree of the expansion, respectively, and the values of these parameters determine the resolution available in the fitting. (It is useful to note that an $L=8$ expansion is usually sufficient to resolve fully at $100 \mathrm{~km}$ resolution a one-dimensional profile of the velocity component orthogonal to a line that transits the polar cap, such as might be obtained from a pass of a low-altitude satellite). The coefficients of the expansion $A_{l m}$ and $B_{l m}$ express the physical content of the solution and are found by performing a singular-value decomposition. The global fitting technique is implemented with a package of software known as "Map Potential", which is also used as a name for the technique. Statistical comparisons of vectors derived using this method with vectors derived using the Merge technique showed that the Map Potential technique is significantly more successful at estimating the convection flow than the original L-shell fitting technique (Provan et al. 2002).

The result for an $L=8$ fit, applied to the line-of-sight velocity data presented in Fig. 2a, is shown in Fig. 2b. The colour-coded velocity vectors represent the fitted velocities at the locations of the line-of-sight velocity data input. The contours of constant electrostatic potential (solid and dashed black lines) also represent flow streamlines for the whole polar ionosphere. The convection pattern consists of two convection cells with antisunward flow across the polar cap that returns to the dayside via sunward flow on the dawn and dusk flanks. The total cross polar cap potential, $\Phi_{P C}$, determined between the centres of the two convection cells, is $117 \mathrm{kV}$ in this case. By combining the data from all northern hemisphere SuperDARN radars, we have effectively 'imaged' the global convection electric field, obtaining a result that is analogous to space-based images of the global distribution of auroral luminosity. One should remember, however, that the solution is optimized in a global sense and meso-scale or small-scale convection studies are best addressed by using local radar data at the highest possible resolution and taking advantage of the commonvolume aspect of the measurements. Also, care must be taken with all SuperDARN convection studies as it is sometimes difficult to distinguish between F-region, E-region and ground backscatter. E-region and ground backscatter are a contaminating factor in ionospheric convection measurements (Chisham and Pinnock 2002).

The line-of-sight velocity dataset used as input for the convection maps is often spatially extensive (as shown in Fig. 2a), but not truly global. To ensure that the solution is realistic over areas of sparse radar coverage, the velocity data are supplemented with data from a statistical model. The selection of model data is keyed to the IMF conditions presumed to prevail at the magnetopause at the time of interest using suitably time-lagged 
a $04 / 06 / 2000$

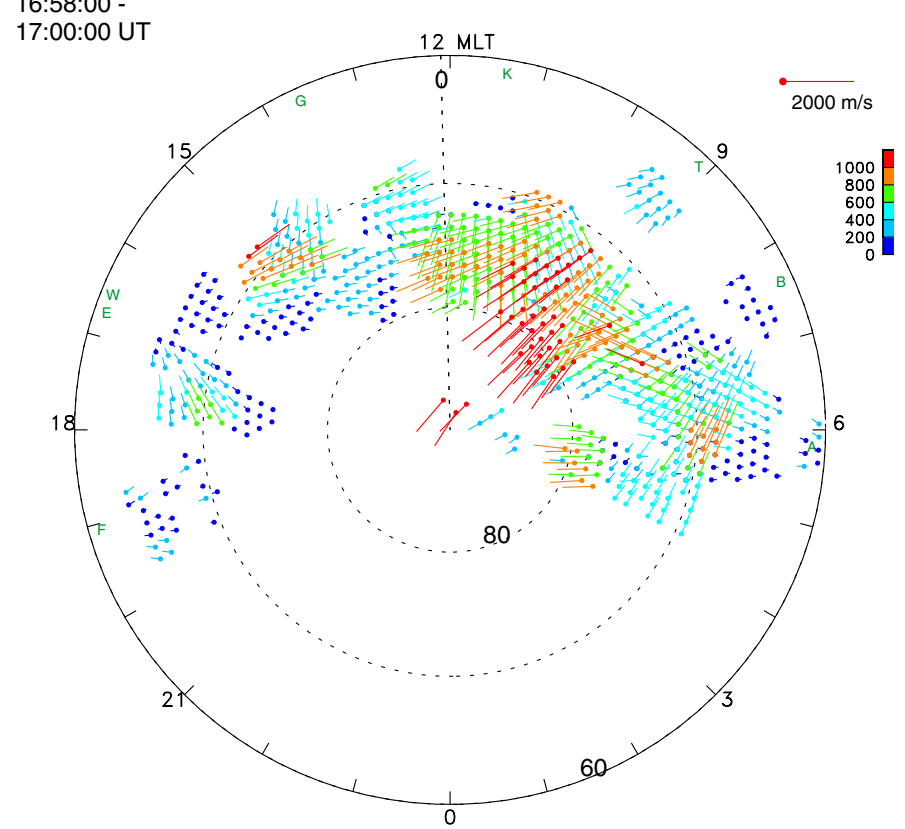

Nrads $/ \mathrm{N}=8 / 810$

b $\quad \begin{gathered}\text { 04/06/2000 } \\ 16: 58: 00 ~- \\ 17: 00: 00 \text { UT }\end{gathered}$

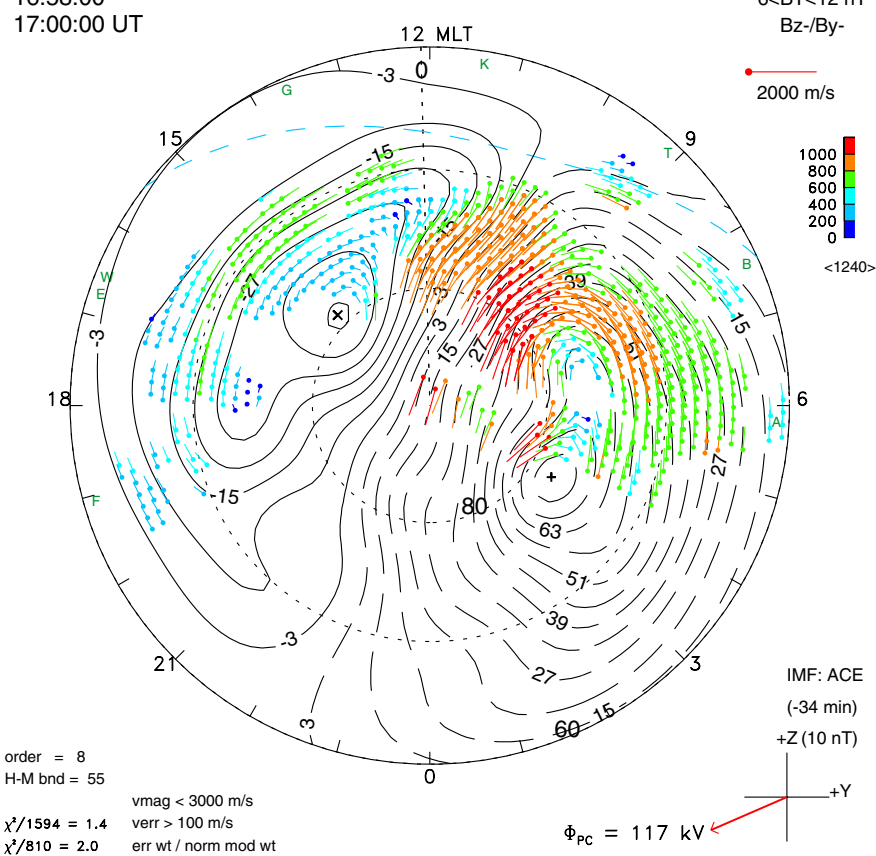


4 Fig. 2 (a) The line-of-sight Doppler velocities measured by the northern hemisphere SuperDARN radars in the 1658-1700 UT interval on April 6, 2000. (b) The Map Potential ionospheric convection map for the same interval. Both maps are presented in a geomagnetic latitude-MLT coordinate system, with magnetic local midnight at the bottom, noon at the top, dawn to the right, and dusk to the left. The small coloured dots show the origin of the velocity vectors and the length and colour of the vectors indicate the magnitude of the flow (see colour table for scale). Flow vectors are only shown in regions where there was line-of-sight velocity input. The full equipotential solution is shown in (b) by the solid (afternoon convection cell) and dashed (morning convection cell) black lines. The dashed blue line (only visible in the dayside ionosphere) represents the Heppner-Maynard convection boundary which constrains the extent of the mapping. The letters at different MLTs mark the MLT locations of the radars that contributed data to the map (see Table 1, Fig. 1). At the bottom right of panel (b) is shown the projection of the prevailing IMF (red arrow) onto the Y-Z GSM plane, and the maximum potential difference across the polar cap $\left(\Phi_{\mathrm{PC}}\right)$ determined from the mapping

data from spacecraft situated in the solar wind. In this case the IMF was measured by the ACE spacecraft with a time lag of $34 \mathrm{~min}$, and its projection in the Y-Z GSM plane is shown in the bottom right of Fig. 2b. The model data are weighted in the fitting so as to just stabilize the solution while minimizing the impact of the statistical model, as discussed by Shepherd and Ruohoniemi (2000). Improvements in the statistical model aspect of the convection mapping technique are continually under development and the continued expansion of the SuperDARN network (see Sect. 9.1) reduces the reliance of the maps on the model data. It is also useful to downweight line-of-sight velocity data outside the equatorward boundary of the convection zone that derives from the work of Heppner and Maynard (1987). In Fig. 2b the Heppner-Maynard boundary is depicted as a dashed blue line. The latitude of this boundary in the midnight meridian $\left(55^{\circ}\right.$ in this case) characterizes the size of the convection zone.

The continued expansion of the SuperDARN network has made possible spatially continuous velocity observations over a sector that exceeds $12 \mathrm{~h}$ of magnetic local time (MLT). As shown by Shepherd and Ruohoniemi (2000), the coverage provided by the radars is sometimes sufficient to effectively determine the entire global convection pattern, i.e., the solution for $\Phi_{P C}$ becomes independent of the selection of statistical model data. This optimal circumstance is presently realized most often in the 1200-2200 UT interval when the radars span the dayside ionosphere and resolve the flows completely between the locations of the centres of the convection cells.

Global convection maps can be generated at the 1- or 2-min resolution of the radar scans, which is suitable for observing the response of ionospheric convection to changes in the solar wind and the IMF. Using internet links to many of the radars, a near real-time mapping of the ionospheric convection pattern is now also possible. Convection patterns are automatically generated and posted to the JHU/APL web site (http://superdarn.jhuapl.edu/) (Ruohoniemi et al. 2001). With the planned extension of the SuperDARN network, global convection mapping in both hemispheres is likely to become a routine SuperDARN data product.

\subsection{The structure of global convection}

The large-scale morphology of ionospheric convection, and its dependence on the prevailing IMF conditions, has been well understood for a number of years, mainly as a result of statistical studies using low-altitude spacecraft (Heppner and Maynard 1987; Rich and Hairston 1994; Weimer 1995) and ground magnetometers (Kamide et al. 1982; FriisChristensen et al. 1985; Papitashvili et al. 1994). Early SuperDARN studies provided a statistical characterization of nightside convection (Ruohoniemi and Greenwald 1995), 


\section{5-10 nT}
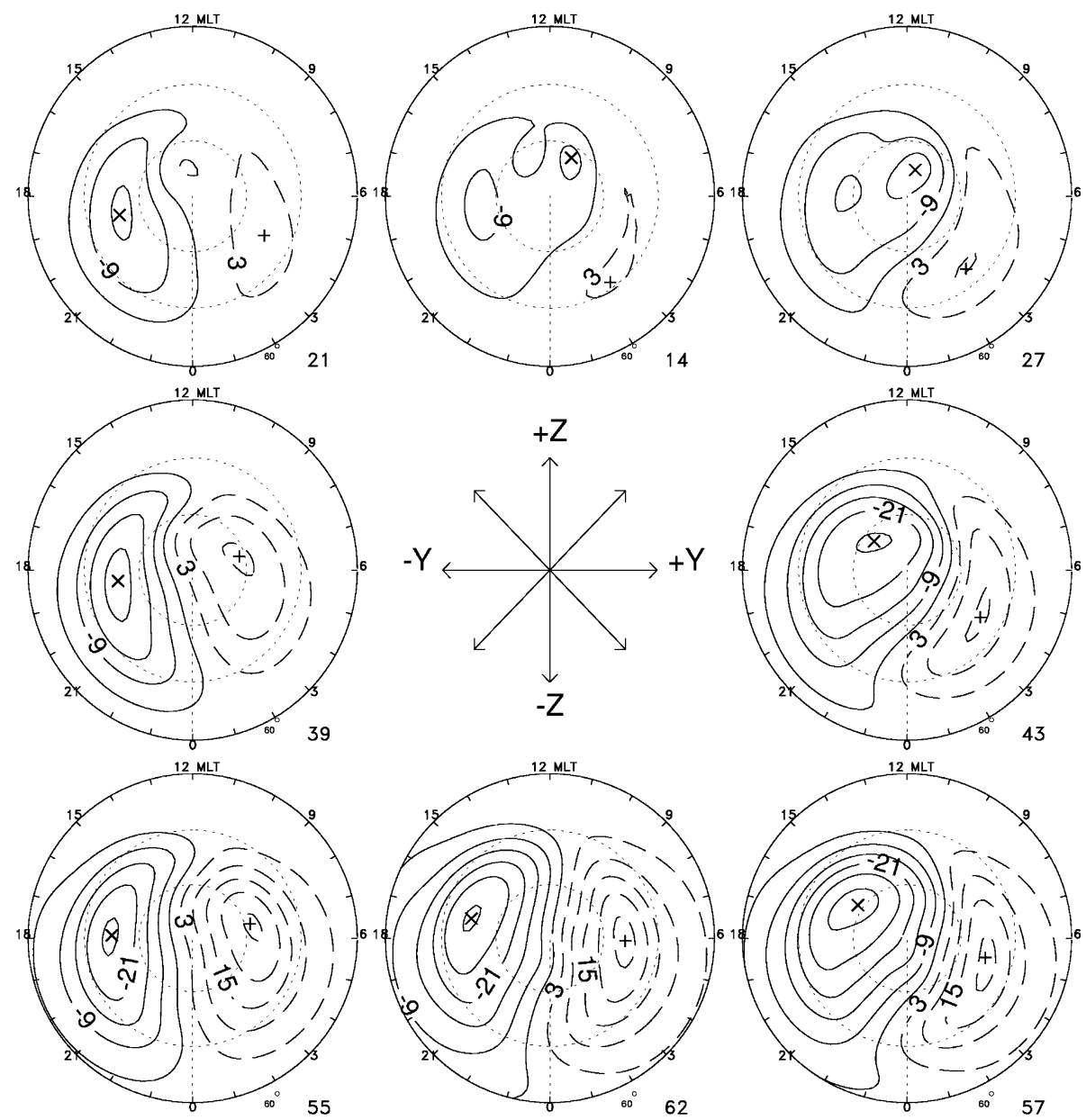

Fig. 3 Statistical patterns of ionospheric convection for eight different IMF clock angle orientations (indicated by the central dial), for when the IMF magnitude is between $5 \mathrm{nT}$ and $10 \mathrm{nT}$. In each panel, magnetic local noon is located at the top, midnight at the bottom, dusk to the left, dawn to the right. The lowest latitude is $60^{\circ}$ AACGM latitude, the dotted circles represent $70^{\circ}$ and $80^{\circ}$ AACGM latitude. The full equipotential solutions are shown by the solid (afternoon convection cell) and dashed (morning convection cell) black lines. The ' $x$ ' and ' + ' represent the locations of the extreme potential values and the number in the bottom right of each panel represents the potential difference between these extremes. This figure is reproduced from Ruohoniemi and Greenwald (2005), copyright by the American Geophysical Union

showing that both IMF $B_{y}$ and season significantly affect the nightside flow patterns. A more complete picture of the statistical dependence of high-latitude convection on the IMF was provided by Ruohoniemi and Greenwald (1996), and recently updated by Ruohoniemi and Greenwald (2005). They combined many years of SuperDARN line-of-sight velocity data to produce global ionospheric maps of electrostatic potential sorted by IMF strength and direction, expressed as series expansions in spherical harmonics. As an example, Fig. 3 shows the statistical patterns from Ruohoniemi and Greenwald (2005) for all IMF directions for IMF magnitudes between $5 \mathrm{nT}$ and $10 \mathrm{nT}$. Significant features in these maps 
include the transition of the dawn (dashed contours) and dusk (solid contours) convection cells into more rounded or crescent shapes depending on the sign of IMF $B_{y}$, the intensification of the two-cell pattern with increasing magnitude of southward IMF (bottom three maps), and the emergence of sunward convection in the dayside ionosphere for increasingly positive IMF $B_{z}$ (top centre map). Although the statistical maps derived by Ruohoniemi and Greenwald (1996, 2005) cannot account for the full range of possible convection configurations they do define a zero-order solution of the global convection. For most IMF conditions the patterns are very similar to those derived from satellite-based statistical studies (Rich and Hairston 1994; Weimer 1995). These statistical convection maps have also been used in comparison with statistical maps of particle precipitation (Newell et al. 2004), helping to place both sets of observations into context. The convection/precipitation comparisons made by Newell et al. (2004) suggested that $<35 \%$ of magnetopause reconnection maps to within the ionospheric cusp region as defined by particle precipitation.

Whereas the morphology of ionospheric convection during intervals dominated by southward IMF was well established before the SuperDARN era, there was disagreement over the form of ionospheric convection during intervals of strongly northward IMF. Early studies (Burke et al. 1979; Reiff and Burch 1985) suggested the existence of four convection cells during northward IMF conditions-two "reverse" cells at high-latitudes driven by lobe reconnection antisunward of the cusp regions, and two "normal" cells at lower latitudes driven by viscous processes at the magnetopause. However, Heppner and Maynard (1987) argued that there might not be four convection cells but only two, highly distorted cells. The statistical study of Rich and Hairston (1994) further suggested that four-cell convection was uncommon or non-existent. Conversely, the statistical study of ionospheric convection by Ruohoniemi and Greenwald (1996) using SuperDARN data showed that, at least statistically, a four-cell structure existed for strong northward IMF. Their statistical convection pattern clearly showed two reverse convection cells poleward of $80^{\circ}$, near the noon meridian, which were almost completely contained within the dayside ionosphere. SuperDARN also provided the first direct observations of complete reverse convection cells (Greenwald et al. 1995b; Huang et al. 2000a) and the complete four-cell convection pattern (Huang et al. 2000b). Figure 4 (from Huang et al. 2000a) shows the occurrence of the two reverse convection cells in 30-min averaged SuperDARN Merge vector maps of the dayside ionosphere during steady northward IMF conditions. The centres of the reverse convection cells are located either side of magnetic local noon $(1200 \mathrm{MLT})$ at $\sim 1030$ and $\sim 1330$ MLT and at $\sim 81.5^{\circ}$ latitude, and there is strong sunward convection flow in the noon meridian at the point where the cells join. These studies further showed that the four-cell convection configuration was stable as long as the IMF conditions remained stable. The reverse convection cells were typically of size $\sim 1000 \mathrm{~km}$ with a potential drop of $\sim 5 \mathrm{kV}$ in each cell. Huang et al. (2000a, b) illustrated the variation of this convection scenario with changing clock angle, showing that the reverse convection cells take $\sim 12 \mathrm{~min}$ to form after a northward turning of the IMF (Huang et al. 2000a), and also showed how the MLT position of the reverse convection cells shifted as the IMF clock angle varied (Huang et al. 2000b), matching the movement of the cusp auroral spot also observed during northward IMF conditions (Milan et al. 2000a). Huang et al. (2000b) observed that as IMF $B_{y}$ became more dominant the shifting of the reverse cells continued, reducing the size of one of the cells until a three-cell convection pattern was apparent, matching the model of Reiff and Burch (1985). Subsequent study has shown ionospheric convection flows consistent with dual lobe reconnection when the IMF clock angle is close to zero, that is, when open magnetic flux is 

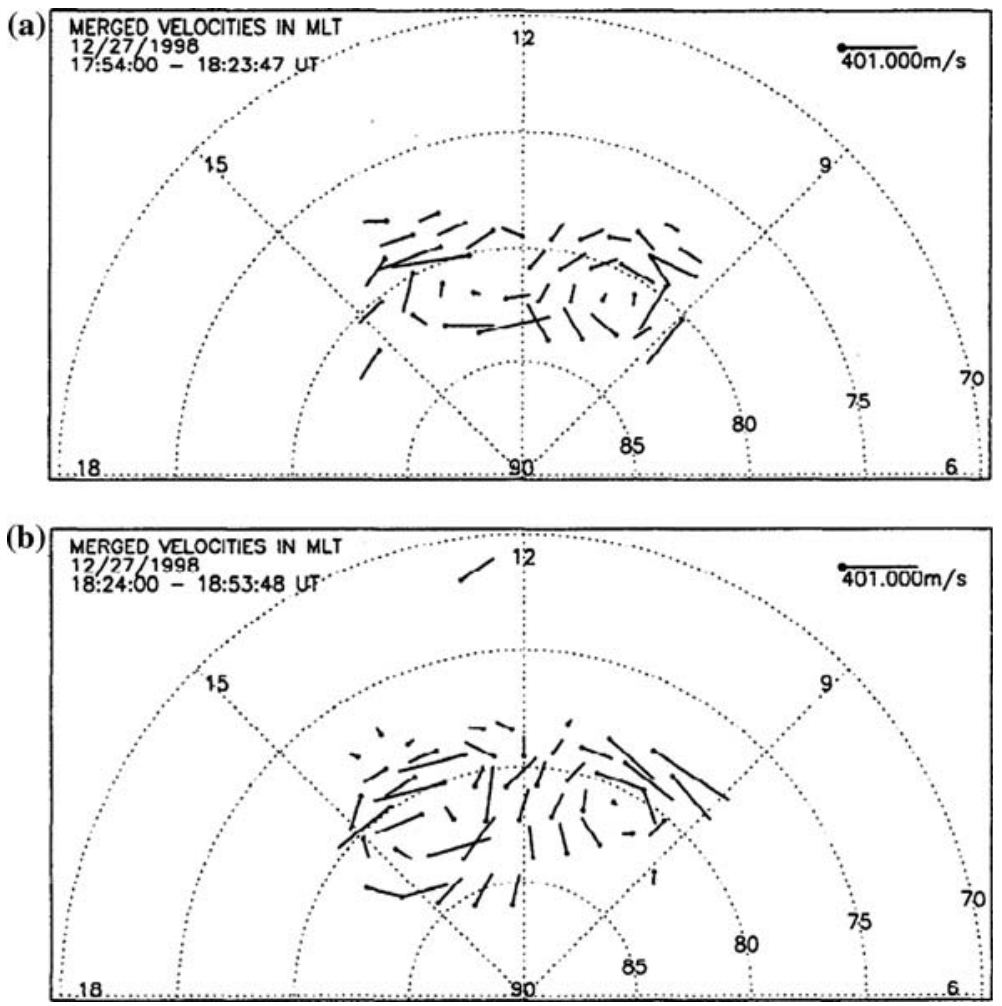

Fig. 4 Merge vector convection maps from December 27, 1998, derived from the intervals (a) 17541824 UT, and (b) 1824-1854 UT, showing the existence of 'reverse' convection cells during northward IMF conditions. The dots at one end of the vectors show the vector locations and the lines indicate the vector magnitude and direction. The velocity scale is indicated by the vector in the top right of each panel. The dotted lines indicate lines of constant AACGM latitude and lines of constant MLT. Only the dayside ionosphere is shown with magnetic local noon at the top, dusk at the left, and dawn on the right. This figure is reproduced from Huang et al. (2000a), copyright by the American Geophysical Union

closed at the dayside magnetopause by simultaneous reconnection of an IMF field line in both lobes (Imber et al. 2006).

\subsection{The dynamics of global convection}

As well as being well-suited to studying the steady-state and time-averaged nature of convection under different conditions, SuperDARN has proven very capable at studying the dynamics of the global convection electric field; its response to variations in the IMF and within the magnetosphere itself, e.g., as a result of substorms (see Sect. 5). With the growth of the SuperDARN network has come the ability to study convection dynamics on a more global scale. Figure 5 shows an example of a time series of the measured ionospheric convection flow coinciding with a southward turning of the IMF which illustrates the almost complete determination of the global convection pattern by the Map Potential method. The first two panels are characterized by the relatively weak convection $\left(\Phi_{P C} \sim\right.$ $15 \mathrm{kV}$ ) that prevailed through a long preceding period of northward IMF. The convection 

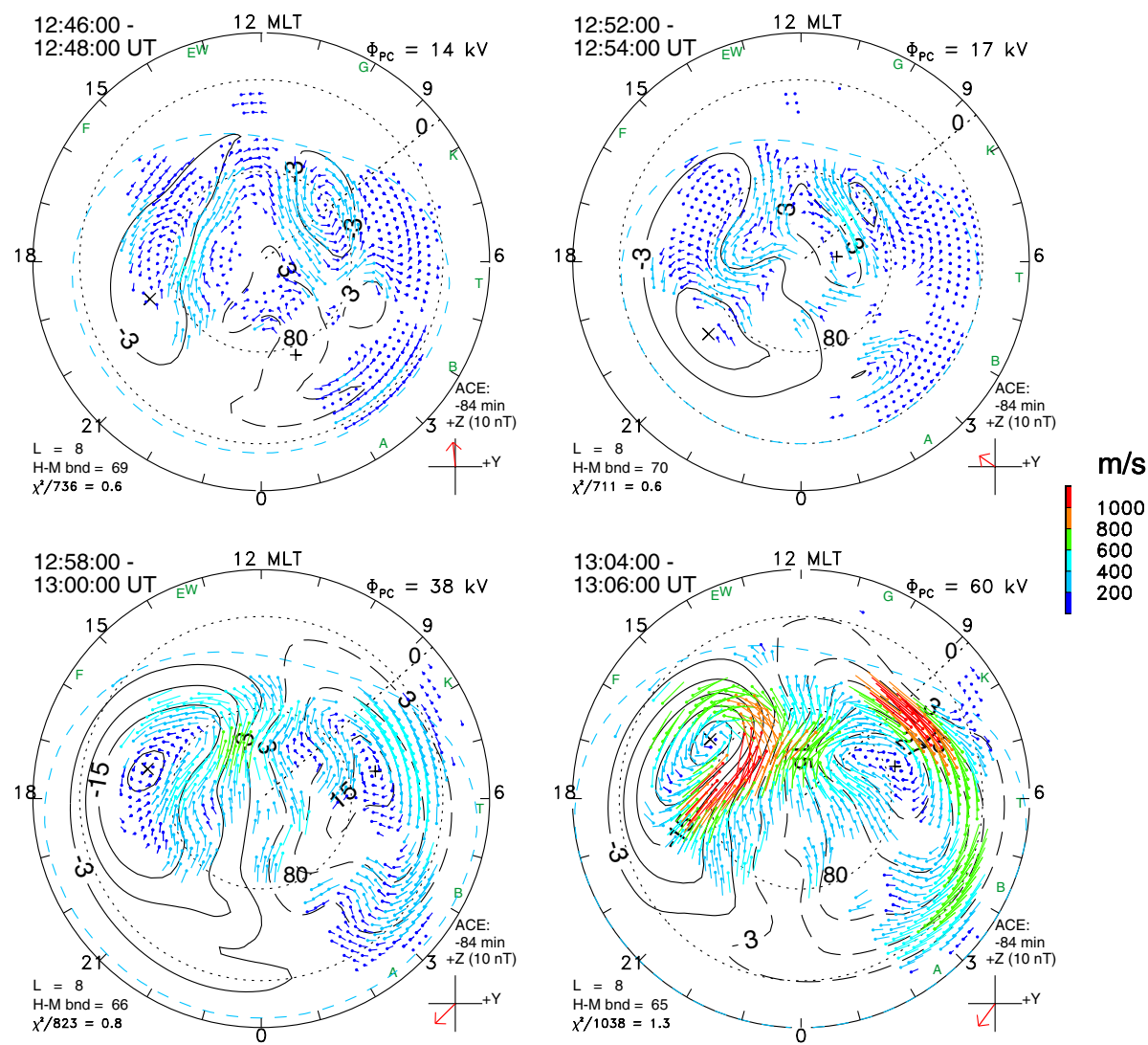

Fig. 5 Four Map Potential ionospheric convection maps for consecutive intervals showing the response of ionospheric convection to a southward turning of the IMF. Flow vectors are only shown in regions where there was line-of-sight velocity input. Each panel is presented in the same format as in Fig. $2 b$

pattern shows reverse (sunward) convection in the high-latitude dayside ionosphere and evidence of viscous convection cells on the flanks. Near 1256 UT the impact of an abrupt southward turning of the IMF can be seen. A two-cell convection pattern with enhanced flow velocities, typical of southward IMF conditions, is established very quickly $(\sim$ mins $)$ over the entire high-latitude region. The convection then rapidly intensifies, with $\Phi_{P C}$ reaching values near to $60 \mathrm{kV}$ within $\sim 10$ mins.

Early models and observations suggested that global convection reconfigured in response to IMF variations on timescales of tens of minutes, and that the onset of a response was delayed by increasing amounts away from the noon sector (Lockwood et al. 1986; Todd et al. 1988; Saunders et al. 1992). A similar scenario was observed in SuperDARN flow velocity data by Taylor et al. (1998) in response to a northward turning of the IMF; sunward flows appeared almost immediately in the noon sector (within $\sim 2$ mins) following the northward turning, but the flow within the radar fields-of-view took $\sim 20$ mins to completely reconfigure. This paradigm of a gradual convection response to IMF changes was challenged by Ridley et al. (1997) who reported that convection 
(measured using the AMIE technique (Richmond and Kamide 1988)) began to reconfigure everywhere nearly simultaneously following the impact of an IMF transition on the magnetosphere. Subsequently, Ruohoniemi and Greenwald (1998) and Shepherd et al. (1999) used SuperDARN measurements of the convection velocity response to IMF transitions to illustrate that global convection can respond simultaneously at all MLTs extending from noon to midnight, reconfiguring the ionospheric convection pattern from strong northward IMF-type convection to strong southward IMF-type convection in a very short ( 2-4 mins) time interval. Such a rapid ionospheric response to IMF variations implied that the solar wind-magnetosphere-ionosphere coupling process is closely controlled by the ionosphere, for example, via a fast magnetosonic wave. Later studies (Nishitani et al. 2002; Lu et al. 2002) used SuperDARN in combination with other instruments to show that there was evidence for a two-stage ionospheric response to southward turnings of the IMF, a first initial onset of the altered global convection pattern (which occurred within $\sim 2$ mins) and a slower reconfiguration to the final convection state occurring first in the dayside ionosphere and propagating slowly to the nightside ionosphere. Freeman (2003) showed that all these observations could be reconciled with a simple mathematical model in which (1) the global convection pattern responds instantaneously to a change in the IMF, and (2) both the pattern and strength of the convection pattern evolve over the reconfiguration timescale $(\sim 10 \mathrm{mins})$.

\subsection{The structure and dynamics of mesoscale convection}

As well as studying convection on the global scale, a very large number of SuperDARN studies have focussed on the structure and dynamics of convection at smaller scales, down to the scale of individual radars, such as the study of vortices associated with FAC or shear flow instabilities (Bristow et al. 1995; Greenwald et al. 1996). Much of this smaller-scale work has focussed on the understanding of convection signatures of FTEs and what these signatures tell us about the reconnection process at the Earth's magnetopause. The idea of pulsed reconnection at the magnetopause was first invoked to explain signatures of magnetic flux transfer across the magnetopause seen by spacecraft during southward IMF conditions (Russell and Elphic 1978, 1979). Subsequently, a large body of work has suggested that impulsive dayside reconnection, in the form of magnetopause FTEs, is the primary mechanism for the transfer of magnetic flux from the dayside magnetosphere to the magnetotail.

Early work identified that transient bursts in ionospheric convection in the dayside cusp region, first measured by incoherent scatter radar (Lockwood et al. 1989, 1990), and transient poleward-moving auroral intensity enhancements, measured by meridian photometers and all-sky cameras (Sandholt et al. 1986, 1992), were ionospheric signatures of FTEs. Pinnock et al. (1993) presented the first HF radar observations of transient convection enhancements thought to be associated with FTEs, using line-of-sight velocity measurements from the PACE Halley radar and DMSP ion drift velocity measurements. Their results showed the first 2-D view of the ionospheric footprint of an FTE-a longitudinally elongated $(>900 \mathrm{~km})$ and latitudinally narrow $(\sim 100 \mathrm{~km})$ channel of enhanced convection which they termed a 'Flow Channel Event'. As the expanding SuperDARN network gradually allowed measurements across larger spatial areas, the longitudinal extent of these flow enhancements was more clearly defined, measured as $\sim 3.5 \mathrm{~h}$ of MLT by Provan et al. (1998) and $\sim 5$ h of MLT by Nishitani et al. (1999). 
Numerous SuperDARN studies have shown that convection flow enhancements of this type are a regular feature of the dayside cusp ionosphere (Pinnock et al. 1995; Rodger and Pinnock 1997; Provan and Yeoman 1999; Provan et al. 1999). The typical signature as observed by SuperDARN can be simply described as a transient increase in line-of-sight velocity which is often seen to propagate poleward, sometimes as an isolated patch of backscatter, starting close to the open-closed field line boundary (OCB) and moving into the polar cap. Over the last 10 years, several terms have been used to describe these phenomena, most notably pulsed ionospheric flows (PIFs). The term poleward-moving radar auroral forms (PMRAFs) has also been used to describe poleward-moving enhancements in backscatter power which are often associated with flow transients such as PIFs. Observations have also confirmed that these convection flow transients are intimately associated with the poleward-moving auroral forms (PMAFs) which are regularly observed in the same region by all-sky cameras and photometers (Milan et al. 1999b; Thorolfsson et al. 2000).

Simultaneous satellite and radar observations were needed to unambiguously prove the connection between FTEs and the ionospheric flow bursts. Elphic et al. (1990) first presented observations illustrating a direct link between FTEs observed by the ISEE spacecraft near the low-latitude magnetopause, convection flow bursts observed by the EISCAT radar, and PMAFs observed by an all-sky camera on Svalbard. There was a wait of nearly 10 years before Neudegg et al. (1999) made the next coincident observations of lowlatitude magnetopause FTEs by the Equator-S spacecraft and convection flow transients measured by SuperDARN, following a southward turning of the IMF. Subsequently, Neudegg et al. (2000) performed a statistical survey of low-latitude magnetopause FTEs and the associated convection flow bursts measured by SuperDARN. In a study of 87 FTEs measured by the Equator-S spacecraft, 69 (77\%) of these had a measurable convection flow burst signature and hence the two signatures were statistically associated with greater than 99\% confidence. Wild et al. (2001, 2003) later presented coincident observations of highlatitude magnetopause FTEs measured by the Cluster spacecraft and convection flow transients measured at conjugate locations in both hemispheres by SuperDARN. The flow transients were found to pulse in close synchronization with the occurrence of the FTEs observed by Cluster. Figure 6, from Wild et al. (2003), presents line-of-sight velocity data from the Finland SuperDARN radar in the northern hemisphere (top panel) and the Syowa East SuperDARN radar in the southern hemisphere (bottom panel). The velocity data are characterized by transient flow enhancements which can be seen most clearly in the middle panel which illustrates the average velocity variation from between the latitudes highlighted by the dashed lines in the top and bottom panels. These flow enhancements are associated with the timing of FTEs observed by the Cluster spacecraft (highlighted by the vertical dotted lines). Similar coincident observations of FTEs measured by the Geotail spacecraft near the dawn magnetopause and PMRAFs measured by SuperDARN were presented by McWilliams et al. (2004). These FTEs were measured during northward IMF conditions when the IMF $B_{y}$ component was strongly positive. They concluded, through the interpretation of combined ground and space observations of the FTE signatures, that the reconnection site was located on the high latitude magnetopause during these conditions, supporting the hypothesis that reconnection occurs preferentially in regions of antiparallel magnetic fields. In another study of this sort Marchaudon et al. (2004a) compared observations of FTE-related transient plasma injections in the high-latitude dayside magnetosphere by the Cluster satellites with ionospheric convection transients identified by SuperDARN, showing a clear one-to-one correlation. They showed that changes in convection in the ionosphere followed those in the magnetosphere (measured by Cluster) with a 2-3 min delay. 

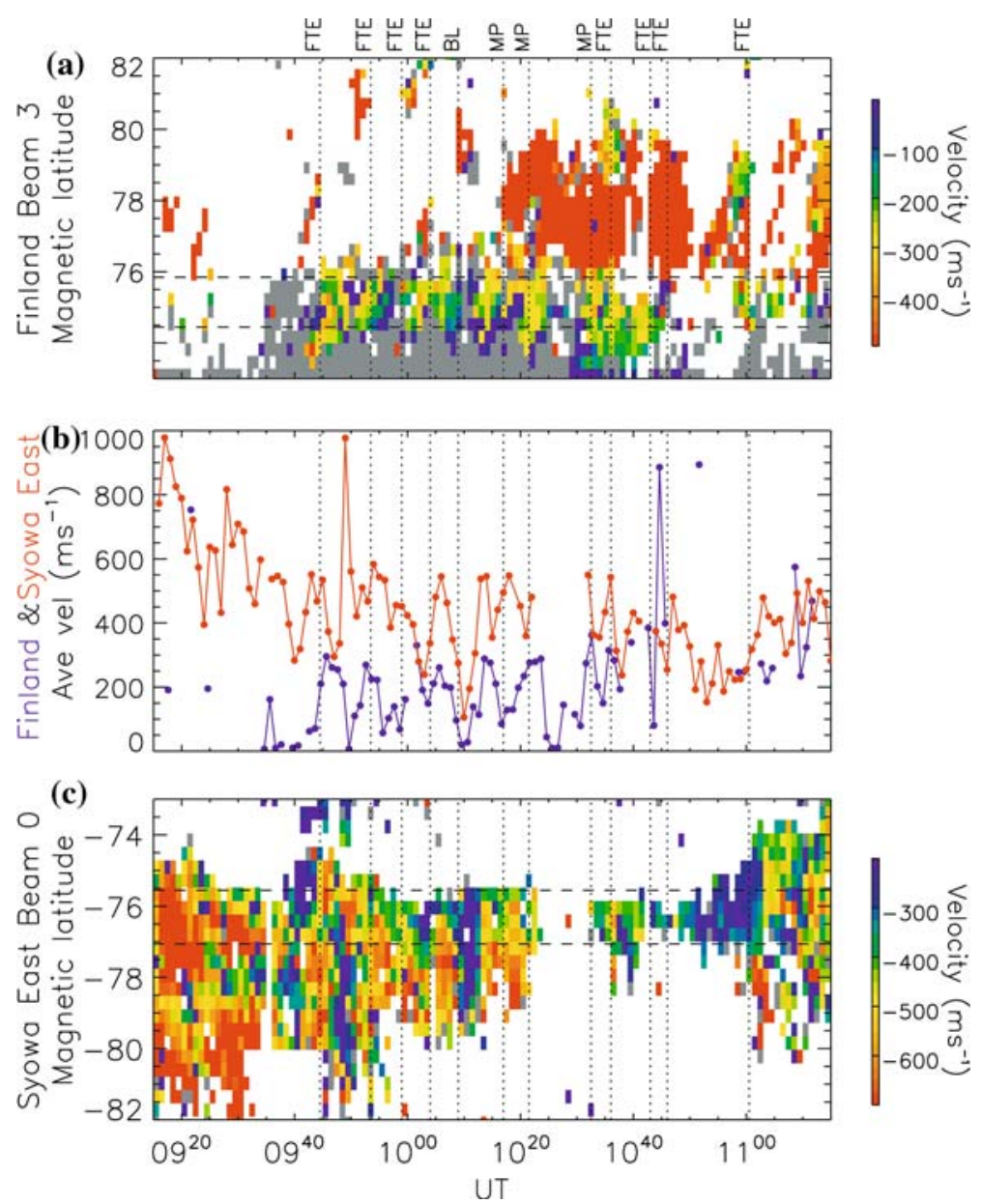

Fig. 6 Line-of-sight Doppler velocity measurements from beam 3 of the Finland SuperDARN radar in the northern hemisphere (top panel) and beam 0 of the Syowa East SuperDARN radar in the southern hemisphere (bottom panel) showing flow transients associated with magnetopause FTEs. Doppler velocity is indicated by the colour scale where negative line-of-sight velocities (yellow to red) represent plasma flow away from the radar. Grey indicates measurements that are not from the ionosphere. Velocity measurements are only presented in regions where an acceptable backscatter power was measured (hence the patchy nature of the velocity measurements). The middle panel presents the temporal variation of the line-of-sight velocity measured by each radar averaged over the latitudinal bands delineated by the horizontal dashed lines in the top and bottom panels. These average velocity variations show bursts of enhanced velocity which correlate with the occurrence of FTEs observed by the Cluster spacecraft as marked by the vertical dotted lines. This figure is reproduced from Wild et al. (2003), copyright by the European Geophysical Union

Although the above studies have fully established that many convection flow bursts measured by SuperDARN are the ionospheric signature of FTEs, it is really only their line-of-sight velocity signature that has been studied in detail; a full understanding of the 2-D convection signature and how it relates to the 2-D auroral and current signatures of FTEs is still outstanding. However, there have been attempts to characterize this 2-D signature. Although not making 2-D observations, Prikryl et al. (1999) suggested that the 
ionospheric flow bursts could be associated with poleward progressing DPY currents (Hall currents modulated by variations in IMF $B_{y}$ ). Many of the recent SuperDARN 2-D observations of dayside flow transients appear to fit with a simple picture of polewardmoving FAC systems which are associated with PMAFs, poleward-moving local convection reversals, and other poleward-moving velocity structures (Chisham et al. 2000b; Thorolfsson et al. 2000; Lockwood et al. 2001). Milan et al. (2000b) presented spacecraft imager observations of the 2-D auroral signature of PMAFs. They identified a bifurcation of the main auroral oval in the afternoon sector ionosphere, the poleward portion of which was interpreted as the PMAF. Simultaneously, SuperDARN measured poleward and westward convection flow consistent with the $B_{y}$ tension force, as well as poleward-moving regions of backscatter. Their observations suggested that PMAFs could be $\sim 7 \mathrm{~h}$ of MLT in length. Lockwood et al. (2001), using the same dataset, showed the existence of upward FAC sheets coinciding with poleward-moving convection features observed by SuperDARN. Chisham et al. (2000b) also suggested that a series of poleward-moving FAC systems were responsible for the transient poleward motions of the convection reversal boundary observed by SuperDARN during an interval of flow burst activity. Figure 7 presents nine consecutive 2-min ionospheric flow patterns showing the convection flow near the magnetic local noon meridian (from Chisham et al. 2000b). These maps were determined using the Merge technique and using data from the Halley and Sanae SuperDARN radars. The flow in each panel is characterized by the convection reversal (from westward to eastward flow) that is typical of the noon sector ionosphere for prevailing south-east IMF. The observations of transient poleward motion of the convection reversal boundary (illustrated by the motion of the bold lines in Fig. 7) led Chisham et al. (2000b) to conclude that the line-of-sight flow bursts that they observed in the single radar data were not due to enhancements in the flow magnitude but to transitions in the flow direction consistent with the poleward motion of the convection reversal. Marchaudon et al. (2004b) made the first direct measurement of the FAC system associated with a FTE (from Ørsted satellite observations), in conjunction with the two-dimensional convection field of the associated convection flow burst measured by SuperDARN. They observed a series of successive small-scale FACs alternating between downward and upward with the most poleward pair of currents at the front edge of the convection flow burst. Recently, Oksavik et al. (2005) introduced a new term, 'FTE currents', to denote the unique pair of FAC sheets that are associated with individual mesoscale FTE flow disturbances, and showed that PMAFs were the optical signature of the upward FTE current. Their observations suggested that the FTE signature convects with the large-scale convection flow and is not just a local disturbance near the convection reversal boundary. Despite these advances, continuous and extensive two-dimensional measurements of the velocity field, auroral and field-aligned current scenarios are needed for a comprehensive understanding of the ionospheric signature of FTEs.

The temporal variation of these ionospheric flow bursts has also been studied in order to understand the temporal variation of FTEs. The recurrence time of the flow burst signatures has been of particular interest. Early studies estimated the typical recurrence time between bursts as being 7-8 mins (Pinnock et al. 1995; Provan et al. 1998) closely matching what had been identified as the average recurrence time for magnetopause FTEs (Rijnbeek et al. 1984; Lockwood and Wild 1993). Prikryl et al. (1998, 1999, 2002) presented observations that implied that, at times, quasi-periodic ionospheric flow bursts were correlated with Alfvénic fluctuations observed in the upstream solar wind, with similar waveforms being observed in the IMF, in the magnetosheath, and in ionospheric convection flows. They suggested that compressional MHD waves in the solar wind were responsible for driving 


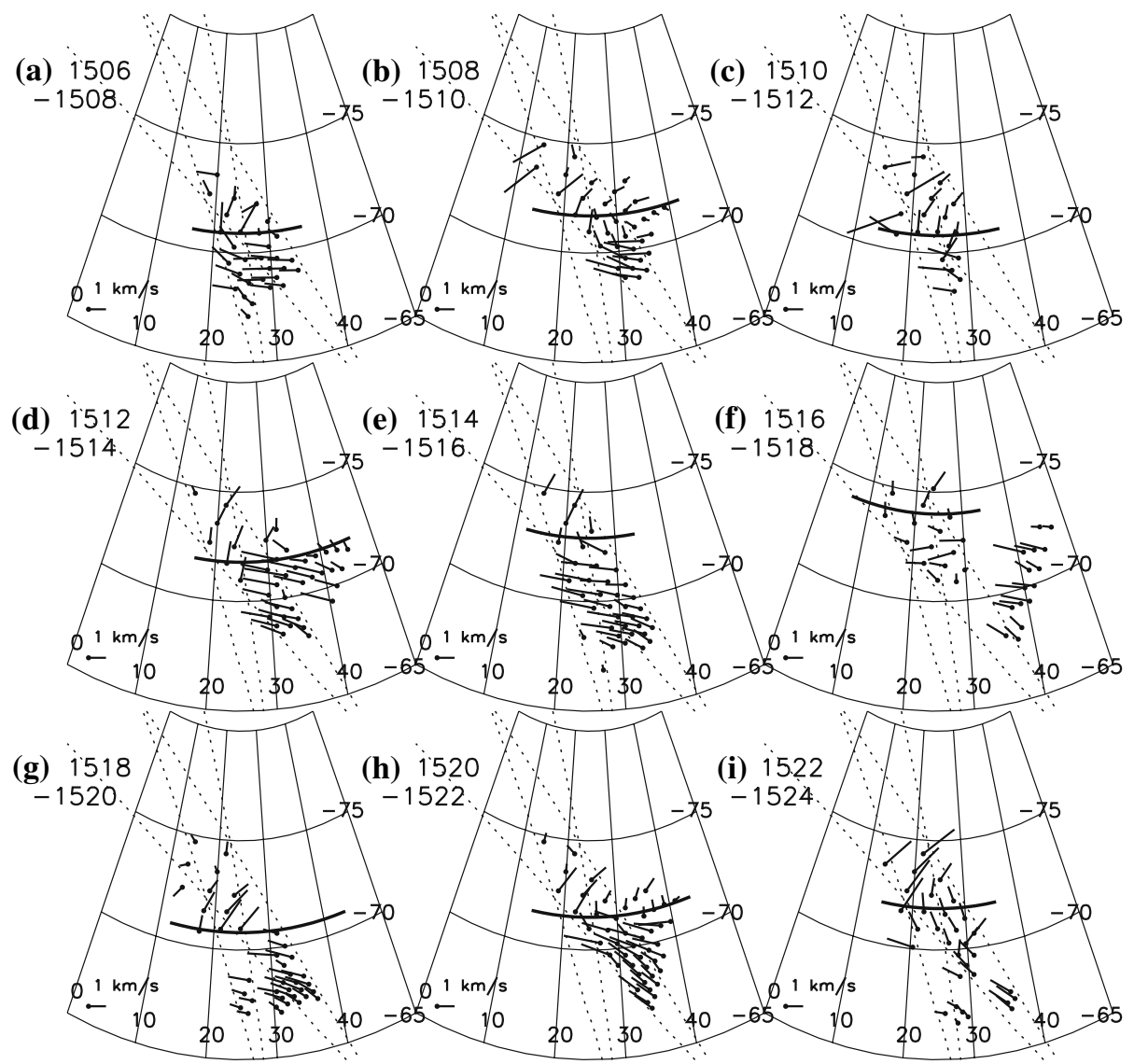

Fig. 7 Nine consecutive 2-min 2-dimensional ionospheric flow patterns (Merge vectors) in the ionospheric cusp, at the time of FTE-related ionospheric flow bursts on May 8, 1998. The dots at the ends of the vectors show the vector locations and the lines show the vector magnitude and direction. The velocity scale is shown by the vector in the bottom left of each panel. The bold line in each frame represents an estimate of the latitude of the convection reversal boundary, when considering all the velocity vectors shown. The vector maps are presented on AACGM co-ordinate grids and the dotted lines indicate regions of high temporal resolution SuperDARN observations from two radars. This figure is reproduced from Chisham et al. (2000b), copyright by the American Geophysical Union

compressional waves in the magnetosphere, and further suggested that these ULF waves modulated reconnection at the dayside magnetopause into pulses, hence the correlated periodicity. In a larger statistical study of recurrence times, McWilliams et al. (2000) determined the distribution of flow burst recurrence times using 2 years of SuperDARN data from the Finland radar, showing that, although the mean recurrence time was $\sim 10$ mins, the recurrence times covered a wide range of timescales (from $\sim 2$ to $>50$ mins). McWilliams et al. (2000) further compared their measured distribution with the distributions of inter-FTE intervals deduced from the ISEE spacecraft (Lockwood and Wild 1993; Kuo et al. 1995), and the distribution of the recurrence time of PMAFs in optical data (Fasel 1995), showing that all the distributions were very similar. Abel and Freeman (2002) argued that the functional form of these occurrence distributions was a 
power law, implying that there is no preferred timescale for these convection velocity fluctuations. They proposed that this scale-free nature could arise from the intermittent, turbulent nature of the IMF causing magnetic reconnection to occur at the magnetopause across a wide range of spatial and temporal scales (Coleman and Freeman 2005).

SuperDARN observations of transient dayside convection flows have also been associated with plasma pressure variations in the solar wind. However, there is some argument as to whether these flows are a result of enhanced magnetopause reconnection stimulated by these pressure variations, or a result of the reconfiguration of the magnetosphere due to its change in size in response to these changes in pressure, or whether both processes occur. Thorolfsson et al. (2001) observed sunward convection flow bursts on closed field lines in the early afternoon ionosphere in response to decreases in solar wind dynamic pressure. They argued that these flow enhancements were unlikely to be driven by reconnection and that they could be explained in terms of a global current model associated with changes in magnetospheric size associated with the pressure changes. Similar arguments were made by Vontrat-Reberac et al. (2002) who suggested that sudden commencements associated with dynamic pressure changes produced high-latitude convection signatures similar to those resulting from transient reconnection. However, in the most comprehensive study of this sort, Cerisier et al. (2005), using SuperDARN observations of convection in combination with Cluster spacecraft observations of plasma injection into the cusp, and auroral images from the IMAGE spacecraft showing enhanced cusp precipitation, showed that pulses in solar wind dynamic pressure were responsible for triggering enhanced reconnection at the magnetopause. This resulted in plasma injections from the magnetosheath into the cusp, followed shortly afterwards by convection bursts on the poleward side of the cusp precipitation, consistent with these flows being a 'fossil' signature of the compression-injection process.

Most of the work on mesoscale transient convection flows described above has concentrated on measurements made in the dayside ionosphere during southward IMF conditions. Mesoscale convection measurements have also been made in the dayside ionosphere during northward IMF conditions. When the interplanetary field points north, it is well established that convection and substorm activity are reduced (e.g. Fairfield and Cahill 1966; Reiff et al. 1981), although observations in the dayside ionosphere suggest that open flux tube production does not cease entirely unless the IMF clock angle falls below $\sim 30^{\circ}-40^{\circ}$ (Sandholt et al. 1998a,b). At the same time, high-latitude reconnection between lobe magnetic field lines and the northward IMF begins, exciting reverse convection cells in the dayside ionosphere as discussed in Sect. 2.2. Milan et al. (2000a) used a combination of SuperDARN convection measurements and Polar UVI images of auroral luminosity to study the ionospheric signature of reconnection during an interval of northward IMF. They identified a region of luminosity near local noon (an auroral spot) which was poleward of the dayside auroral oval and associated this with the ionospheric footprint of a high-latitude reconnection site. The SuperDARN convection measurements were consistent with the presence of a reverse convection cell within the dayside polar cap, with a flow reversal closely co-located with the high-latitude luminosity region. Similar observations were made by Chang et al. (2004) and Provan et al. (2005) using SuperDARN and IMAGE FUV observations. The SuperDARN convection maps showed the four cell convection pattern which is typical of northward IMF conditions (see Sect. 2.2), and the IMAGE FUV observations showed an intense region of proton aurora that was co-located with the region of strong sunward convection between the reverse convection cells. Provan et al. (2005) also showed that the brightness of the proton aurora correlated with bursts in the plasma flow. They suggested that correlated fluctuations in the solar wind dynamic 
pressure and the IMF $B_{z}$ component modulated ionospheric precipitation and dayside reconnection, resulting in fluctuations in the brightness of the proton auroral spot and periodic variations in the dayside high-latitude plasma flow.

A variety of interesting convection phenomena have also been identified in the nightside ionosphere during northward IMF conditions, and a full physical understanding of these phenomena has yet to be established. Huang et al. (2001) reported SuperDARN observations of quasi-sinusoidal nightside flow oscillations during an extended interval of modest northward IMF and small (typically $<45^{\circ}$ ) clock angle. The flow oscillations had amplitudes $\sim 500 \mathrm{~m} / \mathrm{s}$ and a period of $\sim 1 \mathrm{~h}$, and were associated with the formation of large-scale clockwise flow vortices in the post-midnight sector which subsequently propagated toward dawn. Walker et al. $(1998,2002)$ have reported the occurrence of latitudinally restricted $\left(\sim 1^{\circ}\right.$ north-south) bursts of high-speed $(\sim 2 \mathrm{~km} / \mathrm{s})$ westward flow in the pre-midnight sector under similar IMF conditions. These flow bursts had a recurrence time of $\sim 12$ min (four main cycles were observed), and occurred at the equatorward edge of the dusk convection cell. Walker et al. (2002) interpreted these as being the result of sporadic energy release and field dipolarization in the geomagnetic tail associated with a viscously driven twin-vortex flow system. Sutcliffe (1998) noted the existence of Pi2 ULF waves and weak (few tens of nT) midnight-sector bay activity during these events. Senior et al. (2002) also reported the occurrence of large-scale bursty flows in the 'quiet-time' nightside ionosphere during an interval of 'intermediate' clock angles greater than $45^{\circ}$. These flows had a recurrence time of $\sim 1 \mathrm{~h}$, with substructure on timescales of $\sim$ tens of min, similar to flow bursts reported by de la Beaujardière et al. (1994). They took the form of surges of westward 'return' flow in the dusk convection cell, being several degrees wide in latitude, and extending in local time from post-midnight towards dusk.

More recently, Grocott et al. (2003, 2004c, 2005) have used SuperDARN to study nightside convection when the IMF was consistently northward, but dominated by a significant $B_{y}$ component. No classic substorm features were observed during these intervals, yet there was evidence in the ionosphere for flux closure occurring in the magnetotail at rates of $\sim 30-50 \mathrm{kWb} / \mathrm{s}$ (Grocott et al. 2003; Milan et al. 2005a, b). This was manifest as large-scale bursts of flow in the nightside ionosphere, with recurrence timescales of $\sim 1 \mathrm{~h}$ and lasting a few 10 s of minutes. These recurrence properties are similar to those of the flow phenomena described by de la Beaujardière et al. (1994) and Senior et al. (2002) as discussed above. The nature of these flow bursts was found to be strongly correlated with the orientation of IMF $B_{y}$. This is illustrated in Fig. 8, which shows ionospheric convection maps of the nightside ionosphere from the northern (panels a, c, e, g) and southern (panels $\mathrm{b}, \mathrm{d}, \mathrm{f}, \mathrm{h}$ ) hemispheres for positive IMF $B_{y}$ (panels e-h) and negative IMF $B_{y}$ (panels a-d). In the southern hemisphere, the direction of the flow bursts near the midnight meridian is the same as the direction of IMF $B_{y}$ (i.e., duskward for positive $B_{y}$ ), whereas in the northern hemisphere they are directed oppositely. This has been attributed to the flow bursts being the ionospheric signature of magnetotail reconfiguration following reconnection in an asymmetric tail, itself due to previous intervals of prolonged dayside reconnection with the $B_{y}$-dominated IMF (Grocott et al. 2005). These convection bursts have since been implicated in the formation of transpolar arcs (Milan et al. 2005a).

Another mesoscale ionospheric convection phenomena that has been studied by SuperDARN is that known variously as polarization jets (PJs) (Galperin et al. 1973), or subauroral ion drifts (SAIDs) (Spiro et al. 1979). These are fast $(1-4 \mathrm{~km} / \mathrm{s})$, narrow $\left(1-2^{\circ}\right)$ channels of westward plasma flow which occur near the equatorward edge of the auroral oval in the evening sector ionosphere. Freeman et al. (1992) noted a similar phenomenon of wider latitudinal extent than SAIDs, and associated with substorm onset, that they 

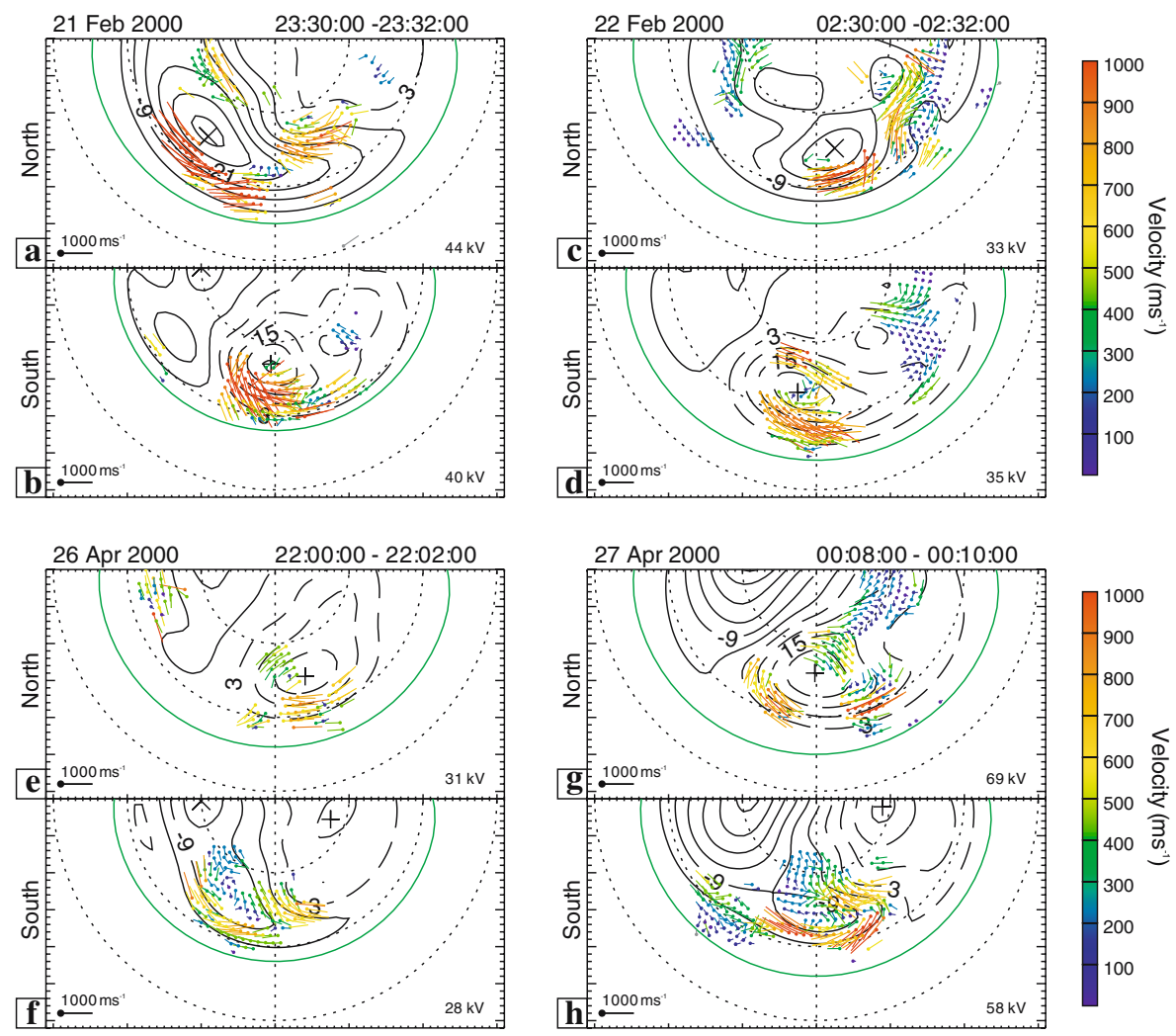

Fig. 8 SuperDARN convection maps of the nightside ionosphere from the northern (a, c, e, g) and southern $(\mathbf{b}, \mathbf{d}, \mathbf{f}, \mathbf{h})$ hemispheres showing the nature of the convection flow for IMF $B_{y}$ negative (a-d) and positive (e-h) conditions. The times of each pair of observations are indicated at the top of each pair of panels. The cross-polar cap potential is indicated in the bottom-right corner of each map. The convection maps are presented in the same format as Fig. 2b. This figure is reproduced from Grocott et al. (2005), copyright by the European Geophysical Union

named SARAS. Foster and Burke (2002) introduced the term 'sub-auroral polarization stream' (SAPS) to encompass all these phenomena, also including broader $\left(3-5^{\circ}\right)$, weaker (100-400 m/s), background flows which persist beyond midnight into the predawn sector. These sub-auroral electric fields play critical roles in energising and transporting ring current ions as well as convecting thermal plasma in the inner magnetosphere and in the mid- to low-latitude ionosphere (Foster and Vo 2002). In SuperDARN observations these phenomena have often been termed auroral westward flow channels (AWFCs) (Parkinson et al. 2003, 2005) and they appear any time between substorm onset and recovery. Koustov et al. (2006) also observed SAPS with the King Salmon SuperDARN radar. However, they pointed out that the expected location of SAPS flows is often equatorward of the typical SuperDARN fields of view. The recently built and planned StormDARN radars (see Sect. 9.1) will be in a better position to regularly observe SAPS, and fully understand their characteristics and generation mechanisms (Oksavik et al. 2006). 


\section{Field-aligned currents}

\subsection{Field-aligned current measurements}

Magnetic FACs are the primary link between the magnetosphere and the ionosphere, carrying electromagnetic energy between the two regions. Hence, the measurement and study of FACs is of prime interest to magnetosphere-ionosphere coupling investigations. The majority of early studies of FACs employed satellite magnetometer observations, which are inherently one-dimensional. However, FACs can also be estimated from measurements of ionospheric convection and conductance. By assuming that the total ionospheric current system is divergence-free, the FAC can be determined from the divergence of the horizontal current. The FAC density $J_{\|}$can then be written as (e.g., Boström 1974),

$$
J_{\|}=-\Sigma_{P} \nabla \cdot \mathbf{E}-\mathbf{E} \cdot \nabla \Sigma_{P}-\hat{\mathbf{B}} \times \mathbf{E} \cdot \nabla \Sigma_{H}
$$

where $\mathbf{E}$ is the ionospheric electric field, $\Sigma_{P}$ and $\Sigma_{H}$ are the ionospheric height-integrated Pedersen and Hall conductivities, respectively, and $\hat{\mathbf{B}}$ is the magnetic field unit vector. Boström (1974) categorized the different terms in this equation according to whether they were primarily controlled by ionospheric or magnetospheric sources. The first term was described as a contribution to the FAC from the spatially varying electric field imposed on the ionosphere by the magnetosphere. The last two terms were considered to be more affected by the structure of the ionosphere due to their $\nabla \Sigma_{P}$ and $\nabla \Sigma_{H}$ dependencies. However, the ionospheric conductance profiles can also be strongly influenced by magnetospheric processes, namely ionization at ionospheric altitudes due to energetic particle precipitation from the magnetosphere.

Continuous and extensive two-dimensional ionospheric FAC measurements require the determination of independent spatiotemporal variations in both the global ionospheric convection and conductance. Generally, it is extremely difficult to measure, or to accurately model, spatiotemporal variations in ionospheric conductance and hence, measurements of this type are rare. Amm et al. (1999) combined SuperDARN convection maps and ground-based magnetometer data to measure FACs using the Method of Characteristics (Inhester et al. 1992). This method combines measurements of ionospheric equivalent currents, determined from ground magnetic variations, with the ionospheric electric field, in order to determine the Hall conductance distribution. Hence, the measurements of the electric field and conductance in this technique are not truly independent. Amm et al. (1999) used this technique to examine the time development of ionospheric convection and FAC patterns following an IMF $B_{y}$ transition. They associated a region of enhanced convection observed by SuperDARN in the noon/early afternoon sector with a region of low conductance. At the northern and southern edges of the enhanced convection region, sheets of downward and upward FACs were observed, respectively. Their results supported cusp FAC production by a rotational discontinuity of the magnetic field at the dayside magnetopause due to reconnection (Lee et al. 1985), rather than by the penetration of the IMF $B_{y}$ component into the magnetosphere.

Bristow and Lummerzheim (2001) improved on this technique by combining SuperDARN convection maps with ionospheric conductances independently determined from a model of photoionization combined with auroral particle precipitation inferred from Polar UVI images (Lummerzheim et al. 1991; Germany et al. 1994). Combining these two-dimensional datasets allowed them to instantaneously image the two-dimensional 


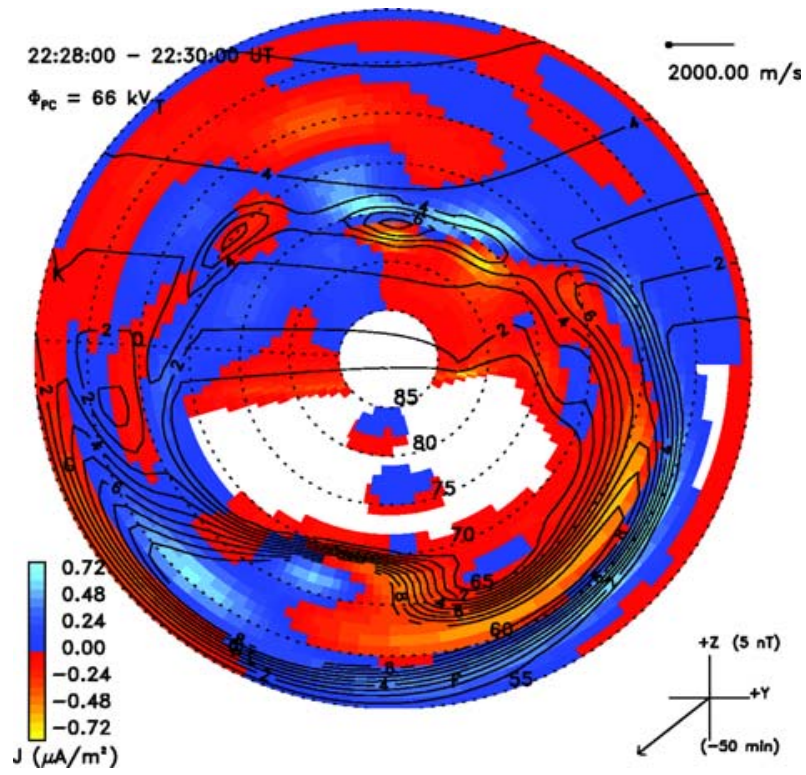

Fig. 9 An estimate of the global distribution of field-aligned currents in the northern hemisphere ionosphere at 2228-2230 UT on April 10, 1997, determined using SuperDARN and Polar UVI data. The colour indicates the magnitude and direction of the current, the blue represents upward current and the red/yellow represents downward current (see colour bar for scale). The black solid contour lines represent contours of Pedersen conductance determined from a combination of the Polar UVI data and a model of photoionization. The projection of the prevailing IMF vector on the Y-Z GSM plane is shown in the bottom-right corner. This figure is adapted from Bristow and Lummerzheim (2001)

FAC pattern and monitor the evolution of the pattern. Bristow and Lummerzheim (2001) showed that FAC enhancements in the nightside ionosphere, as well as intense cusp currents, were closely related to gradients in ionospheric conductance. Figure 9 shows an example of the FACs determined from the SuperDARN convection maps and Polar UVI images for a 2-min interval on April 7, 1997. The colour contours indicate the strength of the FACs, the blue representing upward current and the red/yellow representing downward current. The black contour lines represent Pedersen conductance contours. This figure shows that regions of largest FAC (yellow, light blue) often coincide with large gradients in Pedersen conductance. Bristow and Lummerzheim (2001) also showed that as the ionospheric conductance increased in the nightside ionosphere during a substorm, the electric field was observed to decrease, leading to only a relatively moderate increase in FAC; the conductance and electric field contributions to the FAC system were effectively counter-balancing each other. Kozlovsky et al. (2002) also estimated the total FAC by combining SuperDARN convection maps and ionospheric conductances estimated from a combination of a photo-ionization conductivity model and a model of conductance based on auroral precipitation measurements. The latter was estimated from the incident energy flux and average energy of $0.5-30 \mathrm{keV}$ precipitating electrons obtained from DMSP spacecraft and Polar UVI (Robinson et al. 1987). Kozlovsky et al. (2002) found that during intervals of negative IMF $B_{y}$ the postnoon convection reversal boundary was associated with an upward FAC of $\sim 0.6 \mu \mathrm{A} / \mathrm{m}^{2}$. However, during intervals of positive IMF $B_{y}$, the region of maximum afternoon upward FAC was shifted to the poleward edge of the auroral oval. 


\subsection{Convection vorticity measurements}

As the above studies showed, making global measurements of Hall and Pedersen conductances is presently a challenging undertaking. Consequently, other radar studies of FACs have used the approximation that variations in ionospheric conductivity are generally small and can be neglected, and hence the convection vorticity is a good proxy for the FAC (Sofko et al. 1995) (but see Green et al. (2006), discussed below). Equation 4 can be rewritten in terms of the $\mathbf{E} \times \mathbf{B}$ drift velocity $\mathbf{v}$ as (Sofko et al. 1995),

$$
J_{\|}=\Sigma_{P} \mathbf{B} \cdot(\nabla \times \mathbf{v})+(\mathbf{v} \times \mathbf{B}) \cdot \nabla \Sigma_{P}+|\mathbf{B}| \mathbf{v} \cdot \nabla \Sigma_{H}
$$

When assuming uniform ionospheric conductances this equation reduces to:

$$
\frac{J_{\|}}{\Sigma_{P}}=\mathbf{B} \cdot(\nabla \times \mathbf{v})
$$

Freeman et al. (1990) were the first to apply this assumption to the estimation of FACs, using ionospheric radar data from the SABRE VHF radar system (Nielsen et al. 1983). They identified a region of vorticity extending across the radar field of view which, assuming uniform ionospheric conductances, they associated with a FAC density of a few $\mu \mathrm{Am}^{-2}$ caused by earthward hot plasma transport. As a check on the reliability of the vorticity estimate, they also estimated the divergence of the velocity field to verify that it was divergence-free.

Sofko et al. (1995) subsequently devised a method to determine convection vorticity $(\nabla \times \mathbf{v})$ using SuperDARN Merge velocity vectors. Each SuperDARN radar has sixteen beams, creating up to 256 regions where the beams from two radars intersect and where independent Merge vectors can be determined. These intersecting regions are termed "Merge Cells.', Sofko et al. (1995) applied Stokes' theorem to the calculation of $(\nabla \times \mathbf{v})$, determining the line integral of $\mathbf{v} \cdot \mathbf{d l}$ along a closed path, $\mathbf{d l}$, around the Merge Cell of interest. An example of a SuperDARN FAC (vorticity) map determined from Merge velocity data is presented in Fig. 10a. Here, a positive FAC (red/yellow) represents upward current out of the ionosphere and a negative FAC (blue) represents downward current into the ionosphere. The quadrilateral merge cells, formed by the overlap of two beams from adjacent radars, are evident. The convection pattern presented in Fig. 10a showing westward flow at low latitudes and eastward flow at higher latitudes is typical of the postnoon convection reversal, which has clockwise vorticity (equivalent to upward FAC). These FAC/vorticity maps can also be overlaid onto images of the aurora, in order to compare the relative locations of the FACs estimated from the plasma vorticity and the regions of bright aurora, which are indicative of strong upward FACs. Figure 10b (adapted from McWilliams et al. 2001) shows the same vorticity map as Fig. 10a, but now the FAC estimates are represented by circles (upward FAC) and crosses (downward FAC). The sizes of the circles and crosses are proportional to the magnitude of $\mathbf{B} \cdot(\nabla \times \mathbf{v})$. This vorticity map has been superposed on an image of the postnoon ultraviolet auroral oval from the Polar VIS Earth Camera (grey shaded regions). Much of the upward FAC region (circles) coincides with the bright aurora (dark grey shading) in the postnoon sector, as expected. The downward FAC regions (crosses) are located poleward and equatorward of the bright auroral region.

Vorticity maps can be extended to the entire high-latitude region by using the Map Potential technique to determine a global convection map. An example of a global vorticity map, and the equipotential contours used to calculate it, is presented in Fig. 11b (adapted from 

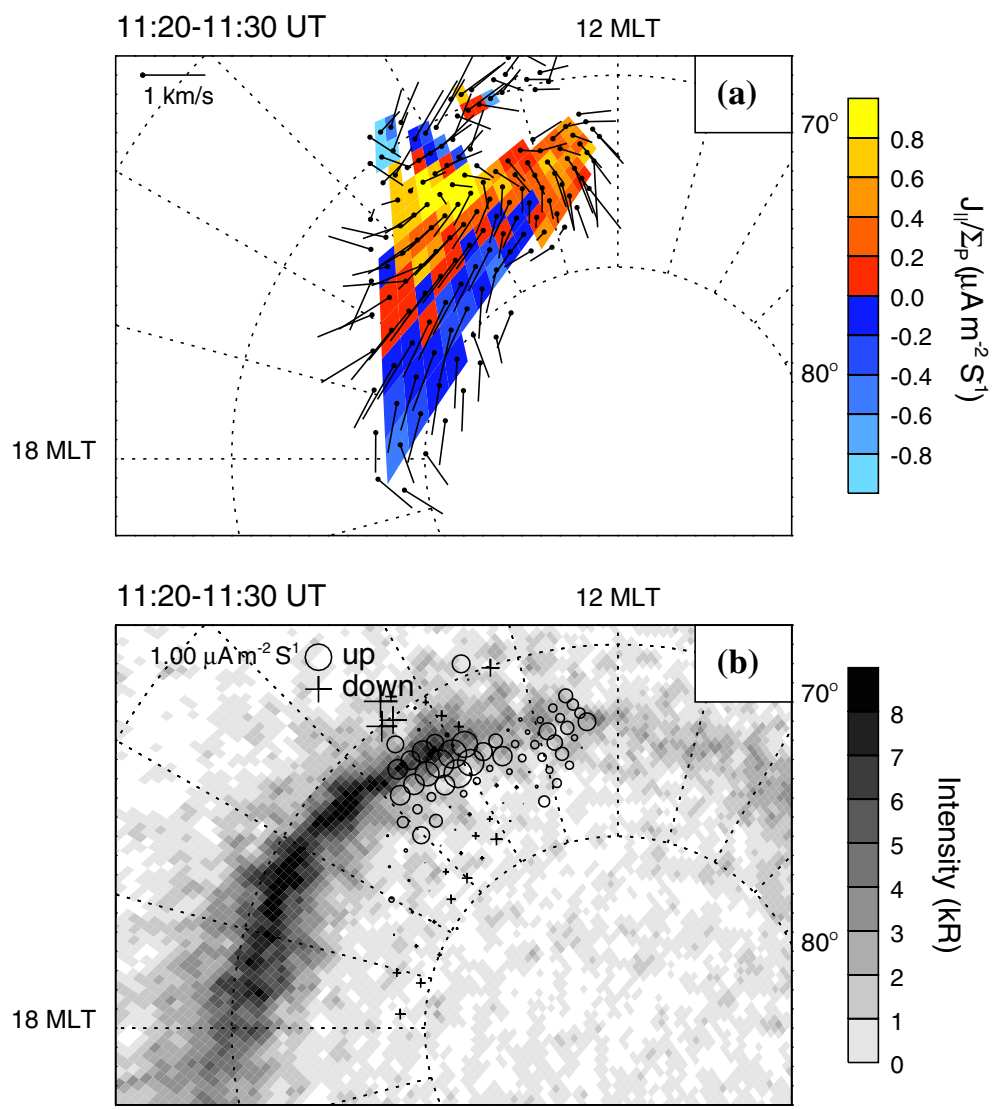

VIS Earth Camera 24-Nov-98 11:25:13 UT (start time), Exp $=32500 \mathrm{~ms}$

Fig. 10 (a) A SuperDARN vorticity map for the interval 1120-1130 UT on November 24, 1998, obtained from Merge velocity vectors using the method of Sofko et al. (1995). Positive vorticity is coloured redyellow and indicates FACs out of the ionosphere, and negative vorticity is blue and indicate FACs into the ionosphere. The Merge vectors are shown in the same format as in Fig. 7. (b) An alternative visualization of the same vorticity map with circles representing upward FACs and crosses representing downward FACs. The size of the symbols is proportional to the size of the current. The FAC estimates have been overlaid onto a Polar VIS Earth Camera auroral image. In both panels the dashed circles represent lines of constant AACGM latitude and the other dashed lines represent MLT meridians. This figure is adapted from McWilliams et al. (2001)

McWilliams et al. 2001). Here, the white solid and dashed lines represent the equipotential contours, the colour contours represent the vorticity, and magnetic local noon is the central meridian of the figure. In the postnoon sector, the large-scale clockwise vorticity gives rise to a large band of upward FAC (red/yellow) at auroral latitudes. In the prenoon sector, the largescale counterclockwise vorticity gives rise to a large band of downward FAC (blue). The morphology of the FACs has a very good qualitative agreement with simultaneous auroral images shown in Fig. 11a; bands of strong upward FAC (red/yellow) are co-located with regions of bright aurora, and bands of strong downward FAC (blue) are co-located with dark regions in the auroral images. McWilliams et al. (2001) concluded from these observations that the FAC pattern and auroral emissions in the footprint of the dayside reconnection region 

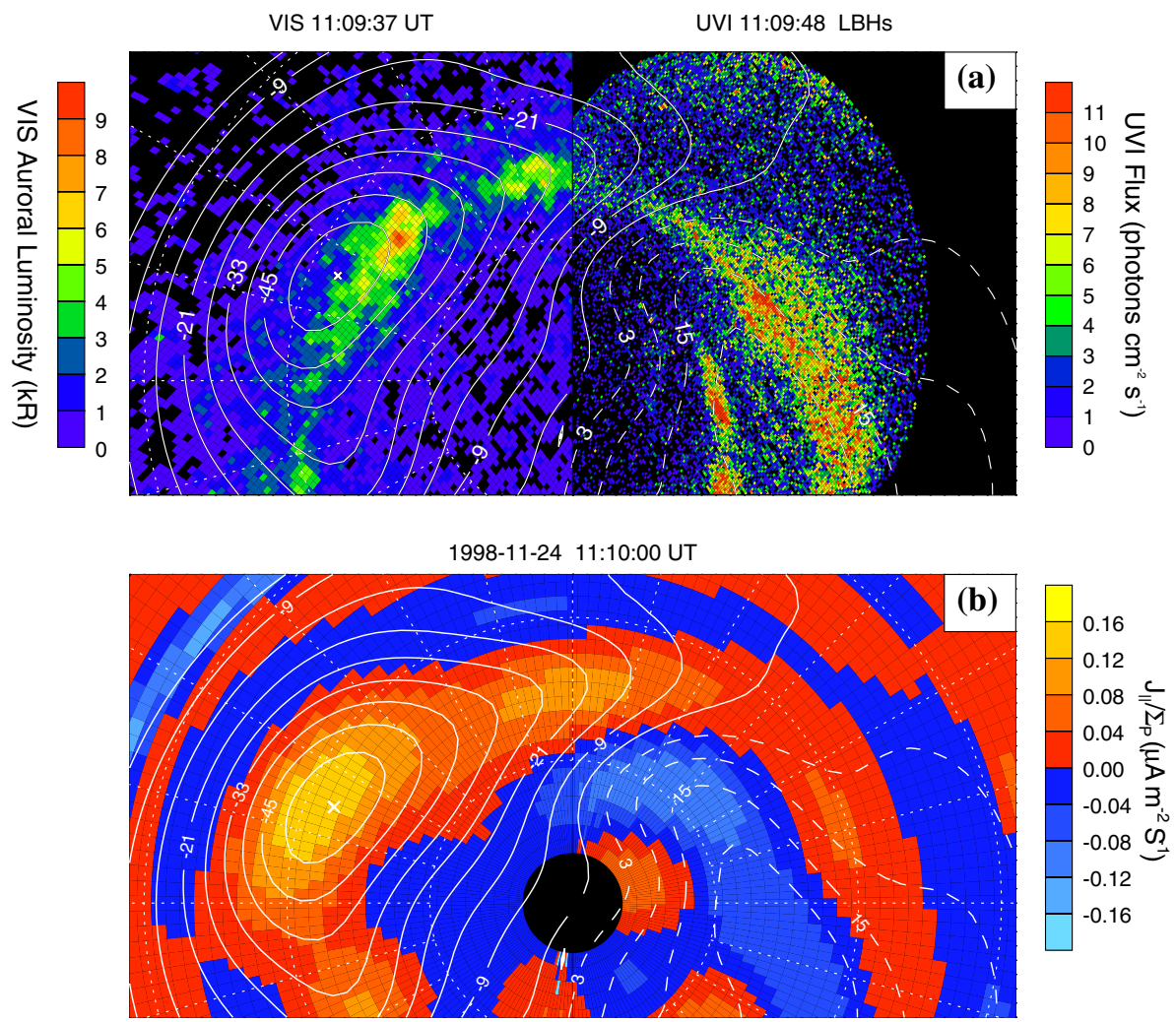

Fig. 11 (a) The dayside ultraviolet aurora measured by the Polar VIS Earth Camera (left) and by Polar UVI (right) around 1110 UT on November 24, 1998. Also shown as white solid and dashed lines are the ionospheric convection equipotential contours determined using the Map Potential technique. (b) The FAC vorticity map, $\mathbf{B} \cdot(\nabla \times \mathbf{v})$, for the same time interval, calculated using the convection velocities derived from the fitted equipotential contours. Negative vorticity values (blue) represent FAC flow into the ionosphere, and positive vorticity values (red-yellow) represent FAC flow out of the ionosphere. This figure is adapted from McWilliams et al. (2001)

were consistent with a dayside current wedge which is excited in response to the removal of magnetic flux from the dayside magnetopause during magnetic reconnection. The current induced on the magnetopause during reconnection, which is effectively a diminution of the Chapman-Ferraro current, can close by FACs at each end of the reconnection X-line. The vorticity maps and auroral images were consistent with a downward FAC on the western end of the reconnection footprint and an upward FAC on the eastern end of the reconnection footprint, in accordance with this current wedge picture. This FAC pair was observed to propagate eastward, in accordance with the antisunward propagation of the reconnection $\mathrm{X}$-line at the magnetopause.

To assess the validity of SuperDARN vorticity maps, Kustov et al. (1997) compared vorticity maps with FACs derived from the IZMEM model (Papitashvili et al. 1994). IZMEM, which models ionospheric convection, electric fields, and FACs, is based on a regression analysis between the IMF and magnetic field measurements from ground magnetometers. It produces total FACs by including a statistical model of conductivity due to particle precipitation, as well as a contribution from modelled photoionization. Kustov 
et al. (1997) examined several events during a variety of relatively stable IMF conditions and showed that the modelled FACs from IZMEM and the vorticity maps from SuperDARN were qualitatively similar in location, magnitude and direction for these stable conditions. More recently, Green et al. (2006) have questioned whether the convection vorticity is a suitable proxy for FACs. They compared FACs determined from SuperDARN convection vorticity measurements with FACs determined from Iridium spacecraft magnetometers and found that the assumption of uniform conductance is often a poor approximation. The assumption works best in the dayside ionosphere where photo-ionization results in a fairly uniform conductance. Away from noon, currents arising from conductance gradients are usually dominant. Using the assumption of uniform conductance does not account for these conductance gradient terms.

\section{Remote sensing of magnetic reconnection}

The study of magnetic reconnection was not originally highlighted by Greenwald et al. (1995a) as a core science objective for SuperDARN. However, SuperDARN has proved an excellent tool for defining the ionospheric signature of magnetic reconnection at the Earth's magnetopause and in the Earth's magnetotail. Studies of the structure and dynamics of global and mesoscale convection (see Sects. 2.2-2.4) have provided a wealth of information about the reconnection process from its effects on ionospheric convection, particularly the effects of transient reconnection such as FTEs. Ionospheric convection signatures have also been used to test theories of reconnection and to remotely measure reconnection rates. Estimates of the magnetopause and magnetotail reconnection rates are made in the ionosphere by measuring the magnetic flux transfer across the ionospheric projection of the reconnection separatrix that exists between regions of different magnetic connectivity. For most IMF orientations the separatrix is the boundary between closed magnetic field lines that have both ends connected to the Earth, and open magnetic field lines which have one end connected to the Earth and the other connected to the IMF. This boundary is termed the OCB. Here we discuss first, how SuperDARN is used to identify the OCB, second, how SuperDARN measurements at the OCB have allowed the remote sensing of reconnection rates, and finally, how SuperDARN observations have been used to test competing reconnection theories.

\subsection{Determining the OCB}

The ability to make continuous and extensive measurements of the ionospheric footprint of the open-closed magnetic field line boundary (OCB), that separates the closed magnetospheric flux from the open flux in the polar caps, is highly beneficial to studies of reconnection. The different topology and connectivity of open and closed geomagnetic field lines results in different plasma properties in the two regions that can be detected in particle precipitation signatures at the ionospheric footprints of these regions. These differences are also indirectly manifest in many measurable physical variables in the ionosphere which has led to the development of a number of proxy signatures for the OCB location. One of these is the Doppler spectral width boundary (SWB) measured by SuperDARN.

The Doppler spectral width of SuperDARN backscatter was first identified as being a potential diagnostic of different geophysical regions by the observation of high spectral 
width values in the ionospheric cusp by Baker et al. (1995). They also showed that the lowlatitude boundary layer (LLBL) region, equatorward of the cusp, was characterized by lower spectral width values. The latitudinal transition between these two spectral width regions became known as the SWB and case study comparisons with datasets from other instrumentation showed the SWB to be a good proxy for the equatorward edge of the cusp (Baker et al. 1995; Rodger et al. 1995; Yeoman et al. 1997a; Milan et al. 1999b), and hence for the dayside OCB. The SWB was also identified as a regular feature of the nightside ionosphere although its relationship with the OCB was not as easily established, with some studies suggesting that the two boundaries were co-located (Lester et al. 2001; Parkinson et al. 2002) and others suggesting that the SWB was located on closed field lines, equatorward of the OCB (Dudeney et al. 1998; Woodfield et al. 2002a, b, c). An asymmetry was evident around midnight with the SWB appearing to be a good OCB proxy in the premidnight sector (Lester et al. 2001) and a poor OCB proxy in the post-midnight sector (Woodfield et al. 2002a, b, c).

Although latitudinal profiles of Doppler spectral width display a characteristic pattern of high spectral widths at high latitudes and low spectral widths at low latitudes (Chisham et al. 2001; Chisham and Freeman 2004), the SWB is not always a sharp feature, and the transition can occur over a number of SuperDARN range gates (100's of km) (Chisham and Freeman 2004). Hence, identifying a 'boundary' is not always a trivial task, although many studies have used subjective 'fit-by-eye' methods. Devising a reliable method for accurately determining the SWB required an understanding of the statistical distributions of spectral width typically found in different regions of the ionosphere. Baker et al. (1995) first studied the distributions of dayside spectral width values, suggesting that the distribution of values seen poleward of the SWB in the cusp region was approximately Gaussian (with a mean value of $\sim 220 \mathrm{~m} / \mathrm{s}$ ) and the distribution of values seen equatorward of the SWB in the LLBL region was approximately exponential (with a mean value of $\sim 50 \mathrm{~m} / \mathrm{s}$ ). The large overlap between these two distributions makes accurate identification of the SWB more difficult (i.e., there are times when the same spectral width values may be seen both poleward and equatorward of the SWB). Subsequent studies observed similar spectral width distributions (Provan et al. 1998; Chisham et al. 2001) and the variation of these distributions with geomagnetic latitude and MLT (Hosokawa et al. 2002; Woodfield et al. 2002c), or with distance from the SWB (Chisham and Freeman 2004) was more clearly defined. The continuous nature of the spectral width distributions across the SWB, identified in some of these studies, led Freeman and Chisham (2004) to suggest that the distributions either side of the SWB may not have distinct functional forms, but instead could be described by one function with varying moments. They discovered that all spectral width distributions could be well described by log-Lévy distributions-a class of distributions that includes the log-normal distribution.

A better understanding of these spectral width distributions led to the development of a reliable and objective method for determining the SWB known as the 'C-F threshold technique' (Chisham and Freeman 2003, 2004). Using this method, Chisham et al. (2004a, $2005 \mathrm{a}, \mathrm{b}, \mathrm{c})$ systematically compared the latitudinal locations of SWBs in 5 years of SuperDARN data with particle precipitation boundaries (PPBs) measured by the Defense Meteorological Satellite Program (DMSP) spacecraft, at all MLTs. They concluded that the SWB is a good proxy for the OCB in the pre-midnight sector (1800-0200 MLT) and noon sector (0800-1200 MLT) but is located $\sim 2-4^{\circ}$ equatorward of the OCB across much of the morning sector (0200-0800 MLT), consistent with the differing results obtained either side of midnight in earlier case studies. Additionally, Chisham et al. (2005c) concluded that in the early afternoon sector (1200-1800 MLT), only SWBs measured 


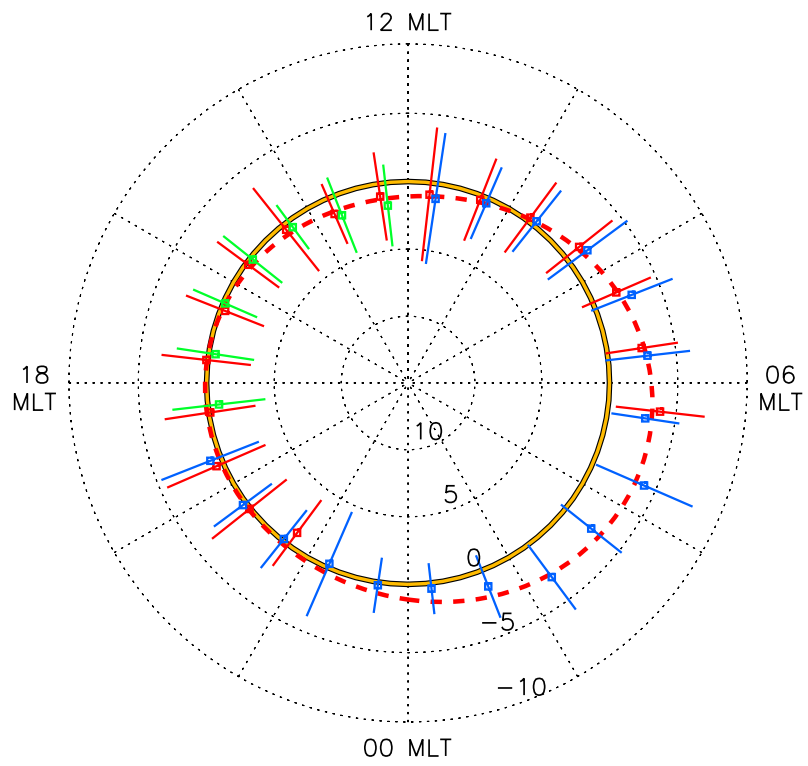

Fig. 12 A statistical comparison of three ionospheric proxies for the OCB (see text for full details). The radial co-ordinate represents the difference in AACGM latitude between each proxy and the DMSP proxy, and the azimuthal co-ordinate represents MLT with magnetic local noon at the top of the figure. The DMSP proxy is shown in yellow at $0^{\circ}$ latitude difference. For the other proxies the mean latitude difference in each 1-h MLT bin is shown by a coloured square and the standard deviations by the radial error bars. The Polar UVI proxy is shown in red and a red dashed line shows a low-order harmonic expansion fit to the mean latitude differences (from Carbary et al. 2003). The SWB proxy is shown in blue in the 1900-2400 MLT sector (from Chisham et al. 2004) and the 0000-1200 MLT sector (from Chisham et al. 2005a). The SWB proxy above $74^{\circ}$ latitude in the 1200-1900 MLT sector is shown in green (from Chisham et al. 2005c)

poleward of $\sim 74^{\circ}$ AACGM latitude were good proxies for the OCB. Figure 12 summarizes the results of Chisham et al. (2004a, b, 2005a, c). The DMSP proxy for the OCB is shown as the yellow circle and all measurements are presented relative to this. The blue symbols represent the mean latitudinal offsets of the SWB from the DMSP OCB proxy in 1-h MLT bins in the 1900-2400 and 0000-1200 MLT sectors. The blue radial error bars show the standard deviation of the latitude difference distributions in each MLT sector. The green symbols represent the mean latitudinal offsets in the 1200-1900 MLT sector only considering SWBs measured poleward of $74^{\circ}$ AACGM latitude.

Although it has been possible to determine an empirical relationship between the SWB and the OCB, a full understanding of the physical processes which result in the enhancement of spectral width is still outstanding. The spatial organization of classes of backscatter spectra in the polar ionospheres (Huber and Sofko 2000; André et al. 2002; Villain et al. 2002; André and Dudok de Wit 2003) suggests that the origin of high spectral width values is related primarily to physical processes rather than instrumental and/or propagation effects. Suggested processes include the variability within the large-scale ionospheric convection pattern (André et al. 2002; Villain et al. 2002), smaller-scale vortical convection structures generated by filamentary FACs (Schiffler et al. 1997; Huber and Sofko 2000), intense particle precipitation (Baker et al. 1995; Ponomarenko and Waters 2003) which can result in strong spatial and temporal non-uniformity in ionospheric irregularities, and low-frequency $(\sim 0.01-10 \mathrm{~Hz})$ waves (André et al. 1999, 2000; 
Hosokawa et al. 2004; Wright et al. 2004; but see also Ponomarenko and Waters 2003). Chisham et al. (2005a) noted that the MLT variation of the latitudinal offset between the SWB and the OCB was identical to that observed between the poleward edge of the Lyman-Birge-Hopfield "Long" (LBHL) auroral oval $(\sim 170 \mathrm{~nm}$ ) measured by the UVI instrument on the Polar spacecraft and the OCB, as determined by Carbary et al. (2003). This is illustrated in Fig. 12 where the red symbols represent the mean latitudinal offsets determined by Carbary et al. (2003) in each 1-h MLT sector. The red radial error bars show the standard deviation of the latitude difference distributions in each MLT sector. The red dashed line represents a low-order harmonic expansion fit to the mean latitudinal offsets. As the intensity of LBHL emissions has been shown to be approximately proportional to the energy flux of precipitating electrons (Germany et al. 1997; Carbary et al. 2004), these results imply a correlation between SuperDARN spectral width and the level of precipitating electron energy flux, with regions of high (low) spectral width associated with regions of low (high) electron energy flux. This correlation may help to address the outstanding question of the source of enhancements in spectral width.

\subsection{Reconnection rate measurements}

The reconnection rate (or reconnection electric field) is defined as the rate of transfer of magnetic flux across unit length of the separatrix between unreconnected and reconnected field lines. Continuous and extensive measurements of reconnection in time and space can presently be achieved only by remotely sensing magnetic reconnection in the magnetosphere from the ionosphere. The reconnection rate is measured in the ionosphere by first detecting regions of different magnetic connectivity (e.g., open and closed magnetic field lines) and then measuring the transport of magnetic flux between them. The reconnection rate equates to the convection electric field at the reconnection separatrix, in the frame of the reconnection separatrix.

The first reconnection rate measurements of this type were made in the nightside ionosphere by de la Beaujardière et al. (1991) using Sondrestrom incoherent scatter radar measurements. Using a single meridional radar beam they measured the plasma velocity across the OCB in the OCB rest frame. Baker et al. (1997) made the first measurements of this type using SuperDARN radars. They used the technique of L-shell fitting to estimate two-dimensional velocity vectors from line-of-sight velocity measurements made by the Goose Bay radar. They combined these with measurements of the SWB to estimate the reconnection rate across an extended longitudinal region. Following this, Pinnock et al. (1999) determined the temporal variation of the reconnection rate at conjugate meridians, using the Goose Bay radar in the northern hemisphere, and the Halley radar in the southern hemisphere. They showed that the dayside reconnection rate values were largest when the radar's meridian was in the throat flow or early afternoon flow regions, and that the reconnection rate in the throat flow region was bursty in nature.

More recently, the growth of the SuperDARN network has allowed measurements of the convection velocity, and hence the reconnection rate, over much larger regions of the ionosphere. Using a combination of SuperDARN and spacecraft imager observations, Milan et al. (2003b) studied the variation of the total net reconnection rate and the relationship between magnetopause and magnetotail reconnection during two substorm cycles, calculated from the rate of change of the area of the open field line region. The size of the open field line region was found to change by a factor of three during the interval. Separating the contributions from magnetopause and magnetotail reconnection using 


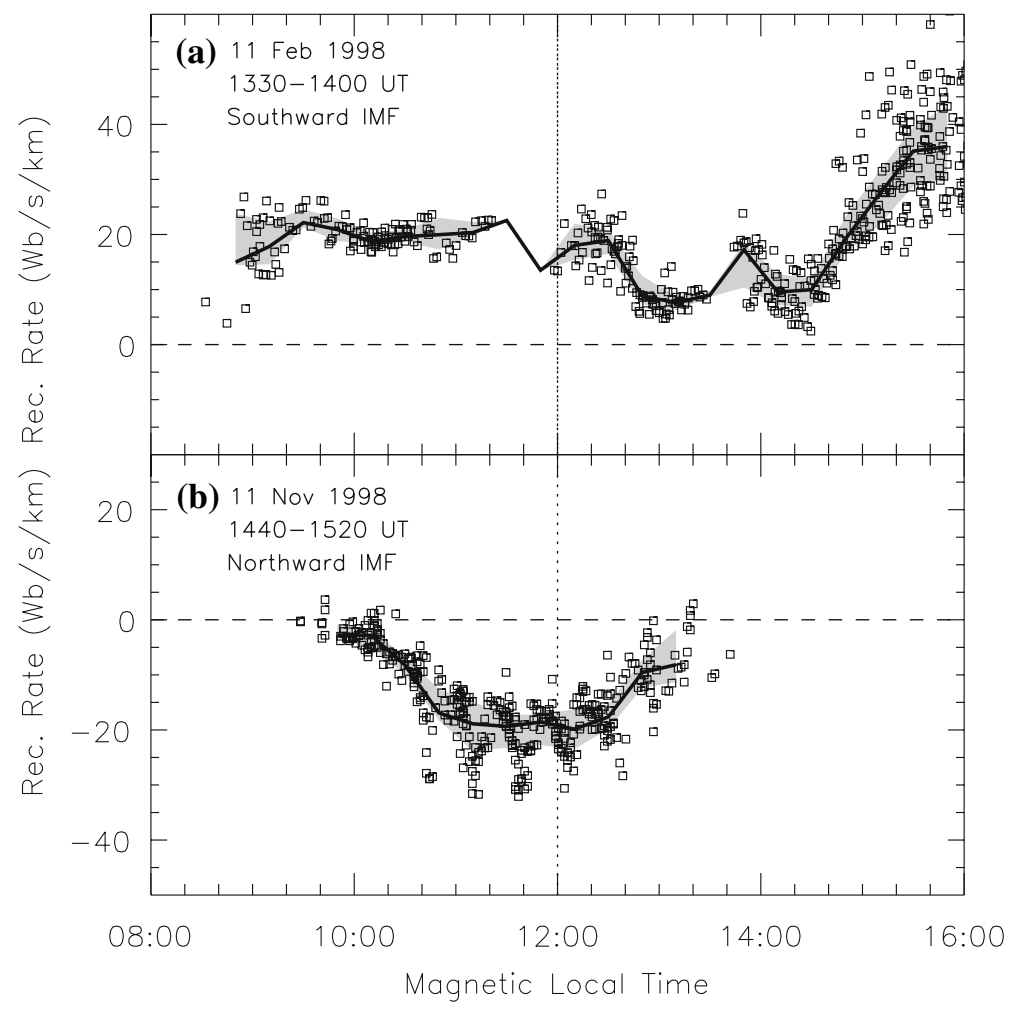

Fig. 13 The spatial variation (with MLT) of remote measurements of the magnetopause reconnection rate made from the ionosphere using SuperDARN observations. (a) The reconnection rate variation during an interval of due southward IMF from 1330 to 1400 UT on February 11, 1998 (from Pinnock et al. 2003). (b) The reconnection rate variation during an interval of due northward IMF from 1440 to 1520 UT on November 11, 1998 (from Chisham et al. 2004b). The square symbols represent individual reconnection rate measurements and the bold line (shaded region) represents a running median (quartile range) of those measurements

SuperDARN measurements of the reconnection rate in the dayside ionosphere, Milan et al. (2003b) showed that nightside reconnection following the first substorm lasted less than $200 \mathrm{~min}$, and likely only $100 \mathrm{~min}$ - the duration of the recovery phase of the first substorm.

Pinnock et al. (2003) studied the extent, and spatial and temporal variation of magnetopause reconnection during steady due southward IMF. They derived the ionospheric projection of the magnetopause reconnection rate across the dayside ionosphere, as summarized in Fig. 13a. The squares represent individual reconnection measurements made at different MLTs over the interval 1330-1400 UT on February 11, 1998, and the bold line (shaded region) represents the median (quartile) variation of these measurements with MLT. This figure shows that, overall, reconnection occurred over the entire MLT extent of existing SuperDARN observations from 0900 to 1600 MLT. Mapping this to the equatorial magnetopause position, calibrated using in-situ spacecraft encounters of the magnetopause, implied the reconnection separatrix length to be at least $38 R_{E}$, extending beyond both the dawn and dusk flanks of the magnetopause. The typical reconnection rate measured in the ionosphere was $\sim 20 \mathrm{~Wb} / \mathrm{s} / \mathrm{km}$. Integrating this over the entire separatrix gives 
a minimum total reconnection rate of $\sim 150 \mathrm{kWb} / \mathrm{s}$, and dividing by the separatrix length at the magnetopause gives an average reconnection rate there of $\sim 0.6 \mathrm{~Wb} / \mathrm{s} / \mathrm{km}$, comparable with independent in-situ spacecraft estimates for the same event (Phan et al. 2000). This study was complemented by a similar analysis of the reconnection rate during an interval of steady, due northward IMF (Chisham et al. 2004b). The ionospheric projection of the magnetopause reconnection rate determined by Chisham et al. (2004b) is summarized in Fig. 13b. The squares represent individual reconnection measurements made at different MLTs over the interval 1440-1520 UT on November 11, 1998, and the bold line (shaded region) represents the median (quartile) variation of these measurements with MLT. For these conditions, the reconnection separatrix was largely contained within the MLT extent of radar observations from 1000 to 1300 MLT, as can be seen by the drop to small reconnection electric fields at the MLT limits of the observations. The reconnection separatrix was found to map to the high-latitude lobe magnetopause, anti-sunward of the cusp, with a length of $\sim 6-11 R_{E}$. The total reconnection rate of $10-16 \mathrm{kWb} / \mathrm{s}$ is an order of magnitude smaller than for the southward IMF case, whereas the average reconnection rate of $\sim 0.2 \mathrm{~Wb} / \mathrm{s} / \mathrm{km}$ at the magnetopause is only a factor of three lower.

Magnetotail reconnection rates have also been estimated using SuperDARN observations in the nightside ionosphere. Lam et al. (2006) studied both spatial and temporal variations in the reconnection rate in the nightside ionosphere during the growth and expansion phases of an isolated substorm using different instrumentation to study the reconnection rate on different spatial scales. On the mesoscale they used Merge vectors from the Kapuskasing and Saskatoon SuperDARN radars and estimates of the OCB from ground-based all-sky imager data. On the larger scale they used SuperDARN Map Potential convection maps and estimates of the OCB from the Polar UVI global auroral imager. They measured localized enhancements of the reconnection rate between 0 and $50 \mathrm{~Wb} / \mathrm{s} / \mathrm{km}$ during both the growth and expansion phases. They deduced that the width of the magnetotail $\mathrm{X}$-line expanded from $\sim 4 \mathrm{~h}$ of MLT to $\sim 7 \mathrm{~h}$ of MLT during the first $15 \mathrm{~min}$ of the substorm expansion phase.

With the present near-total coverage of the polar regions by the SuperDARN fields of view it is now possible to measure both the magnetopause and magnetotail reconnection rates simultaneously. Hubert et al. (2006) were the first to make measurements of this type, using the IMAGE FUV experiment to provide estimates of the OCB over the whole northern hemisphere polar ionosphere, in association with SuperDARN Map Potential estimates of convection. They determined that the dayside reconnection rate was consistent with solar wind properties measured by upstream satellites. On the nightside, they identified the presence of nightside reconnection due to pseudobreakups taking place during a substorm growth phase. They further showed that the nightside reconnection rate was at a maximum at the time of the substorm expansion phase onset, or shortly after (reaching $\sim 120 \mathrm{kWb} / \mathrm{s})$.

\subsection{Testing reconnection theory}

SuperDARN measurements have also been used to test or develop reconnection theory. One of the most contentious issues associated with the understanding of magnetopause reconnection in recent years is what factors determine where reconnection occurs, and specifically, is the magnetic shear between the magnetosheath and magnetospheric magnetic fields the major determining factor? The antiparallel reconnection hypothesis postulates that the magnetic shear is the major controlling factor with the reconnection rate 


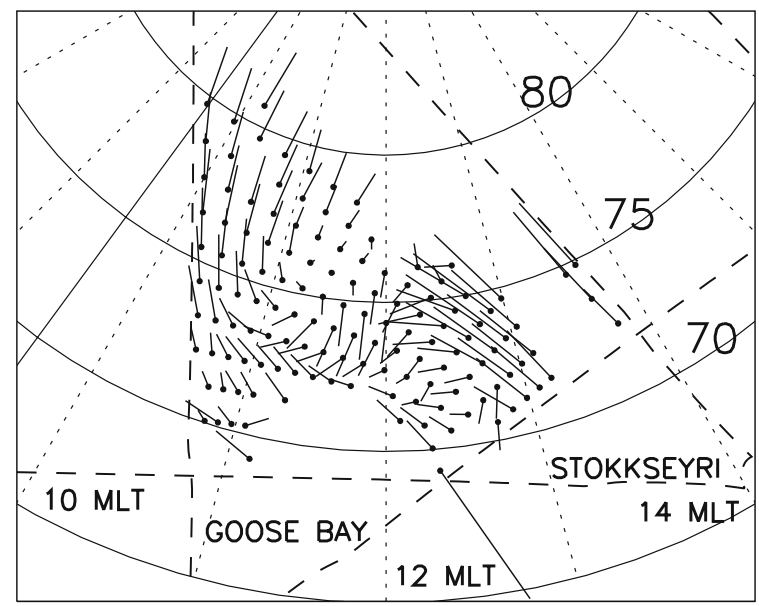

Fig. 14 Two-dimensional Merge velocity vectors from the Goose Bay and Stokkseyri SuperDARN radars. The line-of-sight velocity data from both radars was averaged over a 20-min interval (1340-1400 UT) from December 10, 1997 before determination of the vectors. The Merge vectors are shown in a similar format to Fig. 7. The dashed lines show the fields of view of the two radars and the dotted lines represent MLT meridians (centred on 1200 MLT). This figure is adapted from Coleman et al. (2001)

increasing greatly in regions where the magnetic shear approaches $180^{\circ}$ (antiparallel). The component reconnection hypothesis postulates that reconnection can occur for any magnetic shear and occurs along a tilted merging line passing through the subsolar point where the magnetosheath magnetic field strength is highest, and where the magnetosheath plasma flows stagnate.

Coleman et al. (2001) designed a critical test of these two competing reconnection hypotheses. They used a magnetospheric magnetic field model to show that during intervals when IMF $\left|B_{y}\right| \sim\left|B_{z}\right|$ and $B_{z}<0$, there exist distinct differences between the ionospheric signatures of reconnection predicted by the two hypotheses. Non-zero IMF $B_{y}$ causes the antiparallel region at the magnetopause to split into two high-latitude regions, which diverge further from the subsolar point as the $B_{y}$ component becomes more dominant (Luhmann et al. 1984). When mapped to the ionosphere the outcome is two separate merging lines in each hemisphere, the separation of which is clearest in the winter hemisphere at solstice (large dipole tilt). This prediction does not occur for the component merging hypothesis, which is always characterized by a single continuous merging line. Coleman et al. (2001) also predicted differences in the convection electric field in the noon sector ionosphere for both hypotheses. If the polar cap is expanding, antiparallel merging predicts a region with an equatorward convection flow component near noon, flanked by two regions with poleward flow components, whereas component merging predicts a single poleward flow component region. Figure 14 presents an example of SuperDARN Merge vectors (from Coleman et al. 2001) which illustrated the presence of the distinctive convection signature predicted by antiparallel merging. Poleward flow is clearly seen to both the west and east of the magnetic local noon meridian (centred around 1030 MLT and $\sim 1300$ MLT, respectively) whereas close to noon there is a band of equatorward flow (centred around $\sim 1140$ MLT). Chisham et al. (2002) presented further examples of this distinctive convection signature during intervals where IMF $\left|B_{y}\right| \sim\left|B_{z}\right|$, lending support to 
the hypothesis that antiparallel merging was the dominant form of magnetopause reconnection during these intervals. Other estimates of the magnetopause reconnection location based on conjugate SuperDARN observations (Chisham et al. 2000a) also support the existence of antiparallel reconnection. However, other studies (mainly using spacecraft data) have argued in favour of component reconnection (e.g., Trattner et al. 2004; Fear et al. 2005) and the reasons for this disagreement need to be understood (e.g., Abel et al. 2005).

\section{Substorms}

Magnetospheric substorms are a major contributing factor to large-scale magnetosphereionosphere dynamics and are also associated with a variety of smaller-scale phenomena. They comprise a cycle of energy storage and release that can be broken down into three distinct phases-growth, expansion, and recovery (McPherron 1970). Early studies of substorm current systems identified distinct patterns of ionospheric currents that existed during the substorm cycle (Clauer and Kamide 1985). In comparison to the substorm current systems, relatively little was known about the structure and variation of the electric field during the substorm cycle prior to the advent of SuperDARN. Localized observations using the STARE radar and ground-based magnetometers had shown that the relationship between flows and currents could be complicated due to localized variations in conductivity. The ability to combine observations from a large number of radars makes SuperDARN ideally suited to investigating large-scale variations in convection through the substorm cycle (as discussed partially in Sects. 2.3, 2.4 and 4.2).

\subsection{Substorm growth phase}

In the substorm growth phase, magnetospheric and ionospheric convection are enhanced, driven by reconnection at the dayside magnetopause. The imbalance in reconnection rates at the magnetopause and in the magnetotail during this phase results in the expansion of the area of incompressible open magnetic flux in the polar caps (Siscoe and Huang 1985; Cowley and Lockwood 1992). This polar cap expansion results in the characteristic SuperDARN signature of the substorm growth phase - an equatorward propagation of the equatorward edge of SuperDARN backscatter (Lewis et al. 1997, 1998). However, this signature can generally only be observed clearly for isolated substorms following quiet conditions (Lewis et al. 1998). Using these measurements, or other observations which allow estimates of changes in polar cap area (such as those made by spacecraft auroral imagers), it is possible to estimate the magnetopause reconnection rate during the substorm growth phase, assuming there is little or no magnetotail reconnection (Lewis et al. 1998; Milan et al. 2003b). By comparing these estimates with estimates of the expected dayside reconnection rate based on solar wind parameters it is also possible to estimate the length of the reconnection X-line (Lewis et al. 1998). Yeoman et al. (1999), using SuperDARN radars in both hemispheres, showed evidence of highly conjugate behaviour during a substorm growth phase. The characteristic equatorward progression of radar backscatter was almost identical in both hemispheres, and well matched by a calculation of the expected position of the equatorward boundary of the radar backscatter, based on an estimate of the reconnection rate at the magnetopause and the relationship between the cross-polar cap potential and the change in polar cap area. 
SuperDARN studies of ionospheric flows in the nightside ionosphere during the substorm growth phase have also produced interesting results. Watanabe et al. (1998) identified bursts of enhanced convection flow occurring at the OCB in the midnight sector. These flow enhancements commenced $\sim 1 \mathrm{~h}$ after growth phase onset and continued for $\sim 10-20$ min before substorm onset, moving equatorward with time in association with the expansion of the polar cap. They interpreted these observations as the ionospheric signature of distant magnetotail reconnection and suggested that the enhancement of distant tail reconnection is indirectly coupled with the substorm onset as a result of the rapid nonlinear stretching of the magnetic field. Voronkov et al. (1999) used SuperDARN Merge vectors to study the changes in ionospheric convection in the midnight sector in more detail during the substorm growth phase. They showed that convection intensified at the beginning of the growth phase, forming a flow with a large-amplitude westward component, relating to an increased eastward electrojet. During the growth phase, the location of the flow maximum moved equatorward until finally, just prior to the substorm expansion phase onset, the flow developed significant latitudinal gradients.

Interesting convection features have also been observed in the dayside ionosphere during the substorm growth phase. Greenwald et al. (1996) observed a convection vortex in the early afternoon sector (1430-1530 MLT; 75-80 geomagnetic latitude), near the sunward end of the dusk convection cell, which appeared to be associated with the substorm growth phase. The vortex disappeared at substorm expansion phase onset. A full explanation for this phenomenon is outstanding.

\subsection{Substorm expansion phase}

Early HF radar observations of the convection electric field during the substorm expansion phase were made on the small or meso-scale. Morelli et al. (1995) presented the basic convection flow features associated with the substorm onset region, and Fox et al. (1999) observed a surge of transpolar flow into the midnight sector during a substorm intensification and associated it with a burst of reconnection in the tail. Figure 15 (from Yeoman et al. 2000) presents the ionospheric convection flow near midnight as measured by SuperDARN before and during a substorm expansion phase. The top panel shows the preonset conditions, which consist of a nominal two-cell convection pattern. Just after substorm onset (middle panel) a suppression of the flow (wider-spaced equipotential contours) becomes evident near the midnight meridian, at the location of the substorm bulge, with faster flows (closer-spaced equipotential contours) being diverted around the sides of the bulge consistent with the observations of Morelli et al. (1995). About $10 \mathrm{~min}$ into the expansion phase (lower panel) the twin-vortex pattern reappears as the reduction in ionospheric conductivity allows convection to flow through this region again. In addition to the suppression of the flow seen at substorm onset, there is sometimes a loss of SuperDARN backscatter altogether during the substorm expansion phase. This was found to be a result of the absorption of the HF radio signal by the enhanced electron densities in the substorm precipitation region (Milan et al. 1999a). Hence, studying the expansion phase using the SuperDARN radars can prove problematic. However, there are often large areas of backscatter still present in the vicinity of the substorm enhanced conductivity and precipitation regions which can reveal much about the electrodynamics.

Cowley and Lockwood (1992) postulated that significant large-scale twin-vortex flows centred in the nightside ionosphere would be excited during substorms, analagous to those associated with dayside reconnection-driven convection (Russell 1972; Siscoe and Huang 


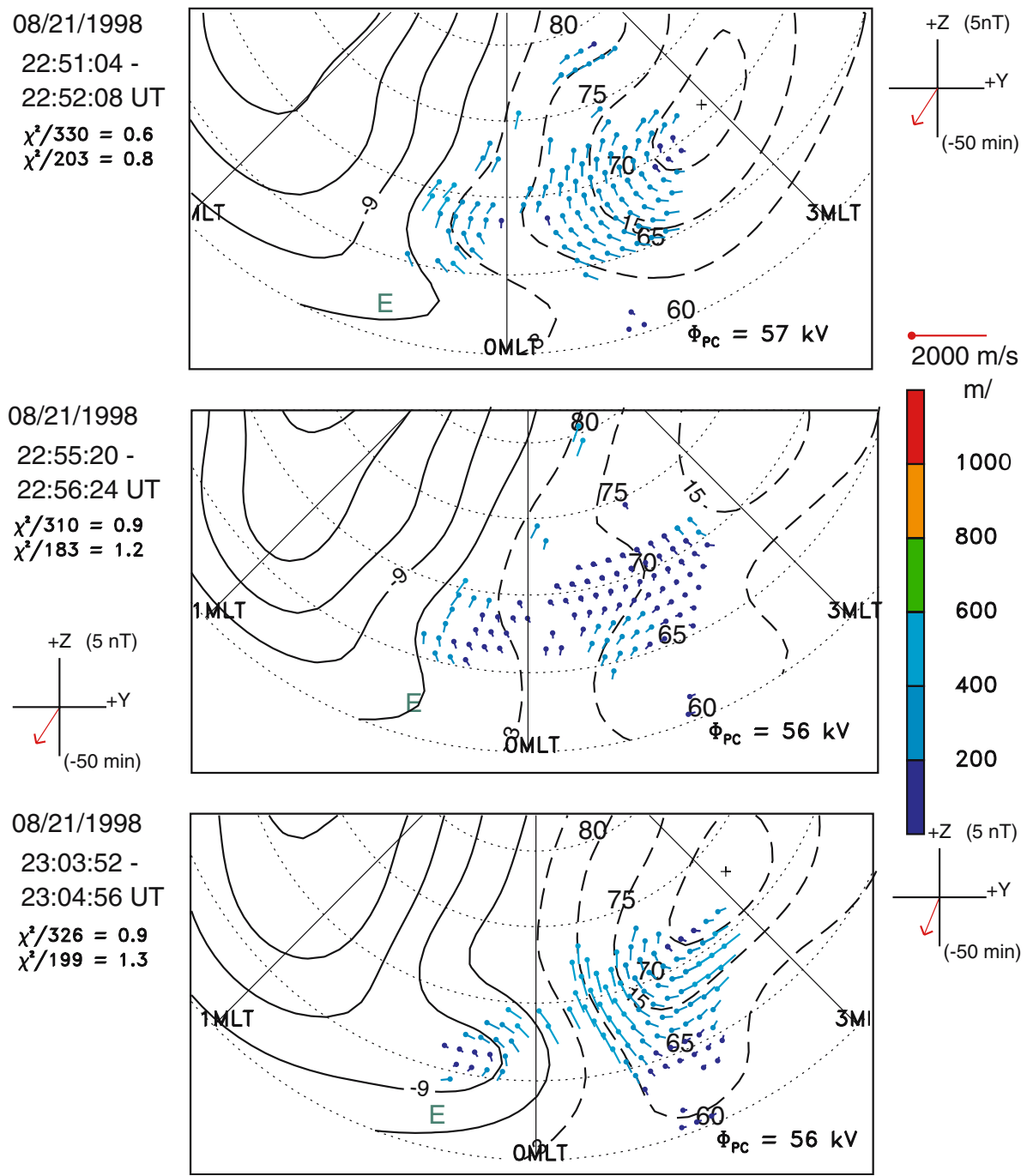

Fig. 15 SuperDARN northern hemisphere convection maps showing the development of nightside ionospheric flows around substorm onset. The convection maps are presented in a similar format to Fig. $2 \mathrm{~b}$. The three panels illustrate the convection before substorm onset (top panel), just after substorm onset (middle panel), and $10 \mathrm{~min}$ after substorm onset (bottom panel), on August 21, 1998. This figure is reproduced from Yeoman et al. (2000), copyright by the European Geophysical Union

1985; Freeman and Southwood 1988). The expansion of the SuperDARN network allowed for the study of these larger-scale substorm-associated flows. Analyses of SuperDARN convection flows, obtained during isolated substorms, found evidence for the excitation of twin-vortex flow cells centred in the nightside ionosphere, which enhance the transpolar voltage by $\sim 40 \mathrm{kV}$ compared with pre-onset values (Grocott et al. 2000, 2002). This is illustrated in Fig. 16, which shows maps of the northern hemisphere high-latitude convection before (top panel) and after (bottom panel) the onset of a substorm. The excitation of strong convection flow (red vectors in the bottom panel) and the enhanced voltage between 

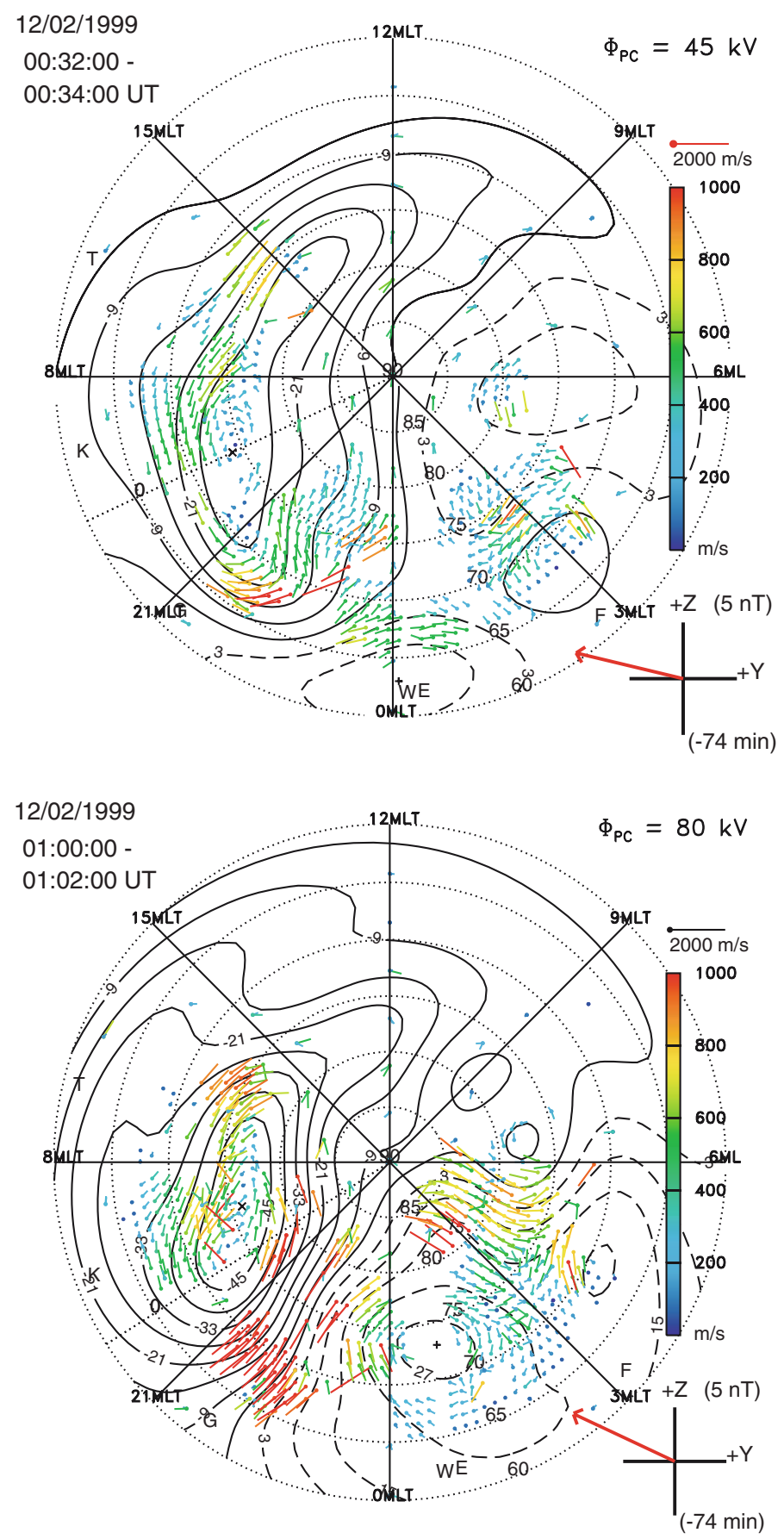

Fig. 16 SuperDARN map potential convection maps from the northern hemisphere on December 2, 1999, showing the excitation of enhanced twin-vortex flow during an isolated substorm. These maps show the ionospheric convection scenario (a) before and (b) after a substorm expansion phase onset at 0044 UT. The convection maps are presented in the same format as Fig. 2b. This figure is reproduced from Grocott et al. (2002), copyright by the European Geophysical Union 
the extremes of the equipotential pattern (from $45 \mathrm{kV}$ up to $80 \mathrm{kV}$ ) are clearly evident. Following this work, Provan et al. (2004) conducted a global statistical study of ionospheric convection flows associated with substorms and found that at substorm expansion phase onset, a flow suppression region occurred in the nightside ionosphere, with fast flows surrounding the suppressed flow region. The cross-polar cap potential increased from $\sim 40 \mathrm{kV}$ just before onset to $\sim 75 \mathrm{kV} 12$ min after onset. The low latitude return flow started to increase in magnitude at onset and continued to increase until $8 \mathrm{~min}$ after onset.

Studies of the dayside convection response to substorms, during steady IMF conditions (when changes in the level of directly driven convection are small), have suggested that the flows evolve over the polar cap driven by some internal process. For example, Jayachandran et al. (2003) showed the existence of enhancements in dayside convection, beginning $\sim 10$ 15 min after substorm onset. Some studies have suggested that convection enhancements occur simultaneously across the ionosphere, with an imposed electric field affecting the global current system. Opgenoorth and Pellinen (1998) measured the electric field response $\sim 6 \mathrm{~h}$ of MLT away from the substorm onset region and observed enhancements coincident with the onset. Contradicting these observations of enhancements in dayside convection, Lyons et al. $(2001,2003)$ identified a global reduction in ionospheric convection at the time of substorm onset. Using SuperDARN measurements of plasma flow in the dayside ionosphere they showed that, for 10 out of 12 isolated substorms, the substorm onset was associated with a reduction in the strength of large-scale convection following changes in the IMF (such as a northward IMF turning). They suggested that substorm expansions may represent an adjustment to conditions of reduced convection following enhanced convection and magnetotail energy storage in the substorm growth phase.

Recently, Liang et al. (2006) (following earlier work by Kamide et al. 1994) discussed observations of two distinct systems in the substorm convection pattern. The first is a postmidnight anticlockwise convection vortex (PoACV) at higher latitudes, and the second is an azimuthally extended clockwise vortex at lower latitudes. They explain these in terms of a combination of the nightside reconnection driven twin-vortex flows and those resulting from field line slippage processes associated with dipolarization (Lui and Kamide 2003).

\subsection{Substorm-associated convection transients}

Whilst it is becoming clear that large-scale electric fields play a significant role in the electrodynamics of the substorm expansion phase, it is also apparent that mesoscale phenomena are integral to the substorm process. Azimuthally localized impulsive events have been observed which begin with intensifications at the poleward boundary of the nightside auroral zone, and which then expand equatorward, reaching close to the equatorward boundary of the oval after $\sim 5$ min (Henderson et al. 1998; Sandholt and Farrugia 2001). These events, termed 'Poleward Boundary Intensifications' (PBIs) (Lyons et al. 1999; Sandholt et al. 2002), have been observed during all phases of the substorm cycle, including during long intervals of magnetic quiet. However, they appear to be more frequent during the substorm expansion phase. They are associated with azimuthally localized 'bursty bulk flows' (BBFs) in the near-Earth plasma sheet (Angelopoulos et al. 1992; Baumjohann et al. 1990) and the associated excitation of ionospheric convection flow observed by SuperDARN and other instruments (de la Beaujardière et al. 1994; Yeoman and Lühr 1997; Grocott et al. 2004a, b; Nakamura et al. 2005). These features are strongly suggestive of the occurrence of localized impulsive reconnection in the magnetotail (Cowley 1998; Cowley et al. 1998). 


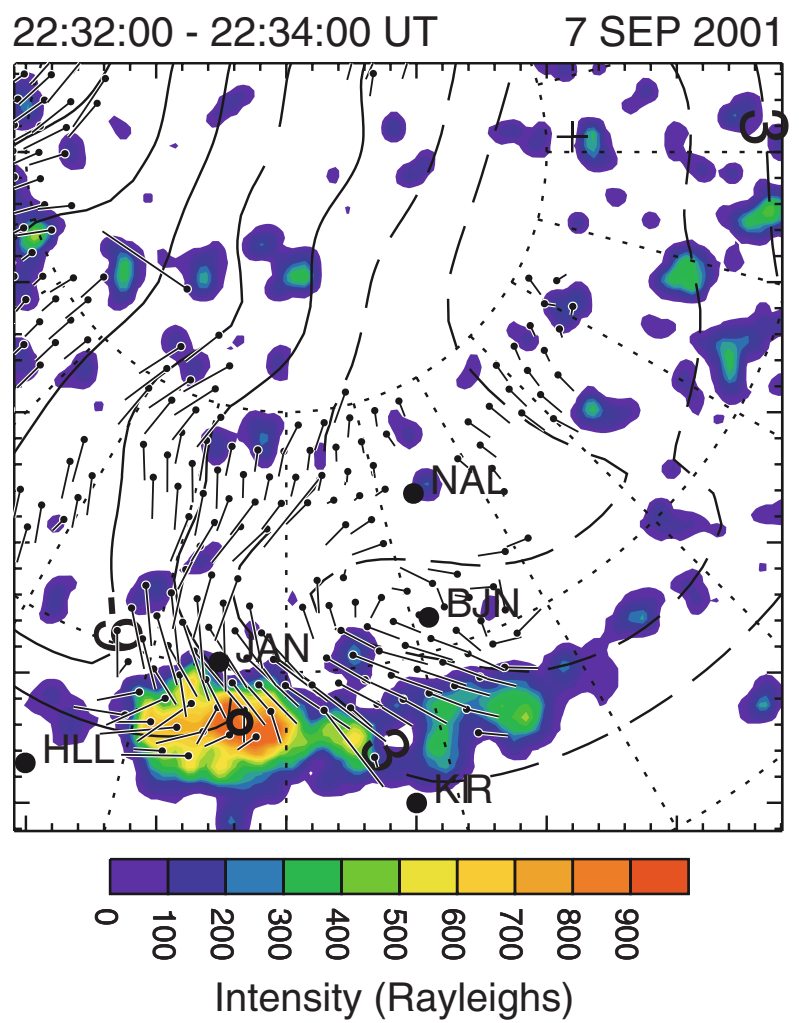

Fig. 17 SuperDARN map potential convection map of the nightside ionosphere in the northern hemisphere for the time interval 2232-2234 UT on September 7, 2001. The dots at the ends of the vectors show the vector origins and the lines indicate the vector magnitude and direction. The solid and dashed continuous lines represent equipotential contours of the global convection flow solution. AACGM latitudes at $10^{\circ}$ intervals are shown by the dotted circles and MLT meridians are shown by the radial dotted lines, with magnetic local midnight at the bottom of the figure. Overlaid on the convection map is a simultaneous auroral image from the IMAGE spacecraft SI13 instrument. The colour bar provides a key to the image intensity. This figure is reproduced from Grocott et al. (2004a), copyright by the European Geophysical Union

Pseudobreakups, occurring during the substorm growth phase, have also been associated with BBFs (Grocott et al. 2004a) and have been shown to accompany significant enhancements in the nightside flux closure rate (Hubert et al. 2006). Grocott et al. (2004a) used SuperDARN to study the ionospheric signature of a BBF which occurred during a growth-phase pseudobreakup, $\sim 10$ min after a southward turning of the IMF and $\sim 50$ 60 min before expansion phase onset. This was the first study to show both the ionospheric flow pattern and the auroral activation associated with a BBF in the magnetosphere. Figure 17 presents the nightside convection map at the time of the BBF illustrating an enhancement in the convective flow in the midnight sector near the convection reversal boundary (longer vectors and closer-spaced equipotential contours toward the bottom of the map), consistent with the BBF being a burst of convective transport in the magnetotail. Simultaneous auroral image data from the IMAGE FUV instrument (colour contours) show a region of strong auroral activity (yellow/red shading) coincident with the enhanced flow, indicative of an upward FAC region. 


\section{MHD waves}

Ultra low frequency (ULF) magnetohydrodynamic (MHD) waves in the magnetosphere provide a significant conduit for energy and momentum transfer through the coupled magnetosphere-ionosphere system, especially in the high-latitude regions covered by SuperDARN. These waves also provide a powerful diagnostic of magnetospheric morphology and dynamics. Magnetospheric ULF waves with periods in the Pc4 and Pc5 ranges (45-600s) and longer can be naturally divided into two distinct classes, those with small azimuthal scale lengths (high effective azimuthal wavenumbers, $|m| \sim 20-100$ ) and those with large azimuthal scale lengths (low $|m| \sim 0-5$ ). In general, ULF waves which have an energy source in the solar wind, external to the Earth's magnetosphere, are characterized by small $m$. Conversely, the energy source for small-scale, high- $m$ ULF waves is typically drifting energetic particle distributions inside the magnetosphere. SuperDARN has proved to be a powerful system for the investigation of both high- $m$ and low- $m$ ULF waves.

The ULF wave field is investigated via its modulation of the ionospheric electric field, and hence, of the Doppler velocity of the naturally occurring ionospheric irregularities measured by the SuperDARN radars. The use of a high-power RF facility, such as the Troms $\emptyset$ heater (Rietveld et al. 1993), to induce irregularities artificially within the fields of view of the SuperDARN radars allows the collection of good quality data at exceptional temporal and spatial resolution, and also provides increased velocity resolution (Wright and Yeoman 1999). In addition to wave observations in ionospheric backscatter, ULF wave modulation of the ionospheric reflection height of ground backscatter also produces a measurable Doppler velocity that can be used to study these ULF waves (Menk et al. 2003). In comparison with the traditional tool for the analysis of ULF waves, ground magnetometer arrays, the overall agreement between the radar and magnetometer observations of large-scale ULF waves is in general good, although the radar measurements tend to suggest larger azimuthal wave numbers, and narrower latitudinal field line resonance widths (Ziesolleck et al. 1998). The differences between the magnetometer and radar measurements are most likely due to the ionospheric modification of the magnetospheric ULF wave signature, which results in the rotation of the wave polarization and the spatial integration and attenuation of the wave magnetic signature detected on the ground. Thus, radar measurements in the ionosphere have a clear advantage over ground magnetometer arrays. The attenuation of the wave magnetic perturbation below the ionosphere is proportional to $e^{-|\mathbf{k}| z}$ (Hughes and Southwood 1976) where $|\mathbf{k}|$ is the field-perpendicular component of the wave number and $z$ is the ionospheric $E$-region height. Thus the advantage of radar measurements becomes particularly important for high- $m$ waves with large $|\mathbf{k}|$. SuperDARN observations of Pc3 waves (10-45s wave period) with low coherence scale lengths ( 30-60 km) (Baker et al. 1998) further show the advantages over ground magnetometer observations.

\subsection{Externally driven waves}

Early observations using the first SuperDARN radar at Goose Bay showed that HF radars were good instruments for studying ULF waves, especially when clear signatures of field line resonances were detected. These early observations revealed the existence of discrete harmonically-related latitude-dependent wave frequencies in the radar field of view (Ruohoniemi et al. 1991), and also provided evidence of a relationship between long period Pc5 wave activity (150-600s) and the formation of auroral arcs (Samson et al. 1991) as 
predicted by Greenwald and Walker (1980). The discrete frequency spectrum of ULF waves in HF radar data, first noted by Ruohoniemi et al. (1991), was investigated further by a number of authors, many of whom proposed that these discrete frequencies represented the natural frequencies of the magnetospheric waveguide. However, other interpretations have been made. Evidence of directly driven field line resonances, where the dominant frequencies are intrinsic properties of the solar wind, has been presented by a number of authors. Rae et al. (2004) presented observations of Alfvén waves in the solar wind which modulated the reconnection rate at the dayside magnetopause. This modulation was observable in Pc5-band velocity fluctuations detected by SuperDARN in the cusp region. Prikryl et al. $(1998,2002)$ also suggested a direct link between Alfvénic solar wind fluctuations and Pc5 field line resonance observations observed equatorward of the cusp on closed field lines. Stephenson and Walker (2002) similarly presented an analysis of upstream solar wind data and SuperDARN velocity data demonstrating that, at least on occasion, common spectral peaks are observed in both, suggesting direct driving of magnetospheric field line oscillations by wave activity in the solar wind.

Higher frequency ULF waves have been studied by SuperDARN by modifying the radar scanning sequence such that increased temporal resolution is available over a restricted spatial area. Baker et al. (1998) employed such a sequence to study the electric field signatures of Pc3 waves in the ionospheric cusp, showing that the coherence scale lengths were $\sim 30-60 \mathrm{~km}$, significantly less than can be determined from magnetometer measurements. They suggested that, as a consequence, Pc3 waves observed by ground-based magnetometers consist of multiple independent bursts of waves. They also suggested that the ground-based magnetic signature may on occasion be due to variations in ionospheric conductivity near the observing site. Matsuoka et al. (2002) also used increased temporal resolution to examine Pc3 waves in the cusp region. They discovered a correlation in Pc3 wave power between radar measurements of the velocity field and magnetosheath magnetic field measurements, suggesting that such wave activity is transmitted from the magnetosheath, down cusp magnetic field lines, to the ionosphere.

High-time resolution scans have also been exploited to examine Pc3 waves at lower latitudes. Here, however, the waves are typically visible as modulations of ground backscatter, as first exploited by Menk et al. (2003). Ponomarenko et al. (2003) developed a new visualistion technique which greatly enhances the ability to identify such modulated ground backscatter returns, and the use of this technique is illustrated in Fig. 18. Here, the temporal variation of the backscatter velocity field measured by a single SuperDARN radar beam is displayed in the top panel using a standard velocity scale for looking at ionospheric backscatter. The majority of ground backscatter velocity modulations are invisible when such a scale is used, as illustrated by the almost uniform grey shading. A compressed dynamic range (middle panel) reveals a wealth of velocity fluctuations in the ground backscatter, as illustrated by the appearance of some striped black and white regions. In addition to the compressed dynamic range, detrending the velocity field (bottom panel) clarifies the wave field still further unearthing a wealth of wave activity as shown by the almost continuous black and white striped regions. Using this method, Ponomarenko et al. (2005) examined a specific Pc3 wave event in detail, identifying the energy source of the wave as upstream ion-cyclotron waves which passed through the magnetopause, propagating across magnetic field lines, until a resonant field line was encountered.

Artificial backscatter experiments have recently provided new insights into low- $m$ ULF waves at higher latitudes, using the new SPEAR (Space Plasma Exploration by Active Radar; Wright et al. 2000) high power HF facility located on Svalbard. Figure 19 presents the results of preliminary experiments where SPEAR-generated backscatter contained the 

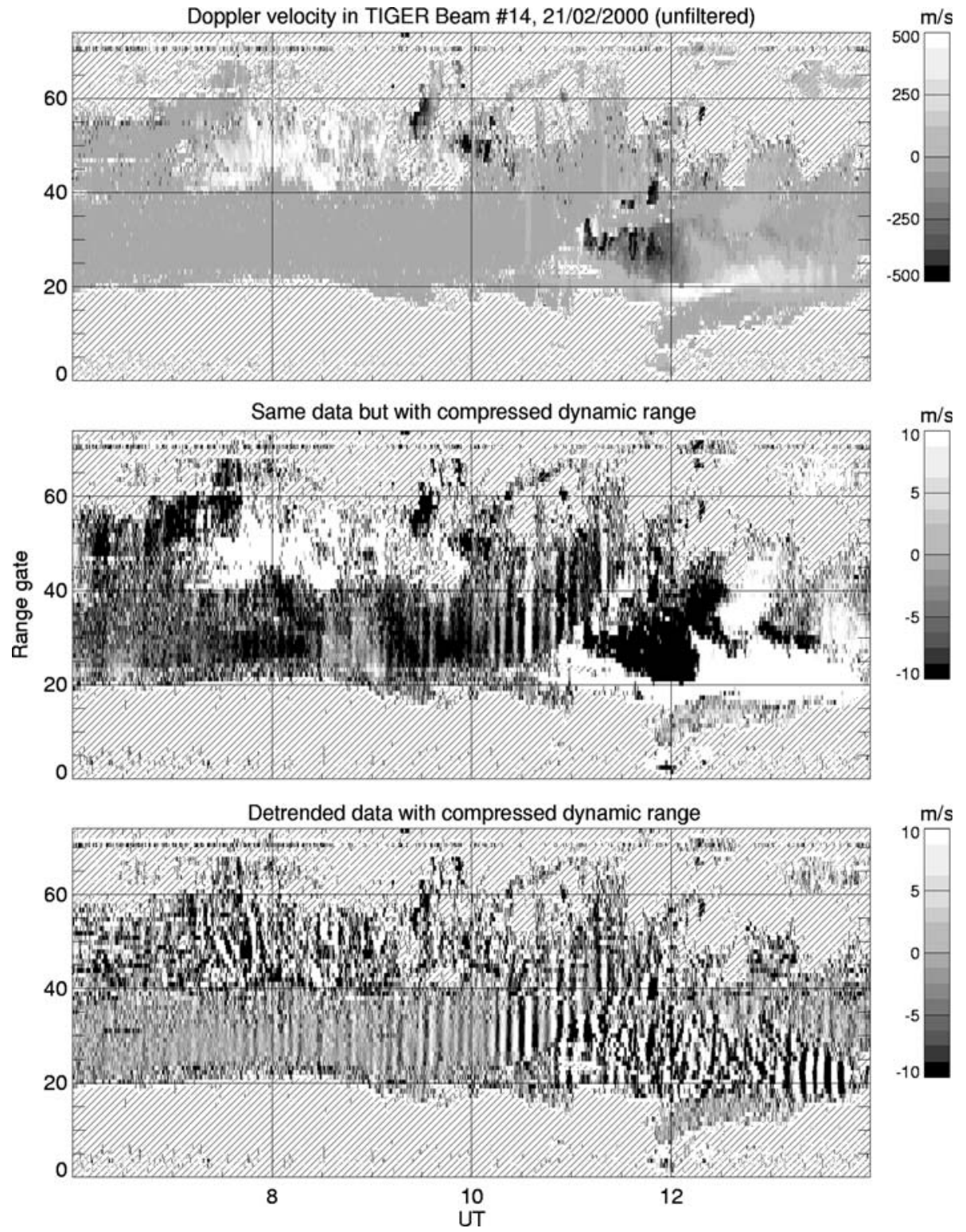

Fig. 18 Line-of-sight Doppler velocity variations of ground backscatter from the TIGER SuperDARN radar displayed in three different ways. In each panel Doppler velocity is indicated according to the grey scale to the right of the figure, and plotted as a function of UT and range gate. The top panel employs a standard velocity scale used for studying ionospheric backscatter. The majority of the ground backscatter velocity modulations are invisible using this visualization. Using a compressed dynamic range (middle panel) reveals increased velocity structure in the ground backscatter. Using a compressed dynamic range after detrending the velocity field (lower panel) clarifies the wave field in the velocity data still further. The slanted-line shading in the three panels highlights the regions where there is no measurable backscatter. This figure is reproduced from Ponomarenko et al. (2002), copyright by the American Geophysical Union 


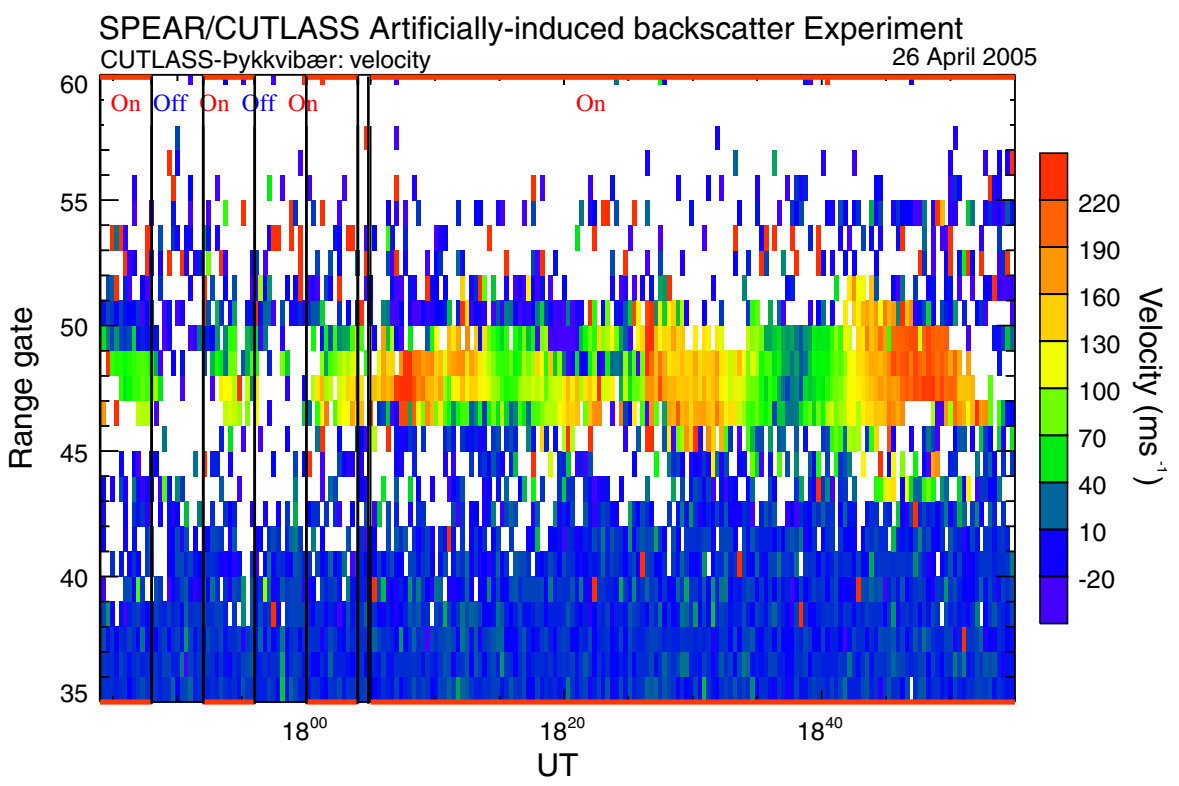

Fig. 19 Line-of-sight Doppler velocity measurements from the Iceland East SuperDARN radar of the ionospheric response to a large-scale Alfvén wave in the magnetosphere with a period 20 min. Doppler velocity is indicated according to the colour scale to the right of the figure and plotted as a function of UT and range gate. The time intervals highlighted 'On' are the intervals when the SPEAR high power beam was being used to heat the ionosphere. The wave is visible in patches of backscatter measured by the Finland SuperDARN radar which were artificially induced by ionospheric heating by the SPEAR high power beam

signature of a long-period ULF wave. These high-latitude measurements took place under quiet geomagnetic conditions, when the OCB lay poleward of the SPEAR location. In Figure 19 three 4-min SPEAR 'on' cycles generate patches of artificial backscatter up to 1805 UT, and then a prolonged SPEAR 'on' cycle reveals the wavefield of a long-period ULF wave ( 15-20 min period) as shown by the quasi-periodic changes in the line-ofsight velocity (between red/yellow and blue/green shaded regions). This represents a wave with a wavelength of around a million $\mathrm{km}$, which occurs on field lines that extend to distances of $\sim 250,000 \mathrm{~km}$ from the Earth.

The relationship between large-scale low- $m$ waves and smaller scale, high- $m$ waves has been explored in some detail with SuperDARN observations. An analysis of the characteristics of both low- $m$ and high- $m$ wave events observed by SuperDARN was presented by Fenrich et al. (1995). They found instances when waves of different type shared common characteristics, although the low- $m$ waves occurred primarily on the magnetospheric flanks, whereas the high- $m$ waves were more likely to be detected near local noon and midnight. They suggested that the common characteristics implied a common source for the two wave types, with a dispersive waveguide being the favoured candidate. Subsequently, Fenrich and Samson (1997) demonstrated that low- $m$ waves derived their energy from a fast mode wave, associated with the magnetospheric waveguide, whereas the high- $m$ waves gained their energy from wave-particle interactions, and overall, actually provided an energy source to the fast mode wave. 


\subsection{Internally driven waves}

The detection of backscatter from irregularities induced by high power HF facilities (see e.g., Yeoman et al. 1997b) has proved to be a particularly powerful technique for the investigation of high- $m$ ULF waves. The spatial and temporal resolution of the data are maximized by this technique, and small velocity fluctuations are more detectable than in most natural backscatter. Fig. 20 shows an example of artificial backscatter induced by the Troms $\varnothing$ heater being observed simultaneously by two of the SuperDARN radars (Finland and Iceland East), between 1300 and 1400 UT on 15 October 1998. The line-of-sight velocity data from Finland beam 5 and Iceland East beam 15 are presented in panels a and $b$, respectively, with the time series of velocity variations at selected range gates from each radar displayed in panels $\mathrm{c}$ and $\mathrm{d}$, respectively. In this instance a $\sim 3.8 \mathrm{mHz}(\sim 260 \mathrm{~s})$ wave was observed in the Iceland East SuperDARN data (panels b and d) and the Troms $\varnothing$ magnetometer data (panels e and f), with an azimuthal wave number of $m \sim 4$, indicative of a large-scale field line resonance. Iceland East beam 15 points in an east-west direction and so this beam is expected to see strong azimuthal velocities associated with such a global toroidal oscillation of magnetospheric field lines. The Finland data were dominated by a higher frequency wave with a frequency of $10 \mathrm{mHz}(100 \mathrm{~s}$ ) (panels a and c), and an azimuthal wave number $m \sim-38 \pm 6$. No evidence of this higher frequency, high- $m$ wave was seen in the Iceland East radar data or in the Troms $\varnothing$ magnetometer data. The data from overlapping beams of the Finland and Iceland East radars were combined to measure the polarization of both the high- $m$ and the low- $m$ waves. The high- $m$ wave was found to be almost linearly polarized in the north-south direction, with the low- $m$ wave being more elliptically polarized. The data were interpreted as representing a low- $m$ fundamental mode field line resonance, whereas the high- $m$ wave was the second harmonic of this field line and thought to be driven by energetic ring current particles through the drift-bounce resonance process (Southwood et al. 1969; Southwood 1976). The presence of a low- $m$ oscillation on the field line, at a frequency determined by the magnetospheric waveguide, was suggested by Wright and Yeoman (1999) to be a seed oscillation, which subsequently enabled the high- $m$ wave to grow in amplitude, providing that free energy was available in an appropriate energy region of the ring current particle distribution function conjugate to the wave observations.

Additional examples of co-existing low- $m$ field line resonances and high- $m$ waves attributed to both the drift resonance and drift-bounce resonance mechanisms have been observed in the afternoon sector magnetosphere by Yeoman and Wright (2001). They observed a wavetrain which displayed three distinct characteristics: A large-scale, elliptically polarized field line resonance, a fundamental mode small-scale poloidal mode wave, and a second harmonic small-scale poloidal mode wave. Both the small-scale waves were close to being linearly polarized and it was hypothesized that they were driven by a common non-Maxwellian particle population with a population inversion in the energy range of $\sim 30-50 \mathrm{keV}$, with the fundamental mode driven by a drift resonance process, and the second harmonic by a drift-bounce resonance process.

Artificial backscatter experiments at Troms $\varnothing$ were also used by Baddeley et al. (2002) who presented high- $m$ wave observations with a frequency of $\sim 15.4 \mathrm{mHz}$ and with an azimuthal wavenumber $m \sim-45 \pm 10$, in the morning sector ionosphere. At the time of these observations the Polar spacecraft was conjugate with Troms $\emptyset$ and it was possible to measure the corresponding magnetospheric particle distributions. An unstable 


\section{SUPERDARN PARAMETER PLOT}

(a)

(b)

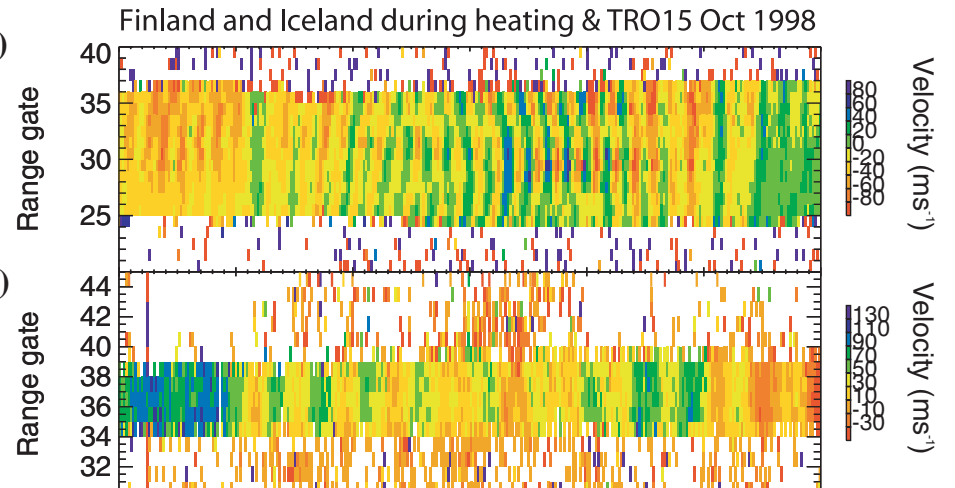

(c)

\section{2}

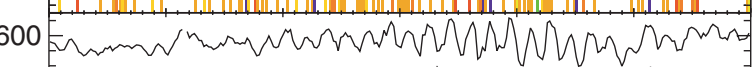

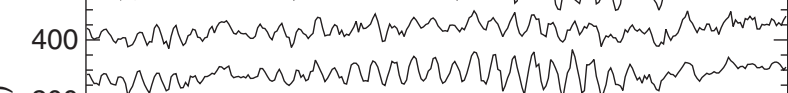

(d) $\frac{\text { ते }}{\frac{0}{0}}$



(e)

(f)

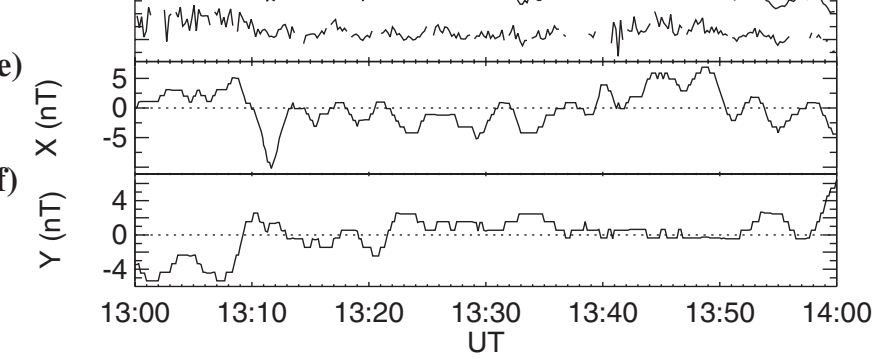

Fig. 20 Line-of-sight Doppler velocity measurements from the Finland and Iceland East SuperDARN radars for the interval 1300-1400 UT from 15 October, 1998, showing the presence of multiple ULF wave signals. (a) Velocity measurements from Finland beam 5, ranges 20-40. (b) Velocity measurements from Iceland East beam 15, ranges 30-45. In panels (a) and (b) Doppler velocity is indicated according to the colour scale to the right of the panel and plotted as a function of UT and range gate. (c) Time series of velocity data from Finland beam 5, range gates 26, 28, 30, 32, and 34. (d) Time series of velocity data from Iceland East beam 15, range gates 34, 35, 36, 37, and 38. In panels (c) and (d) the velocity time series from the successive range gates are offset by $150 \mathrm{~m} / \mathrm{s}$ (for visibility of the data) and the velocity scale is indicated on the left. (e,f) Time series of the north $(\mathrm{X})$ and east $(\mathrm{Y})$ components of geomagnetic variations measured by the Tromsø magnetometer

(non-Maxwellian) distribution of protons was observed on, or near, the Troms $\varnothing$ field line, with a positive gradient in the ion distribution function in the energy range of 8-15 keV. An analysis of the drift-bounce resonance condition showed that the wave was the result of a drift-bounce resonance interaction between a second harmonic standing mode wave and the non-Maxwellian particle population. 


\section{Neutral atmosphere}

Neutral-atmosphere phenomena are studied with SuperDARN indirectly, through their effects on ionospheric plasma. Gravity waves are observed through their ionospheric manifestation, travelling ionospheric disturbances (TIDs), which are perturbations of the ionospheric $F$-region plasma density that travel with the waves. Mesospheric winds are observed by determining the Doppler shifts of signals scattered from the plasma trails left by meteors as they ablate in the upper atmosphere. Polar mesosphere summer echoes (PMSE) are very strong radar echoes from altitudes close to the polar summer mesopause. PMSE represent a potential tool for monitoring the thermal and dynamical structure of the mesopause region.

\subsection{Gravity waves}

The earliest HF radar studies of neutral-atmospheric phenomena were all concerned with the identification of gravity waves (Samson et al. 1989; Samson et al. 1990; Ruohoneimi et al. 1990). Gravity waves propagating in the neutral atmosphere produce perturbations of the neutral velocity, which in turn impart motion to the ionospheric plasma. Flow of the plasma along magnetic field lines leads to corrugations of plasma iso-density surfaces that move along with the gravity waves as they propagate. A radio signal that reflects from this corrugated iso-density surface is focused and defocused, which gives rise to characteristic power enhancements and diminishments in HF radar ground backscatter. Figure 21 shows a typical example of these quasi-periodic power enhancements as measured by the Goose Bay radar. The backscatter is characterized by alternating high power (red) and low power (green) backscatter regions. The enhancements are observed to decrease in range with time which indicates that the waves are propagating towards the radar. The vast majority of gravity wave signatures identified in SuperDARN data are observed to propagate towards

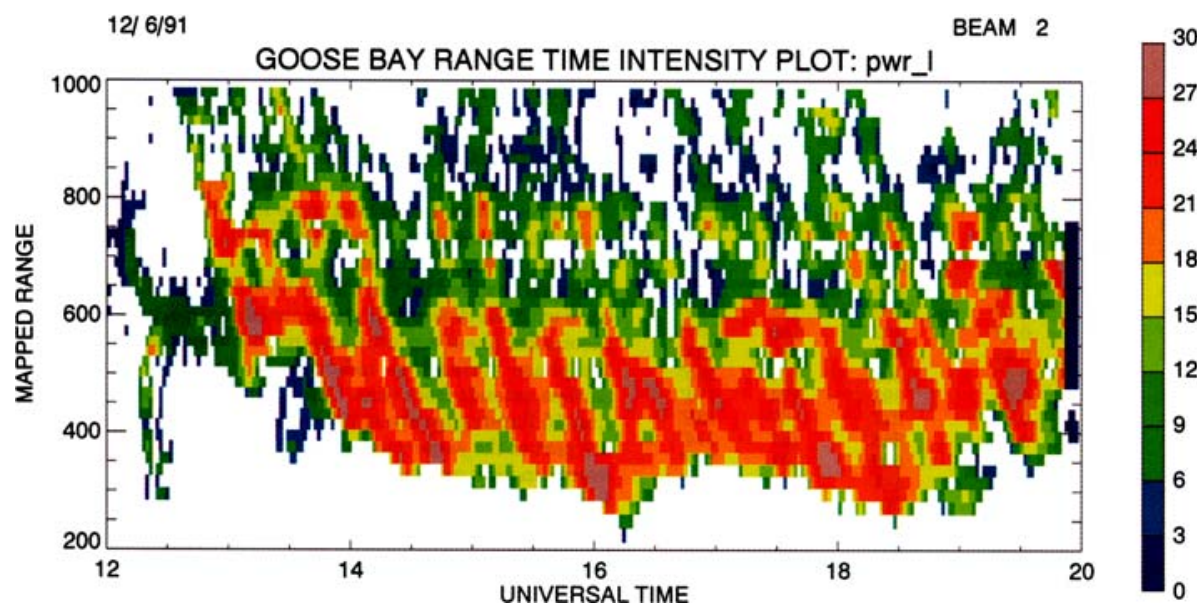

Fig. 21 The backscattered power (in dB) measured by Goose Bay beam 2 between 1200 and 2000 UT on December 6, 1991. Backscatter power is indicated according to the colour scale to the right of the figure and plotted as a function of UT and range in $\mathrm{km}$. The data show very clear signals of equatorward propagating gravity waves which are visible as intensifications in backscatter power (red regions) 
the radar. Hence, their source is usually located well poleward of the radar locations. Typical wave characteristics can also be determined from these observations. The waves have frequencies in the range of $0.3-1.0 \mathrm{mHz}$, have horizontal phase velocities of less than $300 \mathrm{~m} / \mathrm{s}$, and have horizontal wavelengths of a few hundred kilometers. Many of the waves observed in SuperDARN data are due to the Earth-reflected gravity wave mode (Francis 1975). These waves are generated by energy and momentum transfer from ionospheric currents to the neutral atmosphere at altitudes of around 100-140 km. Current surges launch waves upwards into the thermosphere, and downwards towards the ground. The waves launched downward towards the ground can be observed at large distances from their source.

Samson et al. (1990) developed a technique for locating gravity wave sources, generating theoretical phase maps that could be compared directly with HF radar observations. The slope and spacing between the phase fronts depend on the time and range from the source to the observation point. Cross-correlation of the theoretical phase maps with the observed range-time-intensity plots (such as that in Fig. 21) provide estimates of wave source locations and times. Using this method it was found that waves typically originated near the convection reversal boundary, with the majority of the waves originating within the eastward electrojet in the afternoon sector ionosphere. However, under some circumstances the position of the wave source, determined by simple assumptions about the radio propagation path, can lead to errors of up to $30 \%$ in the range determination (Hall et al. 1999; MacDougall et al. 2001). Further study of wave parameters and source locations confirmed that the Earth-reflected model proposed by Samson et al. (1990) adequately described the gravity wave observations of the Goose Bay SuperDARN radar (Bristow et al. 1994; Huang et al. 1998a; Hall et al. 1999). Examination of a large number of events showed waves with frequencies mainly between $0.3 \mathrm{mHz}$ and $0.5 \mathrm{mHz}$, and wavelengths that ranged between $160 \mathrm{~km}$ and $560 \mathrm{~km}$. It was also found that the sources were spatially clustered in two regions: near the magnetospheric cusp, and near $\sim 1600 \mathrm{MLT}$ at about $75^{\circ}$ magnetic latitude. The study of source locations and times also revealed a good correlation with deflections on ground-based magnetometers near the sources. In every case examined by Bristow et al. (1994), it was possible to identify a magnetometer deflection at the time of the estimated wave source. Many events also showed evidence of transient ULF waves. The magnetometer deflections support the theory that the waves are associated to fluctuations in the ionospheric electric field which couple to the neutral atmosphere via Joule heating or Lorentz forcing and produce TIDs.

Comparison of SuperDARN gravity wave observations, ground-based magnetometer observations, and solar wind and IMF observations, led to the proposition that some of the observed waves were directly driven by fluctuations in the IMF (Bristow et al. 1994; Huang et al. 1998b; Sofko and Huang 2000). Huang et al. (1998b), studying a 7-h interval of data, proposed that every gravity wave power fluctuation observed in the radar data could be traced to a ground magnetometer perturbation, and in turn to a direction change of the IMF. From these data, it was concluded that a clear cause and effect relationship existed between the different phenomena; changes in the IMF driving transient reconnection with associated ionospheric electric field fluctuations which result in TIDs via Joule heating or Lorentz forcing.

Comparisons of SuperDARN gravity wave observations with those from other instruments have shown good agreement. Comparisons of SuperDARN and EISCAT observations have shown correlation coefficients in excess of 0.8 (Arnold et al. 1998). Here, the authors compared deviations of the nearest range of F-region ground backscatter observed by SuperDARN to time series of electron density profiles from EISCAT. It was shown that 
the nearest range of ground backscatter, called the skip distance, is a relatively sensitive detector of fluctuations in the reflection height, and hence, is ideal for gravity wave observations. In addition, because the skip distance does not depend on the strength of the received signal, it is more regularly observed than the ground backscatter range profile that was used for earlier gravity wave studies.

While the majority of SuperDARN gravity wave studies have focused on determining the wave source location and wave characteristics such as the wavelength, propagation direction, and velocity, there have been two studies that have attempted to determine the amplitude of the electron density fluctuation induced by the waves. Bristow and Greenwald (1995) used ray-tracing calculations to model the power as a function of range for a flat Earth in a rectangular coordinate system and synthesized power profiles for a model gravity wave. By comparing the modelled profiles to those measured by SuperDARN, the peak density perturbations of the observed waves were estimated. It was determined that the technique could produce estimates for density perturbations of up to about $35 \%$, but no higher. However, it was estimated that the majority of the observed perturbations were in the range of 20-35\%. The technique of using ray-tracing to estimate the level of electron density perturbations was extended by Stocker et al. (2000) in a study where they modelled the change in skip distance for various perturbation levels. Figure 22 shows modeled range-time-intenisty plots derived from ray-tracing for gravity waves with electron density perturbation amplitudes ranging from $5 \%$ to $35 \%$. Their results show narrow regions of strong backscatter (red filaments moving to lower range with time) which are similar to the SuperDARN measurements of TIDs. Clear differences in the skip distance variation (the lowest range extent of the red backscatter power region) are also apparent in the model. Density perturbations of 5\% (panel a) produce variations in the skip distance of $\sim 50 \mathrm{~km}$, while fluctuations of $25 \%$ (panel c) produce variations of $\sim 150 \mathrm{~km}$. Above about $20 \%$ perturbation, the range variation begins to saturate, which lessens the ability to resolve density differences. Stocker et al. (2000) conclude that the technique would be useable for density perturbations up to about $30 \%$.

Additional information about gravity wave parameters can be obtained by exploiting the frequency agility of the SuperDARN radars. Using the multi-channel, multi-frequency capabilities of the two CUTLASS STEREO radars (Lester et al. 2004), the technique using skip distance detection of gravity waves has been extended to extract this information (Karhunen et al. 2006). Since the skip distance is a function of frequency, stepping the radar transmissions through frequencies provides observations from different regions of space. Additionally, since the altitude from which the skip rays reflect is near the F-region peak altitude, it is independent of the frequency. Thus, two-dimensional maps of skipdistance fluctuations obtained at multiple frequencies can provide estimates of gravity wave density fluctuations at nearly constant altitude. From the two-dimensional maps it is possible to determine the wavelength, propagation speed, and propagation direction. Karhunen et al. (2006) exploited this technique to extract wave parameters from their observations. Specifically, a medium-scale wave was present with parameters typical of those observed previously in other SuperDARN studies. Simultaneously, a large-scale wave, with a wavelength in excess of $1,000 \mathrm{~km}$, was detected.

In addition to the many studies examining the properties of individual waves, there have been studies which utilize the larger database of SuperDARN observations. Bristow et al. (1996) developed an automated technique for detecting the presence of gravity wave signatures in SuperDARN data. They found that if the ratio of power in the frequency band between $0.33 \mathrm{mHz}$ and $0.8 \mathrm{mHz}$, to the power outside of the band exceeded $\sim 0.5$, gravity waves were likely to be present. All available SuperDARN data for the period from 

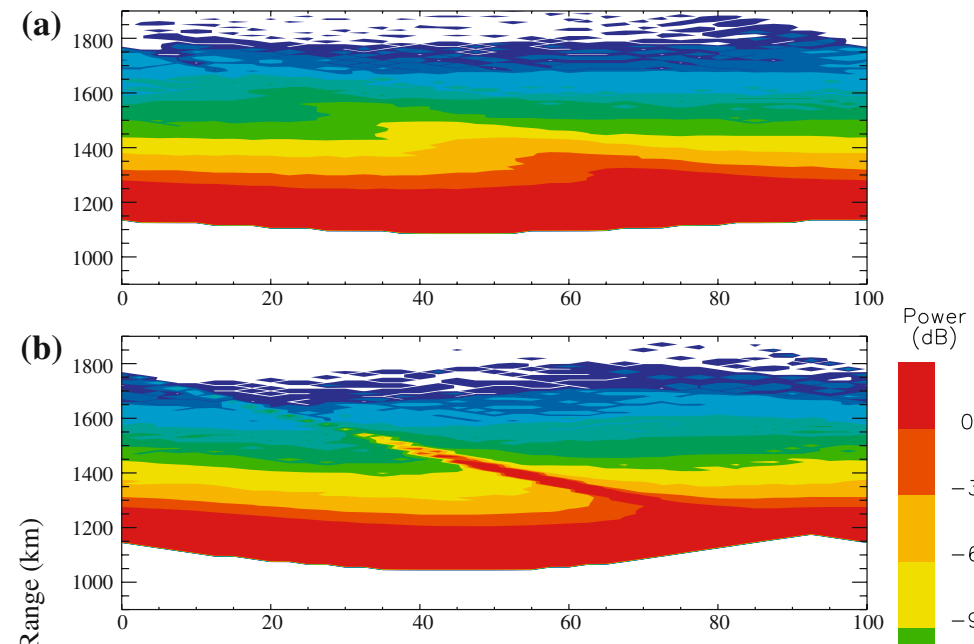

\section{$(\mathrm{dB})$}

(c)
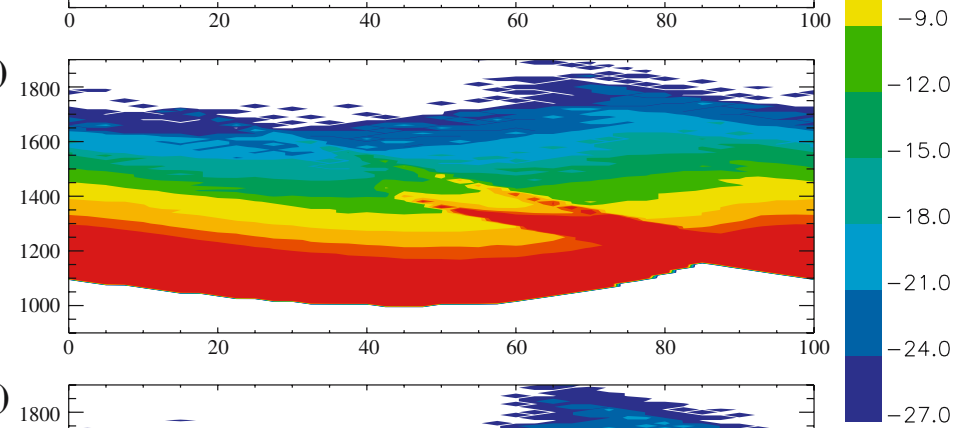

(d)

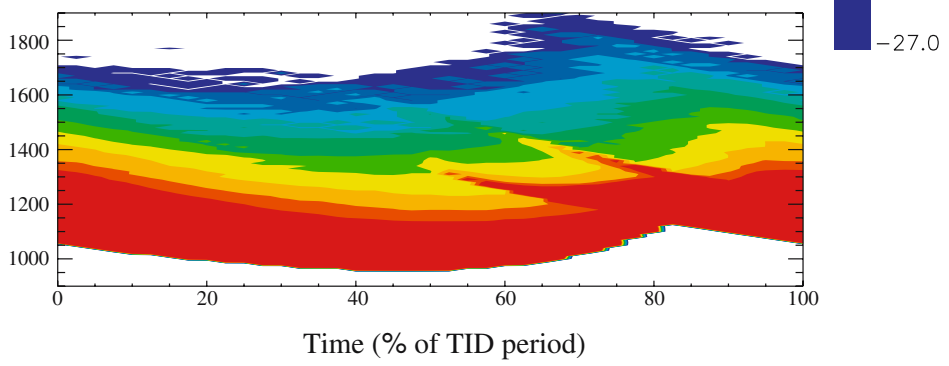

Fig. 22 Simulated backscatter power plots derived from ray tracing for the Finland SuperDARN radar operating at $9.97 \mathrm{MHz}$ on 26 January, 1997. The amplitude of the travelling ionospheric disturbance (TID) electron density perturbation in each panel is (a) $5 \%$, (b) $15 \%$, (c) $25 \%$, and (d) $35 \%$. Backscatter power is indicated according to the colour scale to the right of the figure and plotted as a function of time and range in $\mathrm{km}$. This figure is reproduced from Stocker et al. (2000), copyright by the European Geophysical Union

October 1993 to May 1995 were examined for this criterion. From this analysis, the probability of gravity wave observation versus month was determined. A clear seasonal dependence was identified, with low incidence $(<40 \%$ probability of observation) during the summer months, and high incidence (as much as $80 \%$ probability of observation) during the late autumn and winter months (a similar seasonal variation was noted by Samson et al. (1989)). Motivated by this observation, Bristow et al. (1996) examined the gravity wave dispersion relation for a possible cause. They found that the cold temperatures of the summer mesopause led to strong temperature gradients that caused the vertical 
component of the wavevector to become imaginary, and hence, the waves to be evanescent in that region. This region of evanescence screens waves generated in the ionosphere from reaching the lower atmosphere and hence the Earth-reflected mode is not possible. In the winter no such region exists and the waves are free to propagate.

General properties of the spectrum of ground backscatter power fluctuations were examined by Bristow and Greenwald (1997). Spectra were examined for individual 2-h and 4-h intervals as well as averages of spectra over a 2-year period. Both the average spectra and spectra from individual intervals showed a power law decrease with frequency with a slope of $-5 / 3$. The individual intervals showed peaks at frequencies corresponding to the periods of quasi-monochromatic waves observed in the time series. At times the spectra showed multiple peaks, at harmonics of a low-frequency peak, which may have been due to non-linear wave-wave interactions or wave-mean flow interactions. The observed spectral shape was strikingly similar to observations presented by others and to the 'universal gravity wave spectrum' (Van Zandt 1982). Comparison of spectra from quiet intervals to intervals when quasi-monochromatic perturbations were present showed that, during the active intervals, the power at frequencies above a spectral peak was elevated above that of the quiet intervals, while at frequencies below the peaks, the levels were comparable. This indicates that some energy cascade process is extracting energy from the gravity waves and contributing to a turbulent background.

\subsection{Mesospheric winds}

The identification of a new class of backscatter by Hall et al. (1997) opened up the study of the mesosphere with SuperDARN. They identified a distinct class of backscatter that occurred typically at ranges less than $400 \mathrm{~km}$ and which was a persistent feature of SuperDARN observations, appearing as a grainy, noise-like, band of backscatter with some diurnal variation. The term 'grainy near-range echoes' or, GNREs, was coined to describe this backscatter. Hall et al. (1997) examined the characteristics of GNREs from the Saskatoon radar and observed that their grainy appearance represented the random variation of echo intensity from one integration period to the next and from one range gate to the next. They noted that, despite this level of randomness, their occurrence showed a smooth variation with time of day that was present regardless of magnetic activity. They further noted that these characteristics were similar to the known behaviour of meteors, which led them to hypothesize that meteors were the source of the observed echoes. For further confirmation of this hypothesis, occurrence rates were examined over a period that included a large meteor shower. During the maximum of the Geminid shower, December 13, 1993, the occurrence rate of GNREs increased to 10 times above the rate observed on any other day during that month. Hall et al. (1997) also examined the spectral properties of the echoes. They found that the spectra were characteristically narrow, similar to ground backscatter, and much narrower than is typical of backscatter from ionospheric irregularities. The 1-h averaged Doppler velocities of the echoes were low, and showed variations that were typical of the winds in the mesosphere or lower thermosphere. In particular, diurnal and semi-diurnal variations were clearly evident in the data. Semi-diurnal variations can be clearly seen in the Doppler velocity variations of Meteor backscatter from August 1-8, 1994, in Fig. 23. The vertical dashed lines delineate the day boundaries and each day is characterized by two large-scale wave cycles. Hall et al. (1997) also observed spectral width values that were typically in the range of 4-12 m/s, which corresponds to the values expected for the diffusion coefficients in the $90-100 \mathrm{~km}$ altitude range. The 


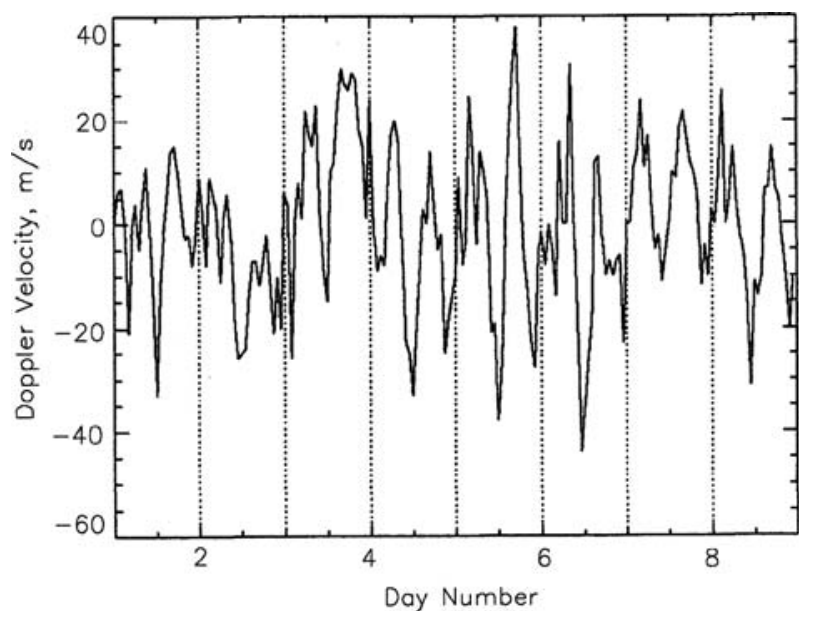

Fig. 23 Hourly averaged line-of-sight Doppler velocities from Saskatoon SuperDARN radar beam 5, range $225 \mathrm{~km}$, for the interval August 1-8, 1994. The velocity fluctuations show clearly the existence of semidiurnal fluctuations. This figure is reproduced from Hall et al. (1997), copyright by the American Geophysical Union

observed Doppler shifts were compared to wind velocity estimates from a closely located MF radar with both radars observing almost identical spectra. The most obvious similarity between the two spectra was a prominent peak at a frequency of two cycles per day, which is due to the semi-diurnal tide (see Fig. 23). The peaks were of similar amplitude and width. In addition, there were peaks at other frequencies that appeared in both datasets, at one cycle per day and at 3 cycles per day. Further detailed comparison of the height-resolved MF radar observations with the SuperDARN observations showed that the phase of the semi-diurnal tide observed in the two datasets matched best at an altitude of about $94 \mathrm{~km}$. This led to the conclusion that the SuperDARN observations came predominantly from a height of about $94 \pm 3 \mathrm{~km}$, which is close to the average height expected for meteor echoes.

Investigation of GNRE in data from the Halley SuperDARN radar revealed mostly similar characteristics to those seen at Saskatoon (Jenkins et al. 1998; Jenkins and Jarvis 1999). One difference was that the count rate at Halley was approximately half that at Saskatoon. A 10-day moving window spectral analysis was used to search for evidence of planetary waves in the Halley data. A quasi-two-day wave was observed along with 10-h and 16-h waves which arise from the interaction of the two-day wave with the semidiurnal tide. Observations at Halley were extended further to form estimates of the wind vector by combining data from multiple beams using a beam-swinging technique (Jenkins and Jarvis 1999). Meteor backscatter observations from multiple SuperDARN radars have also been combined. Bristow et al. (1999) studied a 2-day planetary wave event and compared their observations with those of mesospheric winds from the High Resolution Doppler Imager (HRDI) on the UARS satellite. During the study period, a clear two-day wave was observed in both datasets. The use of multiple radars allowed the determination of wave characteristics such as a zonal wavenumber of 3 and that the wave was westward propagating. Espy et al. (2005) combined meteor wind data from three southern hemisphere SuperDARN radars with observations from the Rothera MF radar in Antarctica to characterize the mesospheric planetary-wave field during the winter of 2002. Their results showed that before an unusual stratospheric warming period in 2002 the wave field was 
dominated by a very long-period wave ( $\sim 43$ days), whereas after the warming events began, the character of the wave field changed, being dominated by a shorter period wave ( $\sim 14$ days). The multiple radar observations allowed the determination of the wavenumber (1) and propagation direction (westward) of these waves.

Coincident northern hemisphere SuperDARN meteor observations and those from the Saskatoon MF radar have been exploited by making estimates of the wind vector from the SuperDARN data and comparing the meridional and zonal components to those obtained by the MF radar (Hussey et al. 2000). In these comparisons the heights of the returns observed by SuperDARN were determined using the observed elevation angle. Comparison of the SuperDARN data with the MF radar observations again showed the best match for an altitude of about $94 \mathrm{~km}$. The average winds from each SuperDARN radar in the northern hemisphere were also compared and showed considerable similarity. The 12-h tide was the dominant feature observed by each radar.

The spectral width of meteor backscatter is related to the diffusion coefficient for the meteor plasma trail, which is in turn related to the altitude from which the signals are scattered. Arnold et al. (2001) examined the spectral width of meteor backscatter echoes and attempted to find a relationship with other geophysical quantities. It was found that the spectral width increased with range from the radar, which indicated a small increase in altitude with range. In local time, it was found that the average spectral width was lowest near noon, and largest near midnight. The difference between the two local times corresponded to about a $3 \mathrm{~km}$ diurnal variation in the hourly average altitude of the backscatter. There was a correlation between spectral width and geomagnetic activity, roughly a $1.1 \mathrm{~m} /$ $\mathrm{s}$ increase in the width for a $10 \%$ increase in Ap. Similarly, there was an increase in width with an increase in the F10.7 cm radio flux, which amounted to $\sim 12 \mathrm{~m} / \mathrm{s}$ change in width between solar maximum and solar minimum values of flux. Finally, an interval containing a storm sudden commencement was examined and spectral widths were compared from before and after the commencement. The observed change in the widths was consistent with the change of the mesospheric temperature profile expected following the storm sudden commencement.

\subsection{Polar mesosphere summer echoes}

Ogawa et al. (2002) presented observations from the Syowa SuperDARN radar that showed unusual echoes at near ranges between $180 \mathrm{~km}$ and $315 \mathrm{~km}$ during quiet geomagnetic conditions in the Antarctic summer (December 1997 and January 1998). The echoes were characterized by a duration of less than $80 \mathrm{~min}$, by quasi-periodic oscillations of velocity and power with periods $\sim 5-20 \mathrm{~min}$, by velocities between -40 and $20 \mathrm{~m} / \mathrm{s}$, and by narrow spectral widths of less than $40 \mathrm{~m} / \mathrm{s}$. These characteristics were not consistent with meteor backscatter leading the authors to speculate that the observations were of PMSE. PMSE are regularly observed at polar latitudes by radars using frequencies in the MF to UHF range, but have rarely been observed by HF radars (see Rapp and Lübken (2004) for a review of observations and current understanding of PMSE).

Ogawa et al. (2003) followed up this study by comparing near-range backscatter observations from the Finland SuperDARN radar with those from an MST radar at Esrange, Sweden. Echoes were observed between 100 and $200 \mathrm{~km}$ range while simultaneously the MST radar observed PMSE. Figure 24 presents contour maps of the echo occurrence rate at four operational HF frequencies as a function of range and elevation angle. The dashed curves describe contours of constant altitude in range-elevation angle 

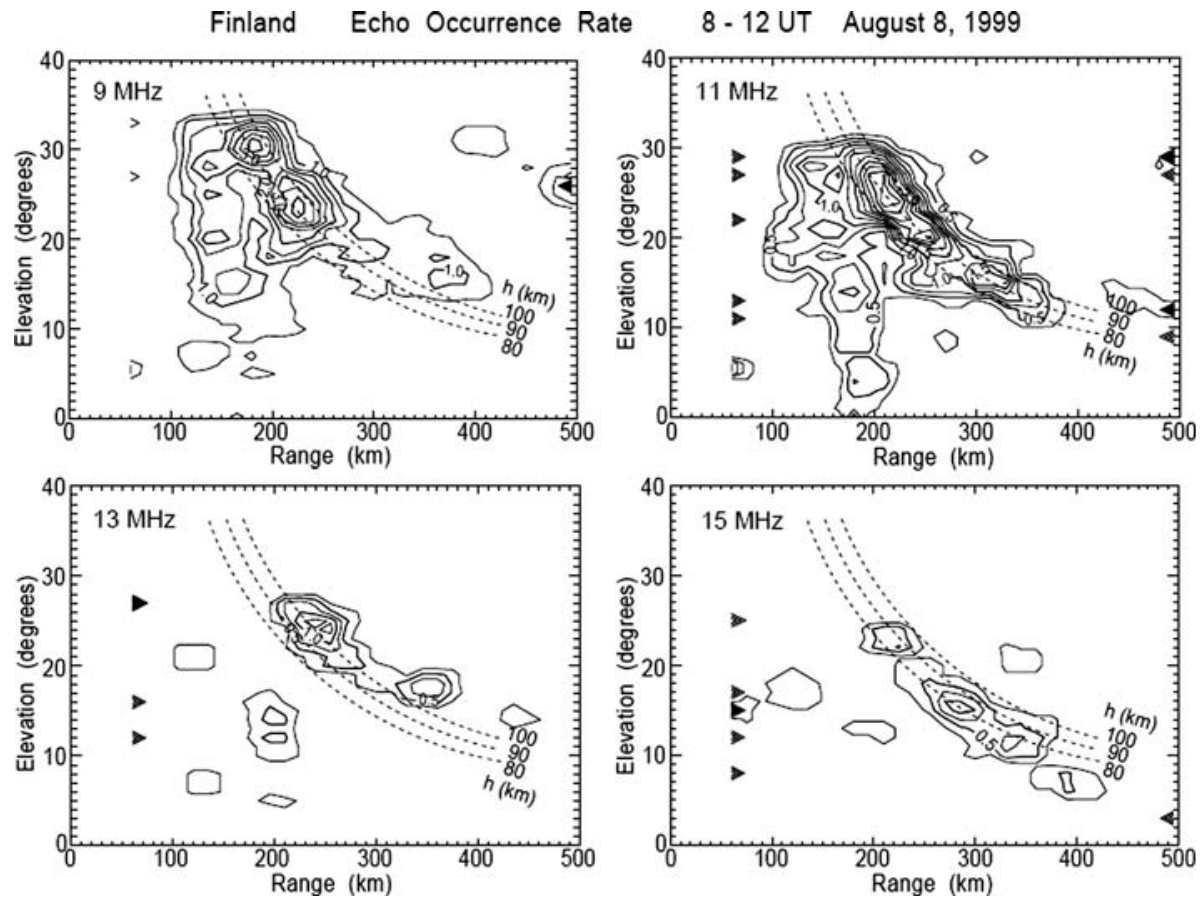

Fig. 24 Contour maps of the echo occurrence rate of near-range echoes, for four SuperDARN operation frequencies $(9,11,13$, and $15 \mathrm{MHz})$, as a function of range and elevation angle, indicating the altitude of PMSEs. The contour lines have intervals of 0.5 for $9 \mathrm{MHz}$ and 0.25 for other frequencies. The relationship between range and elevation angle for three constant altitudes $(h=80,90$, and $100 \mathrm{~km})$ is represented by the dashed curves. This figure is reproduced from Ogawa et al. (2003), copyright by the European Geophysical Union

space. The overlap of the high occurrence regions of SuperDARN echoes with these dashed curves confirms that the echoes originate from altitudes between $80 \mathrm{~km}$ and $100 \mathrm{~km}$, which is consistent with the MST observations. From this evidence, Ogawa et al. (2003) concluded that the source of the echoes was the same in both datasets, and that the long-lived near-range echoes were PMSE. Better understanding of SuperDARN observations of PMSE in the future should open up opportunities for SuperDARN studies of the mesopause.

\section{$8 E$-region ionospheric irregularities}

The instability mechanisms which give rise to field-aligned irregularities in the collisional plasma of the auroral $E$-region ionosphere have been the subject of much study over the last few decades. Other than in situ rocket measurements, the most powerful technique for investigating the nature of the irregularities is studying the Doppler spectra of radio waves coherently scattered from the plasma density perturbations. The wavelength of the probing radio wave determines the irregularity scale-length from which backscatter arises, with radars transmitting in the UHF, VHF, and HF bands being sensitive to scale-lengths from a few centimetres to $10 \mathrm{~s}$ of metres (Moorcroft 2002). 
Though the influence of the $E$ region on HF radar backscatter has been known since the 1960s (e.g. Bates 1965), most work in the 1970s and 1980s was conducted with VHF radars (e.g., Greenwald et al. 1975). At an early point in these studies it was recognized that the Doppler spectra of echoes backscattered from the $E$ region fell into several broad categories, defined mainly by the characteristics of the spectra, specifically the line-of-sight Doppler velocity $\left(u_{\mathrm{los}}\right)$ and the Doppler spectral width. Balsley et al. (1973) introduced the "type" nomenclature, in which there appeared two predominant classes: type I echoes characterized by a narrow spectral peak (low spectral width) Doppler-shifted to near the local ion-acoustic speed, $C_{S}$ (typically $\sim 400 \mathrm{~m} / \mathrm{s}$ ), and type II echoes characterized by broader spectra (high spectral width), and with $u_{\text {los }}$ values that appear close to the line-ofsight component of the $\mathbf{E} \times \mathbf{B}$, or electron drift, velocity ( $\left.v_{\text {los }}\right)$. These have been identified as echoes from two-stream and gradient-drift waves, respectively (Haldoupis 1989; Sahr and Fejer 1996). It is thought that type I echoes are observed when $v_{\text {los }}>C_{S}$, and that type II echoes are observed when the line-of-sight direction is at larger angles to the flow, where $v_{\text {los }}<C_{S}$. Few echoes are observed by VHF radars with $u_{\text {los }}$ in excess of $C_{S}$ and this was thought for some time to be an upper limit for the $E$-region irregularity drift velocity. One of the main differences between $\mathrm{VHF}$ and $\mathrm{HF}$ radar observations of the $E$ region is the frequent observation of $u_{\text {los }}$ values in excess of $C_{S}$ in the HF regime.

The first systematic investigation of the echo types received from the $E$ region by HF radar was from the SHERPA radar operated in Quebec, Canada (Hanuise et al. 1991). This showed the occurrence of two main populations of echoes: narrow width echoes with velocities near $\sim 500 \mathrm{~m} / \mathrm{s}$ and broader width, slower $(<200 \mathrm{~m} / \mathrm{s})$ echoes. These two populations were interpreted as the HF counterparts of type I and II spectra observed at VHF frequencies. However, other studies (Villain et al. 1987, 1990) recognized that the highest Doppler velocities that were observed significantly exceeded reasonable estimates of $C_{S}$, and so could not be categorized as type I echoes. These high-speed echoes appeared within regions of low-speed echoes; these low-speed echoes were interpreted as type II, and hence were thought to give an estimate of the electron drift speed. The high-speed echoes were interpreted as backscatter from electrostatic ion-cyclotron waves, though their appearance in regions of sub-critical perpendicular (horizontal) electron flow suggested that there must be an additional source of free energy, i.e., electron precipitation down the magnetic field.

More recently, SuperDARN observations have challenged this view and it has become clear that the slow background echoes do not represent the background $\mathbf{E} \times \mathbf{B}$ drift but have $u_{\text {los }}$ values that are only $\sim 10-40 \%$ of $v_{\text {los }}$ (Makarevitch et al. 2002; Milan et al. 2003a; Koustov et al. 2005). Understanding that the most ubiquitous echoes are not representative of the electric field prompted a reclassification of the echo-types seen at HF frequencies into five populations i to $\mathrm{v}$, drawing a clear distinction from VHF nomenclature (Milan and Lester 1999, 2001):

- Population $\mathrm{i}$ is the HF analogue of the VHF type I, the echoes being characterized by narrow spectra, with $u_{\text {los }} \sim C_{S}$ when looking at directions along the electron drift direction.

- Population ii echoes have $u_{\text {los }}$ values which appear proportional to $v_{\text {los }}$ (that is, a flow angle behaviour that is roughly a cosine dependence) with a constant of proportionality close to 0.2 (Milan et al. 2003a; Makarevitch et al. 2004; Koustov et al. 2005).

- Population iii echoes grow out of population i, starting with $u_{\text {los }}$ close to $C_{S}$, but increasing in velocity with increasing flow angle (in contrast to a cosine dependence). 
These echoes are characterized by particularly high backscatter power but appear to be sensitive to the radar operating frequency, being seen predominantly near $10-12 \mathrm{MHz}$ (Milan et al. 2003a)

- Like population ii, population iv echoes have $u_{\text {los }}$ values which appear proportional to $v_{\text {los }}$, but with a constant of proportionality close to $\sim 0.8$ (Uspensky et al. 2001; Milan et al. 2003a).

- Population $\mathrm{v}$ echoes have low $u_{\mathrm{los}}$ values that are of opposite sign to that expected for the direction of the electron drift. These have recently been identified as backscatter from high-aspect angles (the high aspect angle irregularity region (HAIR) echoes), that is from density structures not aligned along the magnetic field, whose Doppler velocity is determined by the ion drift rather than the electron drift (Milan et al. 2004; Drexler and St.-Maurice 2005). Aspect angle effects have also been found to be important in modifying the Doppler shift characteristics of other echo types (Makarevitch et al. 2002, 2004).

These five populations are depicted schematically in Fig. 25. The reclassification of these echoes led to a new understanding of the relationship between echo types and electron drift. Specifically, all echo types appear to have $u_{\text {los }}$ values below $v_{\text {los }}$, and so electron precipitation need not be invoked to explain the source of free-energy for the high-speed echoes.

In addition to these five populations, two further populations have been tentatively identified:

- Milan and Lester (1999) identified population vi echoes that appeared to have similar characteristics to population i but with a reversed Doppler shift; these are now understood to be population i echoes that have been observed in the rear field-of-view of the radar (Milan et al. 1997) when the electrojet is located at extremely low latitudes.

- At lower altitudes, a $D$-region population has also been identified (Milan et al. 2001) which has very narrow spectra (comparable to meteor backscatter; Hall et al. 1997), appears in the presence of pulsating aurora, and is associated with significant riometer absorption. For the purposes of this paper we term this population vii. Full investigation of this population requires further work.

These populations are also depicted schematically in Fig. 25.

It is now realized that many echoes from the $E$ region have more than one spectral peak (known as two-peaked E-region echoes or TWOPEEs), and contain backscatter contributions from two or more of the echo types listed above (e.g. Milan et al. 2003a; Danskin et al. 2004). Equally, a broad single peak might contain contributions from one instability type, but from a range of altitudes (Uspensky et al. 1994). There is also interferometer evidence that different echo types arise from slightly differing altitudes within the $E$ region (e.g. Milan et al. 2001, 2003a; Uspensky et al. 2001). This suggests that different irregularity types can occur at the same position, though horizontally stratified, giving rise to co-located echoes with different Doppler characteristics, despite the driving electric field being common to both. There are theoretical arguments to suggest that electron density gradients, either horizontal or vertical, may play some role in modifying the threshold velocity for the two-stream instability at decametre wavelengths so that, for instance, the bottom- and top-side gradients in E-region electron density could be a candidate mechanism for the horizontal stratification of the echo characteristics (St.-Maurice et al. 1994). However, as yet, no realistic geometry has been found that can explain all aspects of the observations (Milan and Lester 2001; Milan et al. 2003a). 
Eastwards electrojet
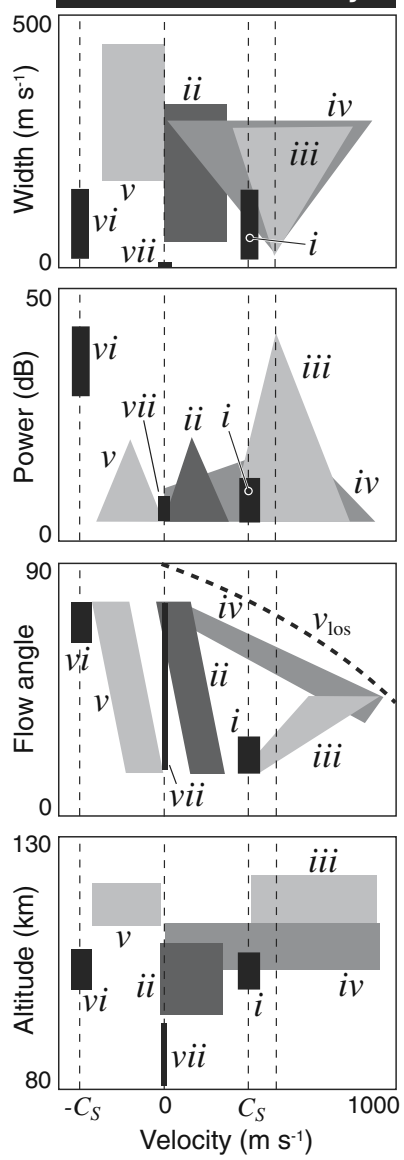

Fig. 25 Schematic representation of the characteristics of the populations of $E$-region echoes observed by SuperDARN (labelled i to vii; see text for full details). The shaded regions indicate the area in parameter space in which each echo class may be found. The ion sound speed $C_{S}$ is indicated by the dashed vertical line in each panel. The Doppler velocities shown are appropriate for measurements from the eastwards electrojet; they should be reversed for measurements from the westwards electrojet. In the third panel the line-of-sight component of the electron drift, $v_{\text {los }}$, is shown for a drift speed of $1.5 \mathrm{~km} / \mathrm{s}$

One of the major drawbacks of studying $E$-region echo characteristics with radars is a lack of knowledge of the background electric field magnitude and orientation. This usually has to be inferred, with wide margins of uncertainty. In an attempt to overcome this, effort has been made to compare echo characteristics with $F$-region backscatter (Milan and Lester 1998; Makarevitch et al. 2004), incoherent scatter radar measurements (Makarevitch et al. 2006), or low-altitude spacecraft measurements (Koustov et al. 2005). In addition, there has been comparison of echo characteristics at widely differing frequencies, for instance in the HF and VHF bands (e.g. Koustov et al. 2001, 2002; Makarevitch et al. 2001). However, in general, such approaches suffer from poor radar geometries and/or conflicting spatial and temporal resolutions. This is a major avenue for further work, especially if novel experimental arrangements can be devised. One possibility is that the 
proposed StormDARN network (see Sect. 9.1) could provide $F$-region measurements of the electric field co-located with SuperDARN observations of $E$-region spectra.

Further information regarding the generation of $E$-region irregularities can be gained from study of the context within which they are observed. For example, their relationship to visible auroral forms (e.g. Milan et al. 2000c, 2001, 2002, 2003b, c) or precipitation regions (Jayanchandran et al. 2000, 2002a, b). It is found that considerable structure in the spatial distribution of echo types is explained by their vicinity to auroral arcs, especially because arc electrodynamics significantly structure the driving electric field (Milan et al. 2003b), but also potentially because of particle precipitation and associated density gradients. Similarly, the observation of slow, long-lived $E$-region plasma structures (SLERPS) has been attributed to gradient-drift waves in diffuse precipitation regions where density gradients are to be expected (Jayanchandran et al. 2000).

\section{Future directions}

SuperDARN has been one of the most effective instruments for the study of magnetospheric, ionospheric, and upper atmospheric science over the last 10 years. In particular, its ability to measure ionospheric convection over a wide range of scales has allowed it to address a multitude of science questions, as detailed above. The SuperDARN network has more than delivered in terms of its original scientific objectives. However, SuperDARN needs to look to the future and to what new questions it can address, and answer. Here, we discuss the future expansion of SuperDARN and explain the rationale for this proposed expansion, we discuss new emerging analysis techniques and how they will allow SuperDARN to address fresh science questions, and finally we discuss new science opportunities.

\subsection{SuperDARN expansion}

The SuperDARN network has grown considerably since the original concept was proposed by Greenwald et al. (1995a). The number of radars operating in the northern hemisphere at the end of 2006 will be 12, while in the southern hemisphere it will be 7, compared with the 8 and 5 planned a decade ago. In addition, further radars are planned for deployment in both the northern and southern hemispheres. The original concept of SuperDARN was to cover the auroral and polar regions of the Earth in both hemispheres. This has nearly been achieved in the northern hemisphere except for the gap that exists in the Russian local time sector. Plans are currently under way to overcome this problem in the next few years. Also, the original network has been extended to include radars both at higher and at lower latitudes than the existing ones.

At higher latitudes, a new radar at Rankin Inlet, Canada, with a field of view centred on the north geomagnetic pole, began operations in May 2006. It is hoped that the Rankin Inlet radar will be complemented by one at Inuvik to form a pair of radars, termed PolarDARN, which will have overlapping fields of view that will incorporate the proposed incoherent scatter radar field of view at Resolute Bay. The initial science goals of these radars will be the study of the ionospheric convection in the polar cap, particularly under northward IMF conditions, when, for the existing SuperDARN radars, the full convection pattern is often not visible. Extension to higher latitudes is also the goal in the southern hemisphere, partly driven by the available sites on the Antarctic 
continent. It is hoped that new SuperDARN radars will be deployed at the Chinese base at Zhongshan, at DOME-C, and at the South Pole station before 2008. If all the planned radars are deployed, complete polar cap coverage will be achieved in Antarctica before the end of the decade.

The current SuperDARN radars at the lowest geomagnetic locations (such as TIGER) have shown that radars at even lower latitude are needed to completely map convection, particularly during substorm expansion and storm times when the auroral oval moves to lower latitudes. Extension to lower latitudes has already taken place with the deployment of a radar at Wallops Island, USA, and in Hokkaido, Japan. Another reason for the extension of the SuperDARN coverage to such latitudes, often referred to as StormDARN, is to compensate for the loss of data coverage during extended periods of high magnetic activity. This loss of data coverage can be attributed to two main causes. One is absorption by enhanced ionization in the $D$ and, to a lesser extent, $E$ regions of the ionosphere. In addition, changes in the maximum electron density in the ionospheric $F 2$ region lead to the inability of the radar signals to propagate to their targets. Moving the radars to lower latitudes removes these two effects on HF propagation, thereby providing measurements of ionospheric convection during storm-time conditions. Furthermore, early results have demonstrated that at certain local times data from the Wallops Island radar make an important contribution to the overall high-latitude convection pattern. The continued extension of StormDARN, in addition to maintaining the existing networks, are important goals in the SuperDARN community for the next 5 years.

\subsection{New analysis techniques/capabilities}

Over the last 10 years there has been a vast investment of effort in the development of high-level data analysis and visualization tools for SuperDARN data. These have made analysis easier and also allowed the production of high-level data products in real time. Foremost amongst these would be the development of the global convection mapping (or map potential) technique (Sect. 2.1) which has been used extensively in studies of ionospheric convection (Sects. 2.2-2.4), FACs (Sect. 3), the remote sensing of magnetic reconnection (Sect. 4), and substorms (Sect. 5). Other high-level techniques of note are the ability to estimate FACs (Sect. 3), to estimate the location of the OCB (Sect. 4.1), and to visualize ULF waves in low velocity ground backscatter (Sect. 6.1). Here we discuss new and emerging techniques and capabilities along with older techniques which have yet to be fully exploited. These, together with the established techniques highlighted above, will be important in allowing SuperDARN to address new science questions.

The major technical development for SuperDARN in the last decade was the introduction of the Stereo capability at the two radars which form CUTLASS (Finland and Iceland East) (Lester et al. 2004). This capability comprises a complete extra receive path for the radar system which provides a second channel, enabling two experimental modes to be run simultaneously. This is achieved by interleaving two pulse sequences at separate frequencies, allowing the two experimental modes to be determined by frequency selection in the receive channel. The Stereo system is extremely flexible and allows a variety of dual modes to be run. Specific examples include employing single, or a small number of, beams on one channel while a full scan mode is run on the other. Such modes are particularly good for high-time resolution experiments. Other modes that have been run include a fixed 
frequency on one mode while sweeping the frequency from one scan to the next on the other channel (e.g. Milan et al. 2004). In addition, it is possible to run two modes with different range resolutions, for example 15 and $45 \mathrm{~km}$. Since the installation in 2003 of the Stereo system at both CUTLASS radars, two further radars have introduced the Stereo capability, Syowa South and the TIGER Unwin radar in the southern hemisphere. The Stereo capability should provide much more flexibility for SuperDARN operations in forthcoming years.

Other technical developments include the introduction of digital receivers, the design of new antennae, and the design of a new phasing matrix. Digital receivers have now been introduced on a number of SuperDARN radars. The additional receiver channels that are provided by digital receivers provide flexibility for signal filtering. The design of the recent Wallops SuperDARN radar (Baker et al. 2007) saw a move away from the standard logperiodic antennae employed by the other SuperDARN radars. The Wallops radar has a twin-terminated folded dipole antenna with an integral corner reflector. This new design reduced the hardware installation cost of the radar and also improved the front-to-back ratio of the transmitted signal at lower frequencies. The Wallops radar design also included a new type of phasing matrix which allows for more flexibility in selecting viewing directions for the transmitted and received signals.

There have also been developments in the techniques used to process the raw ACFs measured by the radars (these represent the basic SuperDARN data product). Almost all of the science undertaken with the SuperDARN radars in the last 10 years has used the backscatter power, Doppler line-of-sight velocity, and Doppler spectral width which are determined from the raw ACF data using a software package known as FitACF. The core of the FitACF algorithm involves a linear fit to the ACF phase, which provides the Doppler velocity, and both a Gaussian and Lorentzian fit to the ACF amplitude which provides two estimates of the backscatter power and spectral width. For $F$-region backscatter it is usually the values determined from the Lorentzian fit that are used in further analysis (Hanuise et al. 1993b). Recently, Ponomarenko and Waters (2006) have made a critical re-evaluation of the FitACF algorithm, revealing inadequate preprocessing of the experimental ACFs before using them to estimate the spectral width. They recommended a number of adjustments to the algorithm which affect the measured spectral width values. This modified FitACF will allow for a total re-evaluation of the mechanisms responsible for enhanced spectral width values such as those measured in the ionospheric cusp region. However, FitACF does not represent the only algorithm for analysing the ACFs measured by the radars. A more advanced analytical treatment of the radar ACFs was provided by Hanuise et al. (1993a, b) and Villain et al. (1996) by applying the theory of collective wave scattering to HF backscatter. They showed that the observed ACF has a Gaussian shape when the correlation length of the plasma turbulent motion is much greater than the observed fluctuation wavelength and a Lorentzian shape for the opposite case. More generally, the ACF has an intermediate shape which exists when the correlation length and the observed fluctuation wavelength are of the same order of magnitude. Using the method of Villain et al. (1996) to fit to this general ACF shape, ionospheric turbulence parameters such as the turbulent diffusion coefficient, the correlation length, and the correlation time of the irregularities can be directly estimated. To date, the use of this technique has been under-exploited. However, this technique may be crucial to future understanding of the physics of ionospheric irregularities (as shown by its use by Ponomarenko and Waters 2006). 
A method has also been developed to examine SuperDARN measurements at an even more fundamental level. In order to better extract meteor backscatter information, and hence mesospheric wind information, from SuperDARN data, Yukimatu and Tsutsumi (2002) have developed what they called a "raw time-series analysis method". Raw data samples from the radar receiver are examined before processing to determine if meteors are present and to determine if there are echoes from other types of backscatter that would interfere with the proper analysis of the meteor data. Figure 26 helps to illustrate the technique. Panels A and B show the seven-pulse multipulse sequence typically used by SuperDARN, and the raw power received for the interval. The multi-pulse technique (Farley 1972) provides a means of obtaining range resolved spectra from overspread targets. As the figure illustrates, there is significant return power over a range of distances that is greater than the spacing between the pulses, hence backscatter from successive pulses overlaps in time. The essence of the technique is to determine which returns in the time series can be attributed to meteors, and of those returns, which do not have a significant contribution from other ranges. Once a set of samples is identified as uncontaminated, the time series of the samples is examined for the expected signature of so-called under-dense meteors, which is a rapid increase in signal amplitude followed by an exponential decay. This technique has two advantages over earlier studies of meteor backscatter. First, it provides a much better means of eliminating contamination of the data by backscatter from non-meteor trails. Both the examination for cross range contamination and the check for an under-dense signature ensure that the targets are meteors. Second, determining that the echoes are due to under-dense meteors ensures that estimates of the decay time can in fact be used to estimate the diffusion coefficient, and in turn provide some estimate of the altitude of the meteor.

There are also a number of higher-level data analysis techniques that have emerged in recent years. For example, Waters et al. (2004) showed that measurements of ionospheric convection can be combined with magnetic perturbations measured by low-altitude satellites to determine the global magnetic poynting flux at high magnetic latitudes. Their technique used magnetic perturbations measured onboard the Iridium satellites, as well as ionospheric convection electric fields measured by SuperDARN. For quasi-steady state fields, Poynting's Theorem is expressed as,

$$
\frac{1}{\mu_{0}} \nabla \cdot(\mathbf{E} \times \mathbf{b})=-\mathbf{J} \cdot \mathbf{E}
$$

where $\mathbf{b}$ is the perturbation magnetic field due to field-aligned and ionospheric currents and $\mathbf{J} \cdot \mathbf{E}$ is the rate of electromagnetic energy dissipation in the atmosphere. Because the technique provides the net energy flux, the influence of neutral winds is automatically included in the calculation. Since no conductivity information is required, this technique can provide a mechanism to test other methods of determining energy flux from groundbased measurements that do require information about conductivity.

\subsection{New science opportunities}

Having reached 10 years of SuperDARN operations it is very timely to discuss what new science areas SuperDARN will be addressing in the next 10 years, in addition to those reviewed in this paper. In particular we would highlight the following opportunities: 


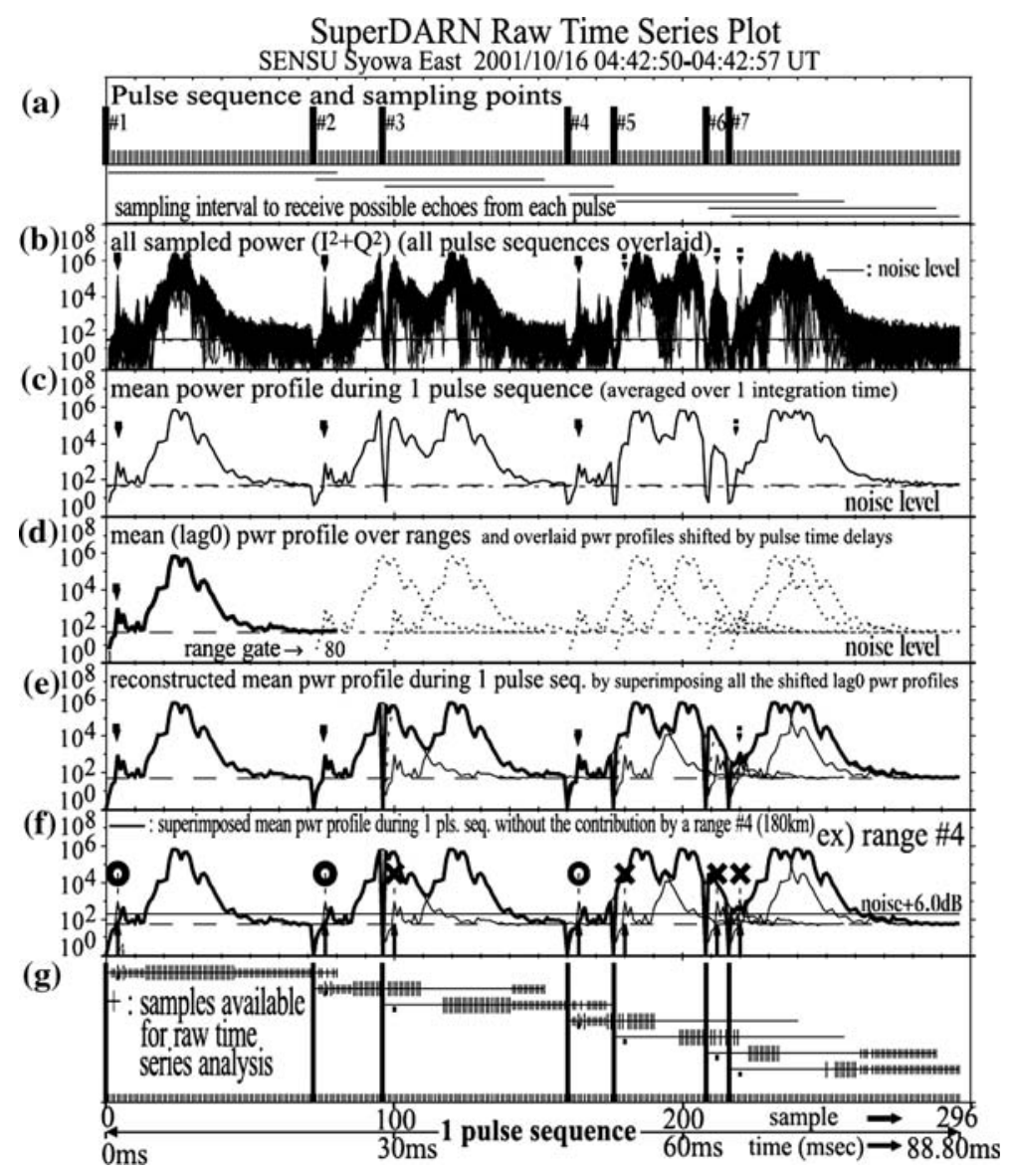

Fig. 26 The SuperDARN pulse sequence and the processing of raw time series data in a single pulse sequence. (a) A typical pulse sequence of SuperDARN ACF observations. The horizontal axis shows time. Seven vertical thick lines represent the unequally spaced transmission pulses. The vertical short ticks show the sampling timings. The horizontal lines show the sampling intervals during which echoes from ranges up to $3,600 \mathrm{~km}$ can be detected from each pulse. This pulse sequence is repeated over a beam integration time. (b) An example of the total sampled power of the backscattered signals from all pulse sequences overlaid during one beam integration time $(\sim 7 \mathrm{~s})$. The horizontal line shows the noise level. (c) The mean power profile when averaged over the integration time. Again the horizontal line shows the noise level. All the samples before the second pulse can be treated as single-pulse observation data. (d) The estimated echo power profile for the single-pulse observation, which is equivalent to the lag-zero power in ACF analysis. Overlaid, as dotted lines, are the mean power profiles shifted by the pulse time delays. (e) The reconstructed power profile during one pulse sequence by superimposing all the shifted range power profiles. This profile is almost completely equivalent to panel (c), as expected. (f) This panel is the same as panel (e) but without the contribution of a test range 4 . The samples that can be used as single-pulse observation data not affected much by range-aliasing echoes from the previous pulses can be determined by comparing panels (e) and (f). Circles and crosses show samples usable and unusable for raw time series analysis for range 4, respectively. (g) A summary of tests for all ranges. Pluses indicate samples available for raw time series analysis. All the available samples which can be treated as single-pulse radar observation data can be extracted and analysed for any range gate in order to investigate the temporal variation of echo power and phase. This figure is reproduced from Yukimatu and Tsutsumi (2002), copyright by the American Geophysical Union 


\subsubsection{Interhemispheric convection symmetries}

With the increasing growth, and planned expansion, of the southern hemisphere SuperDARN network, the opportunity will arise for more global interhemispheric observations. To date, there have been relatively few studies which have employed the complete SuperDARN network in both hemispheres: Chisham et al. (2002) used the observation of interhemispheric asymmetries in dayside convection as support for antiparallel magnetopause reconnection; Grocott et al. (2005) used the observation of interhemispheric asymmetries in nightside convection to understand the effect of IMF $B_{y}$ on magnetotail reconnection. With the advent of global maps of convection in both hemispheres, studies of the interhemispheric symmetry/asymmetry of convection flows will provide further answers to reconnection and substorm questions. Interhemispheric observations around the solstices, when the conjugate ionospheres receive different amounts of sunlight will allow further investigations of the role of ionospheric conductivity on magnetospheric processes such as substorms.

\subsubsection{Multi-instrument data assimilation}

During the lifetime of SuperDARN, a large number of science questions have been addressed using SuperDARN observations in conjunction with other instrumentation, in particular spacecraft missions such as Cluster, Polar and IMAGE (e.g., see Amm et al. (2005) for a review of co-ordinated Cluster and SuperDARN studies). The Cluster 4-spacecraft mission has been extended to 2009 and in combination with the new THEMIS 5 -spacecraft mission will address major outstanding questions in magnetospheric science, such as determining the timing of various phenomena during substorm expansion onset. Part of the THEMIS mission is also a large network of ground-based all-sky imagers in the Canadian MLT sector, with fields of view that overlap with the SuperDARN radars in the same sector. THEMIS and CLUSTER observations, with reconnection signatures observed in both the noon and midnight sectors by ground-based instruments such as SuperDARN, will prove a very powerful combination.

\subsubsection{Mid-latitude electrodynamics}

The extension of the northern hemisphere SuperDARN radars to cover the mid-latitude region, termed StormDARN (discussed above) will open a multitude of opportunities for SuperDARN to venture into new scientific areas. Continuous measurements of the electric field in the vicinity of the footprint of the ring current will play a major role in determining the decay of the ring current following a geomagnetic storm. StormDARN will also enable the study of the electrodynamics of regions where there is intense highly energetic particle precipitation. Such particles have a strong influence on atmospheric chemistry, and hence, ionosphere-thermosphere-lower atmosphere coupling. StormDARN will also enable the propagation of storm-stimulated atmospheric gravity waves to mid- and low-latitude regions to be studied. StormDARN observations will be particularly powerful when used in conjunction with spacecraft data, such as that from the proposed mission Outer Radiation Belt Injection, Transport, Acceleration, and Loss Satellite (ORBITALS) which will study processes in the outer radiation belt. 


\subsubsection{Magnetospheric complexity}

In the last decade most SuperDARN science has been addressed in the form of event studies. Now, with over 10 years of SuperDARN data already collected, and with the increased computational power and data storage facilities available, it is possible to address science questions with large-scale statistical studies of SuperDARN data. There have been some instances of large statistical studies with SuperDARN which have proved very successful: defining statistical maps of ionospheric convection (Ruohoniemi and Greenwald 1996, 2005), determining the distribution of recurrence times of ionospheric flow burst signatures of FTEs (McWilliams et al. 2000; Abel and Freeman 2002), and determining the global relationship between the SuperDARN SWB and the open-closed magnetic field line boundary (Chisham et al. 2004a, 2005a, c). One area where large-scale statistical analysis may have a large impact in the future is in the emerging area of complexity science. Indeed, initial studies have already been made, studying the temporal (Parkinson 2006) and spatial (Abel et al. 2006) scaling of ionospheric convection velocities measured by SuperDARN, and finding evidence for scale-free structure of velocity fluctuations. Future studies of this type will address the complex structure of SuperDARN data products such as convection vorticity and reconnection rate measurements.

\subsubsection{Planetary-wave generation and evolution}

The implementation of digital receivers at a number of SuperDARN radar sites has opened up more opportunities for studies of the neutral atmosphere. Digital receivers provide additional receiver channels that can be dedicated to meteor backscatter and also provide flexibility of signal filtering. This allows more accurate determination of the altitude of meteor backscatter targets. This development, combined with the 'raw time-series analysis method' of Yukimatu and Tsutsumi (2002), should provide an exceptional tool for studying the mesosphere. In particular, the longitudinal span of the radars will allow detailed studies of planetary-wave generation and evolution.

Acknowledgements We are extremely grateful to all the national funding agencies for their continued support of the SuperDARN network and their vision in realising that investment in one radar provides access to global data coverage from multiple radars.

\section{References}

Abel GA, Freeman MP (2002) A statistical analysis of ionospheric velocity and magnetic field power spectra at the time of pulsed ionospheric flows. J Geophys Res 107:1470, doi:10.1029/2002JA009402

Abel GA, Freeman MP, Chisham G (2005) Comment on "Location of the reconnection line for northward interplanetary magnetic field" by K J Trattner SA Fuselier, and S M Petrinec. J Geophys Res 110:A10208, doi:10.1029/2004JA010973

Abel GA, Freeman MP, Chisham G (2006) Spatial structure of ionospheric convection velocities in regions of open and closed magnetic field topology. Geophys Res Lett 33:L24103, doi:10.1029/ 2006GL027919

Amm O, Engebretson MJ, Greenwald RA, Lühr H, Moretto T (1999) Direct determination of IMF $B_{y}$-related cusp current systems, using SuperDARN radar and multiple ground magnetometer data: a link to theory on cusp current origin. J Geophys Res 104:17187-17198

Amm O, Donovan EF, Frey H, Lester M, Nakamura R, Wild JA, Aikio A, Dunlop M, Kauristie K, Marchaudon A, McCrea IW, Opgenoorth HJ, Strømme A (2005) Coordinated studies of the geospace environment using Cluster, satellite and ground-based data: an interim review. Ann Geophys 23: 2129-2170 
André R, Pinnock M, Rodger AS (1999) On the SuperDARN autocorrelation function observed in the ionospheric cusp. Geophys Res Lett 26:3353-3356

André R, Pinnock M, Rodger AS (2000) Identification of the low-altitude cusp by Super Dual Auroral Radar Network radars: a physical explanation for the empirically derived signature. J Geophys Res 105:27081-27093

André R, Pinnock M, Villain J-P, Hanuise C (2002) Influence of magnetospheric processes on winter HF radar spectra characteristics. Ann Geophys 20:1783-1793

André R, Dudok de Wit T (2003) Identification of the ionospheric footprint of magnetospheric boundaries using SuperDARN coherent HF radars. Planet Space Sci 51:813-820

Angelopoulos V, Baumjohann W, Kennel CF, Coroniti FV, Kivelson MG, Pellat R, Walker RJ, Lühr H, Paschmann G (1992) Bursty bulk flows in the central plasma sheet. J Geophys Res 97:4027-4039

Arnold NF, Jones TB, Robinson TR, Stocker AJ, Davies JA (1998) Validation of the CUTLASS HF radar gravity wave observing capability using EISCAT CP-1 data. Ann Geophys 16:1392-1399

Arnold NF, Robinson TR, Byrne PB, Lester M, Chapman PJ (2001) Super Dual Auroral Radar Network HF radar observations of fluctuations in the spectral distribution of near range meteor echoes in the upper mesosphere and lower thermosphere. Ann Geophys 19:425-434

Baddeley LJ, Yeoman TK, Wright DM, Davies JA, Trattner KJ, Roeder JL (2002) Morning sector driftbounce resonance driven ULF waves observed in artificially-induced HF radar backscatter. Ann Geophys 20:1487-1498

Baker KB, Dudeney JR, Greenwald RA, Pinnock M, Newell PT, Rodger AS, Mattin N, Meng C-I (1995) HF radar signatures of the cusp and low-latitude boundary layer. J Geophys Res 100:7671-7695

Baker KB, Rodger AS, Lu G (1997) HF-radar observations of the dayside magnetic merging rate: a geospace environment modeling boundary layer campaign study. J Geophys Res 102:9603-9617

Baker KB, Engebretson MJ, Rodger AS, Arnoldy RL (1998) The coherence scale length of band-limited Pc3 pulsations in the ionosphere. Geophys Res Lett 25:2357-2360

Baker JBH, Greenwald RA, Ruohoniemi JM, Oksavik K, Gjerloev JW, Paxton LJ, Hairston MR (2007) Observations of ionospheric convection from the Wallops SuperDARN radar at middle latitudes. J Geophys Res 112:A01303, doi:10.1029/2006JA011982

Balsley BB, Ecklund WL, Greenwald RA (1973) VHF Doppler spectra of radar echoes associated with a visual auroral form: observations and implications. J Geophys Res 78:1681-1687

Bates HF (1965) Some effects of dense ES clouds on high latitude backscatter observations. J Geophys Res 70:5895-5905

Baumjohann W, Paschmann G, Lühr H (1990) Characteristics of high-speed flows in the plasma sheet. J Geophys Res 95:3801-3809

Boström R (1974) Ionosphere-Magnetosphere Coupling. In: McCormac B (ed) Magnetospheric Physics. D. Reidel, Dordrecht, pp 45-59

Bristow WA, Greenwald RA (1995) Estimating gravity wave parameters from oblique high-frequency backscatter: modeling and analysis. J Geophys Res 100:3639-3648

Bristow WA, Greenwald RA (1997) On the spectrum of thermospheric gravity waves observed by the Super Dual Auroral Radar Network. J Geophys Res 102:11585-11596

Bristow WA, Greenwald RA, Samson JC (1994) Identification of high-latitude acoustic gravity wave sources using the Goose Bay HF radar. J Geophys Res 99:319-332

Bristow WA, Sibeck DG, Jacquey C, Greenwald RA, Sofko GJ, Mukai T, Yamamoto T, Kokubun S, Hughes TJ, Hughes WJ, Engebretson MJ (1995) Observations of convection vortices in the afternoon sector using the SuperDARN HF radars. J Geophys Res 100:19743-19756

Bristow WA, Greenwald RA, Villain J-P (1996) On the seasonal dependence of medium-scale atmospheric gravity waves in the upper atmosphere at high latitudes. J Geophys Res 101:15685-15699

Bristow WA, Yee J-H, Zhu X, Greenwald RA (1999) Simultaneous observations of the July 1996 two-day wave event using the Super Dual Radar Network and the High-Resolution Doppler Imager. J Geophys Res 104:12715-12721

Bristow WA, Lummerzheim D (2001) Determination of field-aligned currents using the Super Dual Auroral Radar Network and the UVI ultraviolet auroral imager. J Geophys Res 106:18577-18587

Burke WJ, Kelley MC, Sagalyn RC, Smiddy M, Lai ST (1979) Polar cap electric field structures with a northward interplanetary magnetic field. Geophys Res Lett 6:21-24

Carbary JF, Sotirelis T, Newell PT, Meng C-I (2003) Auroral boundary correlations between UVI and DMSP. J Geophys Res 108:1018, doi:10.1029/2002JA009378

Carbary JF, Sotirelis T, Newell PT, Meng C-I (2004) Correlation of LBH intensities with precipitating particle energies. Geophys Res Lett 31:L13801, doi:10.1029/2004GL019888

Cerisier J-C, Senior C (1994) Merge: a FORTRAN program. Tech rep, Centre d'Etude des Environnements Terrestres et Planetaires, Cent Nat de la Rech Sci, StMaur, France 
Cerisier J-C, Marchaudon A, Bosqued J-M, McWilliams K, Frey HU, Bouhram M, Laakso H, Dunlop M, Förster M, Fazakerley A (2005) Ionospheric signatures of plasma injections in the cusp triggered by solar wind pressure pulses. J Geophys Res 110:A08204, doi:10.1029/2004JA010962

Chang S-W, Gallagher DL, Spann JF, Mende SB, Greenwald RA, Newell PT (2004) Cusp and LLBL as sources of the isolated dayside auroral feature during northward IMF. J Geophys Res 109:A12222, doi:10.1029/2004JA010619

Chen P-R, Yi L, Nielsen E (1995) Variations of the mean phase velocity of 1-m ionospheric plamsa waves with the plasma electron temperature. J Geophys Res 100:1647-1652

Chisham G, Pinnock M, Rodger AS, Villain J-P (2000a) High-time resolution conjugate SuperDARN radar observations of the dayside convection response to changes in IMF $B_{y}$. Ann Geophys 18:191-201

Chisham G, Pinnock M, Rodger AS (2000b) Poleward-moving HF radar flow bursts in the cusp: transient changes in flow speed or direction? Geophys Res Lett 27:919-922

Chisham G, Pinnock M, Rodger AS (2001) The response of the HF radar spectral width boundary to a switch in the IMF $B_{y}$ direction: ionospheric consequences of transient dayside reconnection? J Geophys Res 106:191-202

Chisham G, Pinnock M (2002) Assessing the contamination of SuperDARN global convection maps by nonF-region backscatter. Ann Geophys 20:13-28

Chisham G, Coleman IJ, Freeman MP, Pinnock M, Lester M (2002) Ionospheric signatures of split reconnection X-lines during conditions of IMF $B_{z}<0$ and $\left|B_{y}\right| \sim\left|B_{z}\right|$ : Evidence for the antiparallel merging hypothesis. J Geophys Res 107:A1323, doi:10.1029/2001JA009124

Chisham G, Freeman MP (2003) A technique for accurately determining the cusp-region polar cap boundary using SuperDARN HF radar measurements. Ann Geophys 21:983-996

Chisham G, Freeman MP (2004) An investigation of latitudinal transitions in the SuperDARN Doppler spectral width parameter at different magnetic local times. Ann Geophys 22:1187-1202

Chisham G, Freeman MP, Sotirelis T (2004a) A statistical comparison of SuperDARN spectral width boundaries and DMSP particle precipitation boundaries in the nightside ionosphere. Geophys Res Lett 31:L02804, doi:10.1029/2003GL019074

Chisham G, Freeman MP, Coleman IJ, Pinnock M, Hairston MR, Lester M, Sofko G (2004b) Measuring the dayside reconnection rate during an interval of due northward interplanetary magnetic field. Ann Geophys 22:4243-4258

Chisham G, Freeman MP, Sotirelis T, Greenwald RA, Lester M, Villain J-P (2005a)A statistical comparison of SuperDARN spectral width boundaries and DMSP particle precipitation boundaries in the morning sector ionosphere. Ann Geophys 23:733-743

Chisham G, Freeman MP, Sotirelis T, Greenwald RA (2005b) The accuracy of using the spectral width boundary measured in off-meridional SuperDARN HF radar beams as a proxy for the open-closed field line boundary. Ann Geophys 23:2599-2604

Chisham G, Freeman MP, Lam MM, Abel GA, Sotirelis T, Greenwald RA, Lester M (2005c) A statistical comparison of SuperDARN spectral width boundaries and DMSP particle precipitation boundaries in the afternoon sector ionosphere. Ann Geophys 23:3645-3654

Clauer CR, Kamide Y (1985) DP-1 and DP-2 current systems for the March 22, 1979 substorms. J Geophys Res 90:1343-1354

Coleman IJ, Chisham G, Pinnock M, Freeman MP (2001) An ionospheric convection signature of antiparallel merging. J Geophys Res 106:28995-29007

Coleman IJ, Freeman MP (2005) Fractal reconnection structures on the magnetopause. Geophys Res Lett 32:L03115, doi:10.1029/2004GL021779

Cowley SWH (1998) Excitation of flow in the Earth's magnetosphere-ionosphere system: observations by incoherent-scatter radar. In Egeland A, Moen J, Lockwood M (eds) Polar cap boundary phenomena. Kluwer Academic Publ, Dordrecht, p 127

Cowley SWH, Lockwood M (1992) Excitation and decay of solar wind-driven flows in the magnetosphereionosphere system. Ann Geophys 10:103-115

Cowley SWH, Khan H, Stockton-Chalk A (1998) Plasma flow in the coupled magnetosphere-ionosphere system and its relationship to the substorm cycle. In Kokobun S, Kamide Y (eds) Substorms-4. Terra Sci Publ Co, Tokyo, pp 623-628

Danskin DW, Koustov AV, Makarevitch RA, Lester M (2004) Observations of double-peaked E region coherent spectra with the CUTLASS Finland HF radar. Radio Sci 39:RS2006, doi:10.1029/ 2003RS002932

Davies JA, Lester M, Milan SE, Yeoman TK (1999) A comparison of velocity measurements from the CUTLASS Finland radar and the EISCAT UHF system. Ann Geophys 17:892-902 
Davies JA, Yeoman TK, Lester M, Milan SE (2000) A comparison of F-region ion velocity observations from the EISCAT Svalbard and VHF radars with irregularity drift velocity measurements from the CUTLASS Finland HF radar. Ann Geophys 18:589-594

de la Beaujardière O, Lyons LR, Friis-Christensen E (1991) Sondrestrom radar measurements of the reconnection electric field. J Geophys Res 96:13907-13912

de la Beaujardière O, Lyons LR, Ruohoniemi JM, Friis-Christensen E, Danielsen C, Rich FJ, Newell PT (1994) Quiet-time intensifications along the poleward boundary near midnight. J Geophys Res 99: $287-298$

Drayton RA, Koustov AV, Hairston MR, Villain J-P (2005) Comparison of DMSP cross-track ion drifts and SuperDARN line-of-sight velocities. Ann Geophys 23:2479-2486

Drexler J, St-Maurice J-P (2005) A possible origin for large aspect angle "HAIR" echoes seen by SuperDARN radars in the E region. Ann Geophys 23:767-772

Dudeney JR, Rodger AS, Pinnock M, Ruohoniemi JM, Baker KB (1991) Studies of conjugate plasma convection in the vicinity of the Harang discontinuity. J Atmos Terr Phys 53:249-263

Dudeney JR, Rodger AS, Freeman MP, Pickett J, Scudder J, Sofko G, Lester M (1998) The nightside ionospheric response to IMF $B_{y}$ changes. Geophys Res Lett 25:2601-2604

Elphic RC, Lockwood M, Cowley SWH, Sandholt PE (1990) Flux transfer events at the magnetopause and in the ionosphere. Geophys Res Lett 17:2241-2244

Espy PJ, Hibbins RE, Riggin DM, Fritts DC (2005) Mesospheric planetary waves over Antarctica during 2002. Geophys Res Lett 32:L21804, doi:10.1029/2005GL023886

Fairfield DH, Cahill LJ Jr (1966) Transition region magnetic field and polar magnetic disturbances. J Geophys Res 71:155-169

Farley DT (1972) Multi-pulse in coherent scatter correlation function measurements. Radio Sci 7:661-666

Farrugia CJ, Lund EJ, Sandholt PE, Wild JA, Cowley SWH, Balogh A, Mouikis C, Möbius E, Dunlop MW, Bosqued J-M, Carlson CW, Parks GK, Cerisier J-C, Kelly JD, Sauvaud J-A, Rème H (2004) Pulsed flows at the high-altitude cusp poleward boundary, associated ionospheric convection and particle signatures, during a Cluster-FAST-SuperDARN-Søndrestrom conjunction under a southwest IMF. Ann Geophys 22:2891-2905

Fasel GJ (1995) Dayside poleward moving auroral forms: a statistical study. J Geophys Res 100: 11891-11905

Fear RC, Fazakerley AN, Owen CJ, Lucek EA (2005) A survey of flux transfer events observed by Cluster during strongly northward IMF. Geophys Res Lett 32:L18105, doi:10.1029/2005GL023811

Fenrich FR, Samson JC, Sofko G, Greenwald RA (1995) ULF high- and low-m field line resonances observed with the Super Dual Auroral Radar Network. J Geophys Res 100:21535-21547

Fenrich FR and Samson JC (1997) Growth and decay of field line resonances. J Geophys Res 102:20031-20039

Foster JC and Burke WJ (2002) SAPS, A new categorization for subauroral electric fields. EOS, Trans Am Geophys Union 83(36):393-394

Foster JC, Vo HB (2002) Average characteristics and activity dependence of the subauroral polarisation stream. J Geophys Res 107:1475, doi:10.1029/2002JA009409

Fox NJ, Cowley SWH, Davda VN, Enno G, Friis-Christensen E, Greenwald RA, Hairston MR, Kivelson MG, Lester M, Lockwood M, Lühr H, Milling DK, Murphree JS, Pinnock M, Reeves GD (1999) A multipoint study of a substorm occurring on 7 December 1992 and its theoretical implications. Ann Geophys 17:1369-1384

Francis SH (1975) Global propagation of atmospheric gravity waves - a review. J Atmos Terr Phys 37:1011-1054

Freeman MP, Southwood DJ (1988) The effect of magnetospheric erosion on mid- and high-latitude ionospheric flows. Planet Space Sci 36:509-522

Freeman MP, Southwood DJ, Lester M, Waldock JA (1990) Measurement of field-aligned currents by the SABRE coherent scatter radar. In Russell CT, Priest ER, Lee LC (eds) Physics of magnetic flux ropes, vol 58. Geophysical monograph series, American Geophysical Union, Washington, pp 575-580

Freeman MP, Ruohoniemi JM, Greenwald RA (1991) The determination of time-stationary two-dimensional convection patterns with single-station radars. J Geophys Res 96:15735-15749

Freeman MP, Southwood DJ, Lester M, Yeoman TK, Reeves GD (1992) Substorm-associated radar auroral surges. J Geophys Res 97:12173-12185

Freeman MP (2003) A unified model of the response of ionospheric convection to changes in the interplanetary magnetic field. J Geophys Res 108:1024, doi:10.1029/2002JA009385

Freeman MP, Chisham G (2004) On the probability distributions of SuperDARN Doppler spectral width measurements inside and outside the cusp. Geophys Res Lett 31:L22802, doi:10.1029/2004GL020923 
Friis-Christensen E, Kamide Y, Richmond AD, Matsushita S (1985) Interplanetary magnetic field control of high-latitude electric fields and currents determined from Greenland magnetometer data. J Geophys Res 90:1325-1338

Galperin YI, Ponomarev VN, Zosimova AG (1973) Direct measurements of ion drift velocity in the upper ionosphere during a magnetic storm, 2. Results of measurements during the November 3, 1967, magnetic storm. Cosmic Res (Russian) 11:283-292

Germany GA, Torr DG, Richards PG, Torr MR, John S (1994) Determination of ionospheric conductivities from FUV auroral emissions. J Geophys Res 99:23297-23305

Germany GA, Parks GK, Brittnacher M, Cumnock J, Lummerzheim D, Spann JF, Chen L, Richards PG, Rich FJ (1997) Remote determination of auroral energy characteristics during substorm activity. Geophys Res Lett 24:995-998

Green DL, Waters CL, Anderson BJ, Korth H, Barnes RJ (2006) Comparison of large-scale Birkeland currents determined from Iridium and SuperDARN data. Ann Geophys 24:941-959

Greenwald RA, Walker ADM (1980) Energetics of long period resonant hydromagnetic waves. Geophys Res Lett 7:745-748

Greenwald RA, Ecklund WL, Balsley BB (1975) Radar observations of auroral electrojet currents. J Geophys Res 80:3635-3641

Greenwald RA, Weiss W, Nielsen E, Thomas NR (1978) STARE: a new radar auroral backscatter experiment in northern Scandinavia. Radio Sci 12:1021-1039

Greenwald RA, Baker KB, Hutchins RA, Hanuise C (1985) An HF phased-array radar for studying small-scale structure in the high-latitude ionosphere. Radio Sci 20:63-79

Greenwald RA, Baker KB, Ruohoniemi JM, Dudeney JR, Pinnock M, Mattin N, Leonard JM, Lepping RP (1990) Simultaneous conjugate observations of dynamic variations in high latitude dayside convection due to changes in IMF $B_{y}$. J Geophys Res 95:8057-8072

Greenwald RA, Baker KB, Dudeney JR, Pinnock M, Jones TB, Thomas EC, Villain J-P, Cerisier J-C, Senior C, Hanuise C, Hunsucker RD, Sofko G, Koehler J, Nielsen E, Pellinen R, Walker ADM, Sato N, Yamagishi H (1995a) DARN/SuperDARN: a global view of the dynamics of high-latitude convection. Space Sci Rev 71:761-796

Greenwald RA, Bristow WA, Sofko GJ, Senior C, Ceriser J-C, Szabo A (1995b)Super Dual Auroral Radar Network radar imaging of dayside high-latitude convection under northward interplanetary magnetic field: toward resolving the distorted two-cell versus multicell controversy. J Geophys Res 100:19661-19674

Greenwald RA, Ruohoniemi JM, Bristow WA, Sofko GJ, Villain J-P, Huuskonen A, Kokubun S, Frank LA (1996) Mesoscale dayside convection vortices and their relation to substorm phase. J Geophys Res 101:21697-21713

Grocott A, Cowley SWH, Davies JA (2000) Comparison of ionospheric electric currents and plasma convection patterns observed during substorms. In Proc fifth internat conf on substorms, ESA SP-443, ESA. Noordwijk, The Netherlands, pp 295-298

Grocott A, Cowley SWH, Sigwarth JB, Watermann JF, Yeoman TK (2002) Excitation of twin-vortex flow in the nightside high-latitude ionosphere during an isolated substorm. Ann Geophys 20:1577-1601

Grocott A, Cowley SWH, Sigwarth JB (2003) Ionospheric flows and magnetic disturbance during extended intervals of northward but $B_{y}$-dominated IMF. Ann Geophys 21:509-538

Grocott A, Yeoman TK, Nakamura R, Cowley SWH, Rème H, Klecker B (2004a) Multi-instrument observations of the ionospheric counterpart to a bursty bulk flow in the near-Earth plasma sheet. Ann Geophys 22:1061-1075

Grocott A, Yeoman TK, Cowley SWH, Rème H (2004b) Multi-instrument observations of bursty bulk flows and their ionospheric counterpart. In: Proc seventh internat conf on substorms, UDK-52-854, FMI, Helsinki, Finland, pp 103-106

Grocott A, Badman SV, Cowley SWH, Yeoman TK, Cripps PJ (2004c) The influence of IMF $B_{y}$ on the nature of the nightside high-latitude ionospheric flow during intervals of positive IMF $B_{z}$. Ann Geophys 22:1755-1764

Grocott A, Yeoman TK, Milan SE, Cowley SWH (2005) Interhemispheric observations of the ionospheric signature of tail reconnection during IMF-northward non-substorm intervals. Ann Geophys 23: $1763-1770$

Haldoupis C (1989) A review on radio studies of the auroral E-region ionospheric irregularities. Ann Geophys 7:239-258

Hall GE, MacDougall JW, Moorcroft DR, St-Maurice J-P, Manson AH, Meek CE (1997) Super Dual Auroral Radar Network observations of meteor echoes. J Geophys Res 102:14603-14614

Hall GE, MacDougall JW, Moorcroft DR, St-Maurice J-P (1999) Finding gravity wave source positions using SuperDARN. J Geophys Res 104:67-78 
Hanuise C, Greenwald RA, Baker KB (1985) Drift motions of very high latitude F region irregularities: Azimuthal Doppler analysis. J Geophys Res 90:9717-9725

Hanuise C, Villain J-P, Cerisier J-C, Senior C, Ruohoniemi JM, Greenwald RA, Baker KB (1991) Statistical study of high-latitude E-region Doppler spectra obtained with the SHERPA HF radar. Ann Geophys 9:273-285

Hanuise C, Senior C, Cerisier J-C, Villain J-P, Greenwald RA, Ruohoniemi JM, Baker KB (1993a) Instantaneous mapping of high-latitude convection with coherent HF radars. J Geophys Res 98: $17387-17400$

Hanuise C, Villain J-P, Gresillon D, Cabrit B, Greenwald RA, Baker KB (1993b) Interpretation of HF radar ionospheric Doppler spectra by collective wave scattering theory. Ann Geophys 11:29-39

Henderson MG, Reeves GD, Murphree JS (1998) Are north-south aligned auroral structures an ionospheric manifestation of bursty bulk flows? Geophys Res Lett 25:3737-3740

Heppner JP, Maynard NC (1987) Empirical high-latitude electric field models. J Geophys Res 92: 4467-4489

Hosokawa K, Woodfield EE, Lester M, Milan SE, Sato N, Yukimatu AS, Iyemori T (2002) Statistical characteristics of Doppler spectral width as observed by the conjugate SuperDARN radars. Ann Geophys 20:1213-1223

Hosokawa K, Yamashita S, Stauning P, Sato N, Yukimatu AS, Iyemori T (2004) Origin of the SuperDARN broad Doppler spectra: simultaneous observation with Oersted satellite magnetometer. Ann Geophys 22:159-168

Huang C-S, Andre DA, Sofko GJ (1998a) High-latitude ionospheric perturbations and gravity waves 1. Observational results. J Geophys Res 103:2131-2141

Huang C-S, Andre DA, Sofko GJ (1998b) Observations of Solar wind directly-driven auroral electrojet and gravity waves. J Geophys Res 103:23347-23356

Huang C-S, Murr D, Sofko GJ, Hughes WJ, Moretto T (2000a) Ionospheric convection response to changes of interplanetary magnetic field $B_{z}$ component during strong $B_{y}$ component. J Geophys Res 105 : 5231-5243

Huang C-S, Sofko GJ, Koustov AV, Andre DA, Ruohoniemi JM, Greenwald RA, Hairston MR (2000b) Evolution of ionospheric multicell convection during northward interplanetary magnetic field with $\left|B_{z}\right|$ $B_{y} \mid>1$. J Geophys Res 105:27095-27107

Huang C-S, Sofko GJ, Koustov AV, MacDougall JW, Greenwald RA, Ruohoniemi JM, Villain JP, Lester M, Watermann J, Papitashvili VO, Hughes WJ (2001) Long-period magnetospheric-ionospheric perturbations during northward interplanetary magnetic field. J Geophys Res 106:13091-13104

Huber M, Sofko GJ (2000) Small-scale vortices in the high latitude F region. J Geophys Res 105:2088520897

Hubert B, Milan SE, Grocott A, Cowley SWH, Grard J-C (2006) Dayside and nightside reconnection rates inferred from IMAGE-FUV and Super Dual Auroral Radar Network data. J Geophys Res 111:A03217, doi:10.1029/2005JA011140

Hughes WJ, Southwood DJ (1976) The screening of micropulsation signals by the atmosphere and ionosphere. J Geophys Res 81:3234-3240

Hussey GC, Meek CE, Andre D, Manson AH, Sofko GJ, Hall CM (2000) A comparison of Northern Hemisphere winds using SuperDARN meteor trail and MF radar wind measurements. J Geophys Res 105:18053-18066

Imber SM, Milan SE, Hubert B (2006) The auroral and ionospheric flow signatures of dual lobe reconnection. Ann Geophys 24:3115-3129

Inhester, B, Untiedt J, Segatz M, Kuerschner M (1992) Direct determination of the local ionospheric Hall conductance distribution from two-dimensional electric and magnetic field data. J Geophys Res 97:4073-4083

Jayachandran PT, St-Maurice J-P, MacDougall JW, Moorcroft DR (2000) HF detection of slow long-lived E region plasma structures. J Geophys Res 105:2425-2442

Jayachandran PT, MacDougall JW, St-Maurice J-P, Moorcroft DR, Newell PT, Prikryl P (2002a) Coincidence of the ion precipitation boundary with the HF E-region backscatter boundary in the dusk-midnight sector of the auroral oval. Geophys Res Lett 29:1256 doi:10.1029/2001GL014184

Jayachandran PT, Donovan EF, MacDougall JW, Moorcroft DR, St-Maurice J-P, Prikryl P (2002b) SuperDARN E-region backscatter boundary in the dusk-midnight sector - tracer of equatorward boundary of the auroral oval. Ann Geophys 20:1899-1904

Jayachandran PT, MacDougall JW, Donovan EF, Ruohoniemi JM, Liou K, Moorcroft DR, St Maurice J-P (2003) Substorm associated changes in the high-latitude ionospheric convection. Geophys Res Lett 30:2064 doi:10.1029/2003GL017497 
Jenkins B, Jarvis MJ (1999) Mesospheric winds derived from SuperDARN HF radar meteor echoes at Halley, Antarctica. Earth Planets Space 51:685-689

Jenkins B, Jarvis M J, Forbes DM (1998) Mesospheric wind observations derived from Super Dual Auroral Radar Network (SuperDARN) HF radar meteor echoes at Halley, Antarctica: preliminary results. Radio Sci 33:957-965

Kamide Y, Ahn B-H, Akasofu S-I, Baumjohann W, Friis-Christensen E, Kroehl HW, Maurer H, Richmond AD, Rostoker G, Spiro RW (1982) Global distribution of ionospheric and field-aligned currents during substorms as determined from six IMS meridian chains of magnetometers - initial results. J Geophys Res 87:8228-8240

Kamide Y, Richmond AD, Emery BA, Hutchins CF, Ahn BH, de la Beaujardière O, Foster JC, Heelis RA, Kroehl HW, Rich FJ, Slavin JA (1994) Ground-based studies of ionospheric convection associated with substorm expansion. J Geophys Res 99:19451-19466

Karhunen TJT, Robinson TR, Arnold NF, Lester M (2006) Determination of the parameters of travelling ionospheric disturbances in the high-latitude ionosphere using CUTLASS coherent scatter radars. J Atmos Sol Terr Phys 68:558-567

Koustov AV, Igarashi K, Andre D, Ohtaka K, Sato N, Yamagishi H, Yukimatu A (2001) Observations of 50and 12-MHz auroral coherent echoes at the Antarctic Syowa station. J Geophys Res 106:12875-12887

Koustov AV, Danskin DW, Uspensky MV, Ogawa T, Janhunen P, Nishitani N, Nozawa S, Lester M, Milan SE (2002) Velocities of auroral coherent echoes at 12 and 144 MHz. Ann Geophys 20:1647-1661

Koustov AV, Danskin DW, Makarevitch RA, Gorin JD (2005) On the relationship between the velocity of E-region HF echoes and E $\times$ B plasma drift. Ann Geophys 23:371-378

Koustov AV, Drayton RA, Makarevich RA, McWilliams KA, St-Maurice J-P, Kikuchi T, Frey HU (2006) Observations of high-velocity SAPS-like flows with the King Salmon SuperDARN radar. Ann Geophys 24:1591-1608

Kozlovsky A, Koustov A, Lyatsky W, Kangas J, Parks G, Chua D (2002) Ionospheric convection in the postnoon auroral oval: Super Dual Auroral Radar Network (SuperDARN) and polar ultraviolet imager (UVI) observations. J Geophys Res 107:1433, doi:10.1029/2002JA009261

Kuo H, Russell CT, Lee G (1995) Statistical studies of flux transfer events. J Geophys Res 100:3513-3519

Kustov AV, Papitashvili VO, Sofko GJ, Schiffler A, Feldstein YI, Gromova LI, Levitin AE, Belov BA, Greenwald RA, Ruohoniemi MJ (1997) Dayside ionospheric plasma convection, electric fields, and field-aligned currents derived from SuperDARN radar observations and predicted by the IZMEM model. J Geophys Res 102:24057-24067

Lam MM, Pinnock M, Donovan EF (2006) Observations of nightside magnetic reconnection during substorm growth and expansion phases. J Geophys Res 111:A05209, doi:10.1029/2005JA011356

Lee LC, Kan JR, Akasofu S-I (1985) On the origin of the cusp field-aligned currents. J Geophys 57:217-221

Lester M, Milan SE, Besser V, Smith R (2001) A case study of HF radar spectra and $630.0 \mathrm{~nm}$ auroral emission in the pre-midnight sector. Ann Geophys 19:327-339

Lester M, Chapman PJ, Cowley SWH, Crooks SJ, Davies JA, Hamadyk P, McWilliams KA, Milan SE, Parsons MJ, Payne DB, Thomas EC, Thornhill JD, Wade NM, Yeoman TK, Barnes RJ (2004) Stereo CUTLASS - a new capability for the SuperDARN HF radars. Ann Geophys 22:459-473

Lewis RV, Freeman MP, Rodger AS, Reeves GD, Milling DK (1997) The electric field response to the growth phase and expansion phase onset of a small isolated substorm. Ann Geophys 15:289-299

Lewis RV, Freeman MP, Reeves GD (1998) The relationship of HF radar backscatter to the accumulation of open magnetic flux prior to substorm onset. J Geophys Res 103:26613-26619

Liang J, Sofko GJ, Frey HU (2006) Postmidnight convection dynamics during substorm expansion phase. J Geophys Res 111:A04205, doi:10.1029/2005JA0011483

Lockwood M, van Eyken AP, Bromage BJI, Willis DM, Cowley SWH (1986) Eastward propagation of a plasma convection enhancement following a southward turning of the interplanetary magnetic field. Geophys Res Lett 13:72-76

Lockwood M, Sandholt PE, Cowley SWH, Oguti T (1989) Interplanetary magnetic field control of dayside auroral activity and the transfer of momentum across the dayside magnetopause. Planet Space Sci 37:1347-1365

Lockwood M, Sandholt PE, Farmer AD, Cowley SWH, Lybekk B, Davda VN (1990) Auroral and plasma flow transients at magnetic noon. Planet Space Sci 38:973-993

Lockwood M, Wild MN (1993) On the quasi-periodic nature of magnetopause flux transfer events. J Geophys Res 98:5935-5940

Lockwood M, Milan SE, Onsager T, Perry CH, Scudder JA, Russell CT, and Brittnacher M (2001) Cusp ion steps, field-aligned currents and poleward moving auroral forms. J Geophys Res 106:29555-29569 
Lu G, Richmond AD, Ruohoniemi JM, Greenwald RA, Hairston M, Rich FJ, Evans DS (2001) An investigation of the influence of data and model inputs on assimilative mapping of ionospheric electrodynamics. J Geophys Res 106:417-433

Lu G, Holzer TE, Lummerzheim D, Ruohoniemi JM, Stauning P, Troshichev O, Newell PT, Brittnacher M, Parks G (2002) Ionospheric response to the interplanetary magnetic field southward turning: fast onset and slow reconfiguration. J Geophys Res 107:1153, 10.1029/2001JA000324

Luhmann JG, Walker RJ, Russell CT, Crooker NU, Spreiter JR, Stahara SS (1984) Patterns of potential magnetic field merging sites on the dayside magnetopause. J Geophys Res 89:1739-1742

Lui ATY, Kamide Y (2003) A fresh perspective of the substorm current system and its dynamo. Geophys Res Lett 30:1958, doi:10.1029/2003GL017835

Lummerzheim D, Rees MH, Craven JD, Frank LA (1991) Ionospheric conductances derived from DE-1 auroral images. J Atmos Terr Phys 53:281-292

Lyons LR, Nagai T, Blanchard GT, Samson JC, Yamamoto T, Mukai T, Nishida A, Kokubun S (1999) Association between Geotail plasma flows and auroral poleward boundary intensifications observed by CANOPUS photometers. J Geophys Res 104:4485-4500

Lyons LR, Ruohoniemi JM, Lu G (2001) Substorm-associated changes in large-scale convection during the November 24, 1996, geospace environment modelling event. J Geophys Res 106:397-405

Lyons LR, Liu S, Ruohoniemi JM, Solovyev SI, Samson JC (2003) Observations of dayside convection reduction leading to substorm onset. J Geophys Res 108:1119, doi:10.1029/2002JA009670

MacDougall JW, Andre DA, Sofko GJ, Huang C-S, Kustov AV (2001) Traveling ionospheric disturbance properties deduced from SuperDARN. Ann Geophys 18:1550-1559

Makarevitch RA, Ogawa T, Igarashi K, Koustov AV, Sato N, Ohtaka K, Yamagishi H, Yukimatu A (2001) On the power-velocity relationship for 12 -and $50-\mathrm{MHz}$ auroral coherent echoes. J Geophys Res 106:15455-15469

Makarevitch RA, Koustov AV, Sofko GJ, Andre D, Ogawa T (2002) Multifrequency measurements of HF Doppler velocity in the auroral E region. J Geophys Res 107:A1212, doi:10.1029/2001JA000268

Makarevitch RA, Honary F, Koustov AV (2004) Simultaneous HF measurements of E- and F-region Doppler velocities at large flow angles. Ann Geophys 22:1177-1185

Makarevich RA, Honary F, Howells VSC, Koustov AV, Milan SE, Davies JA, Senior A, McCrea IW, Dyson PL (2006) A first comparison of irregularity and ion drift velocity measurements in the E-region. Ann Geophys 24:2375-2389

Marchaudon A, Cerisier J-C, Bosqued J-M, Dunlop MW, Wild JA, Décréau PME, Förster M, Fontaine D, Laakso H (2004a) Transient plasma injections in the dayside magnetosphere: one-to-one correlated observations by Cluster and SuperDARN. Ann Geophys 22:141-158

Marchaudon A, Cerisier J-C, Greenwald RA, Sofko GJ (2004b) Electrodynamics of a flux transfer event: experimental test of the Southwood model. Geophys Res Lett 31:L09809, doi:10.1029/2004GL019922

Matsuoka H, Yukimatu AS, Yamagishi H, Sato N, Sofko GJ, Fraser BJ, Ponomarenko P, Liu R, Goka T (2002) Coordinated observations of Pc 3 pulsations near cusp latitudes. J Geophys Res 107:1400, doi:10.1029/2002JA000065

Maynard NC, Ober DM, Burke WJ, Scudder JD, Lester M, Dunlop M, Wild JA, Grocott A, Farrugia CJ, Lund EJ, Russell CT, Weimer DR, Siebert KD, Balogh A, Andre M, Rème H (2003) Polar, Cluster and SuperDARN evidence for high-latitude merging during southward IMF: temporal/spatial evolution. Ann Geophys 21:2233-2258

McPherron RL (1970) Growth phase of magnetospheric substorms. J Geophys Res 75:5592-5599

McWilliams KA, Yeoman TK, Provan G (2000) A statistical survey of dayside pulsed ionospheric flows as seen by the CUTLASS Finland HF radar. Ann Geophys 18:445-453

McWilliams KA, Yeoman TK, Sigwarth JB, Frank LA, Brittnacher M (2001) The dayside ultraviolet aurora and convection responses to a southward turning of the interplanetary magnetic field. Ann Geophys 19:707-721

McWilliams KA, Sofko GJ, Yeoman TK, Milan SE, Sibeck DG, Nagai T, Mukai T, Coleman IJ, Hori T, Rich FJ (2004) Simultaneous observations of magnetopause flux transfer events and of their associated signatures at ionospheric altitudes. Ann Geophys 22:2181-2199

Menk F W, Yeoman TK, Wright DM, Lester M, Honary F (2003) High-latitude observations of impulsedriven ULF pulsations in the ionosphere and on the ground. Ann Geophys 21:559-576

Milan SE, Jones TB, Robinson TR, Thomas EC, Yeoman TK (1997) Interferometric evidence for the observation of ground backscatter originating behind the CUTLASS coherent HF radars. Ann Geophys 15:29-39

Milan SE, Lester M (1998) Simultaneous observations at different altitudes of ionospheric backscatter in the eastward electrojet. Ann Geophys 16:55-68 
Milan SE, Lester M (1999) Spectral and flow angle characteristics of backscatter from decametre irregularities in the auroral electrojets. Adv Space Res 23:1773-1776

Milan SE, Davies JA, Lester M (1999a) Coherent HF radar backscatter characteristics associated with auroral forms identified by incoherent radar techniques: a comparison of CUTLASS and EISCAT observations. J Geophys Res 104:22591-22604

Milan SE, Lester M, Cowley SWH, Moen J, Sandholt PE, Owen CJ (1999b) Meridian-scanning photometer, coherent HF radar and magnetometer observations of the cusp: a case study. Ann Geophys 17:159-172

Milan SE, Lester M, Cowley SWH, Brittnacher M (2000a) Dayside convection and auroral morphology during an interval of northward interplanetary magnetic field. Ann Geophys 18:436-444

Milan SE, Lester M, Cowley SWH, Brittnacher M (2000b) Convection and auroral response to a southward turning of the IMF: Polar UVI, CUTLASS and IMAGE signatures of transient flux transfer at the magnetopause. J Geophys Res 105:15741-15756

Milan SE, Lester M, Sato N, Takizawa H, Villain J-P (2000c) Investigation of the relationship between optical auroral forms and HF radar E region backscatter. Ann Geophys 18:608-617

Milan SE, Lester M (2001) A classification of spectral populations observed in HF radar backscatter from the E region electrojets. Ann Geophys 19:189-204

Milan SE, Lester M, Sato N, Takizawa H (2001) On the altitude dependence of the spectral characteristics of decametre-wavelength E region backscatter and the relationship with optical auroral forms. Ann Geophys 19:205-217

Milan SE, Sato N, Lester M, Yeoman TK, Murata Y, Doi H, Saemundsson T (2002) The spectral characteristics of E region radar echoes co-located with and adjacent to visual auroral arcs. Ann Geophys 20:795-805

Milan SE, Lester M, Sato N (2003a) Multi-frequency observations of E-region HF radar aurora. Ann Geophys 21:761-777

Milan SE, Lester M, Cowley SWH, Oksavik K, Brittnacher M, Greenwald RA, Sofko G, Villain J-P (2003b) Variations in the polar cap area during two substorm cycles. Ann Geophys 21:1121-1140

Milan SE, Sato N, Lester M, Murata Y, Shinkai Y, Doi H, Frey HU, Saemundsson T (2003c) E-region echo characteristics governed by auroral arc electrodynamics. Ann Geophys 21:1567-1575

Milan SE, Lester M, Yeoman TK, Robinson TR, Uspensky MV, Villain J-P (2004) HF radar observations of high-aspect angle backscatter from the E region. Ann Geophys 22:829-847

Milan SE, Hubert B, Grocott A (2005a) Formation and motion of a transpolar arc in response to dayside and nightside reconnection. J Geophys Res 110: A01212 doi:10.1029/2004JA010835

Milan SE, Wild JA, Grocott A, Draper NC (2005b) Space- and ground-based investigations of solar windmagnetosphere-ionosphere coupling. In 35th COSPAR Scientific Assembly, Paris France, p 2501

Moorcroft DR (2002) Outstanding issues in the theory of radar aurora: evidence from the frequency dependence of spectral characteristics. J Geophys Res 107:A1301, doi:A01212 10.1029/ 2001JA009218

Morelli JP, Bunting RJ, Cowley SWH, Farrugia CJ, Freeman MP, Friis-Christensen E, Jones GOL, Lester M, Lewis RV, Lühr H, Orr D, Pinnock M, Reeves GD, Williams PJS, Yeoman TK (1995) Radar observations of auroral zone flows during a multiple-onset substorm. Ann Geophys 13:1144-1163

Nakamura R, Amm O, Laakso H, Draper, N C, Lester M, Grocott A, Klecker B, McCrea IW, Balogh A, Reme H, Andre M (2005) Localized fast flow disturbance observed in the plasma sheet and in the ionosphere. Ann Geophys 23:553-566

Neudegg DA, Yeoman TK, Cowley SWH, Provan G, Haerendel G, Baumjohann W, Auster U, Fornacon KH, Georgescu E, Owen CJ (1999) A flux transfer event observed at the magnetopause by the Equator-S spacecraft and in the ionosphere by the CUTLASS HF radar. Ann Geophys 17:707-711

Neudegg DA, Cowley SWH, Milan SE, Yeoman TK, Lester M, Provan G, Haerendel G, Baunjohann W, Nikutowski B, Buchner J, Aster U, Fornacon K-H, Georgescu E (2000) A survey of magnetopause FTEs and associated flow bursts in the polar ionosphere. Ann Geophys 18:416-435

Newell PT, Ruohoniemi JM, Meng C-I (2004) Maps of precipitation by source region, binned by IMF, with inertial convection streamlines. J Geophys Res 109:A10206, doi:10.1029/2004JA010499

Nielsen E, Greenwald RA (1979) Electron flow and visual aurora at the Harang discontinuity. J Geophys Res 84:4189-4200

Nielsen E, Guettler W, Thomas EC, Stewart CP, Jones TB, Hedberg A (1983) A new radar auroral backscatter experiment. Nature 304:712-714

Nielsen E, Schlegel K (1985) Coherent radar Doppler measurements and their relationship to the ionospheric electron drift velocity. J Geophys Res 90:3498-3504

Nishitani N, Ogawa T, Pinnock M, Freeman MP, Dudeney JR, Villain J-P, Baker KB, Sato N, Yamagishi H, Matsumoto H (1999) A very large scale flow burst observed by the SuperDARN radars. J Geophys Res 104:22469-22486 
Nishitani N, Ogawa T, Sato N, Yamagishi H, Pinnock M, Villain J-P, Sofko G, Troshichev O (2002) A study of the dusk convection cell's response to an IMF southward turning. J Geophys Res 107:10.1029/ 2001JA900095

Ogawa T, Nishitani N, Sato N, Yamagishi H, Yukimatu AS (2002) Upper mesosphere summer echoes detected with the Antarctic Syowa HF radar. Geophys Res Lett 29:1157, doi:10.1029/2001GL014094

Ogawa T, Arnold NF, Kirkwood S, Nishitani N, Lester M (2003) Finland HF and Esrange MST radar observations of polar mesosphere summer echoes. Ann Geophys 21:1047-1055

Oksavik K, Moen J, Carlson HC, Greenwald RA, Milan SE, Lester M, Denig WF, Barnes RJ (2005) Multiinstrument mapping of the small-scale flow dynamics related to a cusp auroral transient. Ann Geophys 23:2657-2670

Oksavik K, Greenwald RA, Ruohoniemi JM, Hairston MR, Paxton LJ, Baker JBH, Gjerloev JW, Barnes RJ (2006) First observations of the temporal/spatial variation of the sub-auroral polarization stream from the SuperDARN Wallops HF radar. Geophys Res Lett 33:L12104, doi:10.1029/2006GL026256

Opgenoorth HJ, Oksman J, Kaila KU, Nielsen E, Baumjohann W (1983) Characteristics of eastward drifting omega bands in the morning sector of the auroral oval. J Geophys Res 88:9171-9185

Opgenoorth HJ, Pellinen RJ (1998) The reaction of the global convection electrojets to the onset and expansion of the substorm current wedge. In: Kokobun S, Kamide Y (eds) Substorms-4. Terra Sci Publ Co, Tokyo, pp 663-668

Ossakow SL, Chataverdi PK (1979) Current convective instability in the diffuse aurora. Geophys Res Lett 6:332-334

Palmroth M, Janhunen P, Pulkkinen TI, Aksnes A, Lu G, Østgaard N, Watermann J, Reeves GD, Germany GA (2005) Assessment of ionospheric Joule heating by GUMICS-4 MHD simulation, AMIE, and satellite-based statistics: towards a synthesis. Ann Geophys 23:2051-2068

Papitashvili VO, Belov BA, Faermark DS, Feldstein YI, Golyshev SA, Gromova LI, Levitin AE (1994) Electric-potential patterns in the northern and southern polar-regions paramaterized by the interplanetary magnetic field. J Geophys Res 99:13251-13262

Parkinson ML, Dyson PL, Pinnock M, Devlin JC, Hairston MR, Yizengaw E, Wilkinson PJ (2002) Signatures of the midnight open-closed magnetic field line boundary during balanced dayside and nightside reconnection. Ann Geophys 20:1617-1630

Parkinson ML, Pinnock M, Dyson PL, Ye H, Devlin JC, Hairston MR (2003) On the lifetime and extent of an auroral westward flow channel observed during a magnetospheric substorm. Ann Geophys 21: 893-913

Parkinson ML, Pinnock M, Wild JA, Lester M, Yeoman TK, Milan SE, Ye H, Devlin JC, Frey HU, Kikuchi $\mathrm{T}$ (2005) Interhemispheric asymmetries in the occurrence of magnetically conjugate sub-auroral polarisation streams. Ann Geophys 23:1371-1390

Parkinson ML (2006) Dynamical critical scaling of electric field fluctuations in the greater cusp and magnetotail implied by HF radar observations of $F$-region Doppler velocity. Ann Geophys 24:689-705

Phan TD, Kistler LM, Klecker B, Haerendel G, Paschmann G, Sonnerup BUO, Baumjohann W, BavassanoCattaneo MB, Carlson CW, Dilellis AM, Fornacon KH, Frank LA, Fujimoto M, Georgescu E, Kokubun S, Moebius E, Mukai T, Oieroset M, Paterson WR, Reme H (2000) Extended magnetic reconnection at the Earth's magnetopause from detection of bi-directional jets. Nature 404:848-850

Pinnock M, Rodger AS, Dudeney JR, Greenwald RA, Baker KB, Ruohoniemi JM (1991) An ionospheric signature of possible enhanced magnetic field merging on the dayside magnetopause. J Atmos Terr Phys 53:201-212

Pinnock M, Rodger AS, Dudeney JR, Baker KB, Newell PT, Greenwald RA, and Greenspan ME (1993) Observations of an enhanced convection channel in the cusp ionosphere. J Geophys Res 98:3767-3776

Pinnock M, Rodger AS, Dudeney JR, Rich F, Baker K (1995) High spatial and temporal observations of the ionospheric cusp. Ann Geophys 13:919-925

Pinnock M, Rodger AS, Baker KB, Lu G, Hairston M (1999) Conjugate observations of the day-side reconnection electric field: a GEM boundary layer campaign. Ann Geophys 17:443-454

Pinnock M, Chisham G, Coleman IJ, Freeman MP, Hairston M, Villain J-P (2003) The location and rate of dayside reconnection during an interval of southward interplanetary magnetic field. Ann Geophys 21:1467-1482

Ponomarenko PV, Waters CL (2003) The role of Pc1-2 waves in spectral broadening of SuperDARN echoes from high latitudes. Geophys Res Lett 30:1122, doi:10.1029/2002GL016333

Ponomarenko PV, Menk FW, Waters CL (2003) Visualization of ULF waves in SuperDARN data. Geophys Res Lett 30:1926, doi:10.1029/2003GL017757

Ponomarenko P V, Menk FW, Waters CL, Sciffer MD (2005) Pc3-4 ULF waves observed by the SuperDARN TIGER radar. Ann Geophys 23:1271-1280 
Ponomarenko PV and Waters CL (2006) Spectral width of SuperDARN echoes: measurement, use and physical interpretation. Ann Geophys 24:115-128

Prikryl P, Greenwald RA, Sofko GJ, Villain J-P, Ziesolleck CWS, Friis-Christensen E (1998) Solar-wind driven pulsed magnetic reconnection at the dayside magnetopause, Pc5 compressional oscillations, and field line resonances. J Geophys Res 103:17307-17322

Prikryl P, MacDougall JW, Grant IF, Steele DP, Sofko GJ, Greenwald RA (1999) Observations of polar patches generated by solar wind Alfvén wave coupling to the dayside magnetosphere. Ann Geophys 17:463-489

Prikryl P, Provan G, McWilliams KA, Yeoman TK (2002) Ionospheric cusp flows pulsed by solar wind Alfvén waves. Ann Geophys 20:161-174

Provan G, Yeoman TK, Milan SE (1998) CUTLASS Finland radar observations of the ionospheric signatures of flux transfer events and the resulting plasma flows. Ann Geophys 16:1411-1422

Provan G, Yeoman TK (1999) Statistical observations of the MLT, latitude and size of pulsed ionospheric flows with the CUTLASS Finland radar. Ann Geophys 17:855-867

Provan G, Yeoman TK, Cowley SWH (1999) The influence of the IMF $B_{y}$ component on the location of pulsed flows in the dayside ionosphere observed by an HF radar. Geophys Res Lett 26:521-524

Provan G, Yeoman TK, Milan SE, Ruohoniemi JM, Barnes R (2002) An assessment of the "map-potential", and "beam-swinging"' techniques for measuring the ionospheric convection pattern using data from the SuperDARN radars. Ann Geophys 20:191-202

Provan G, Lester M, Mende SB, Milan SE (2004) Statistical study of high-latitude plasma flow during magnetospheric substorms. Ann Geophys 22:3607-3624

Provan G, Lester M, Cowley SWH, Grocott A, Milan SE, Hubert B, Khan H (2005) Modulation of dayside reconnection during northward interplanetary magnetic field. J Geophys Res 110:A10211, doi:10.1029/ 2004JA010980

Rae IJ, Fenrich FR, Lester M, McWilliams KA, Scudder JD (2004) Solar wind modulation of cusp particle signatures and their associated ionospheric flows. J Geophys Res 109:A03223, doi:10.1029/ 2003JA010188

Rapp M, Lübken F-J (2004) Polar mesosphere summer echoes (PMSE): review of observations and current understanding. Atmos Chem Phys 4:2601-2633

Reiff PH, Spiro RW, Hill TW (1981) Dependence of polar cap potential drop on interplanetary parameters. J Geophys Res 86:7639-7648

Reiff PH, Burch JL (1985) IMF $B_{y}$-dependent plasma flow and Birkeland currents in the dayside magnetosphere, 2, A global model for northward and southward IMF. J Geophys Res 90:1595-1609

Rich FJ, Hairston M (1994) Large-scale convection patterns observed by DMSP. J Geophys Res 99: 3827-3844

Richmond AD, Kamide Y (1988) Mapping electrodynamic features of the high-latitude ionosphere from localized observations: technique. J Geophys Res 93:5741-5759

Ridley AJ, Lu G, Clauer CR, Papitashvili VO (1997) Ionospheric convection during nonsteady interplanetary magnetic field conditions. J Geophys Res 102:14563-14579

Rietveld MT, Kohl H, Kopka H, Stubbe P (1993) Introduction to ionospheric heating at Troms $\varnothing-$ I. Experimental overview. J Atmos Terr Phys 55:577-599

Rijnbeek RP, Cowley SWH, Southwood DJ, Russell CT (1984) A survey of dayside flux transfer events observed by ISEE 1 and 2 magnetometers. J Geophys Res 89:786-800

Robinson RM, Vondrak RR, Miller K, Dabbs T, Hardy D (1987) On calculating ionospheric conductances from the flux and energy of precipitating electrons. J Geophys Res 92:2565-2569

Rodger AS, Mende SB, Rosenberg TJ, Baker KB (1995) Simultaneous optical and HF radar observations of the ionospheric cusp. Geophys Res Lett 22:2045-2048

Rodger AS, Pinnock M (1997) The ionospheric response to flux transfer events: the first few minutes. Ann Geophys 15:685-691

Ruohoniemi JM, Greenwald RA, Baker KB, Villain J-P, McCready MA (1987) Drift motions of small-scale irregularities in the high-latitude F region: an experimental comparison with plasma drift motions. J Geophys Res 92:4553-4564

Ruohoniemi JM, Greenwald RA, Villain J-P, Baker KB, Newell PT, Meng C-I (1988) Coherent HF radar backscatter from small-scale irregularities in the dusk sector of the subauroral ionosphere. J Geophys Res 93:12871-12882

Ruohoniemi JM, Greenwald RA, Baker KB, Villain J-P, Hanuise C, Kelly J (1989) Mapping high-latitude plasma convection with coherent HF radars. J Geophys Res 94:13463-13477

Ruohoniemi JM, Greenwald RA, Baker KB, Samson JC (1990) Goose Bay radar observations of Earth-reflected gravity waves in the high-latitude ionosphere. In: Goodman J (ed) The effect of the 
ionosphere on radiowave signals and system performance, proceedings of the ionospheric effects symposium

Ruohoniemi JM, Greenwald RA, Baker KB, Samson JC (1991) HF radar observations of Pc-5 field line resonances in the midnight early morning MLT sector. J Geophys Res 96:15697-15710

Ruohoniemi JM, Greenwald RA (1995) Observations of IMF and seasonal effects in high-latitude convection. Geophys Res Lett 22:1121-1124

Ruohoniemi JM, Greenwald RA (1996) Statistical patterns of high-latitude convection obtained from Goose Bay HF radar observations. J Geophys Res 101:21743-21763

Ruohoniemi JM, Baker KB (1998) Large-scale imaging of high-latitude convection with Super Dual Auroral Radar Network HF radar observations. J Geophys Res 103:20797-20811

Ruohoniemi JM, Greenwald RA (1998) The response of high-latitude convection to a sudden southward IMF turning. Geophys Res Lett 25:2913-2916

Ruohoniemi JM, Barnes RJ, Greenwald RA, Shepherd SG (2001) The response of the high-latitude ionosphere to the coronal mass ejection event of April 6, 2000: a practical demonstration of space weather nowcasting with the Super Dual Auroral Radar Network HF radars. J Geophys Res 106:30085-30097

Ruohoniemi JM, Greenwald RA (2005) Dependencies of high-latitude plasma convection: consideration of interplanetary magnetic field, seasonal, and universal time factors in statistical patterns. J Geophys Res 110:A09204, doi:10.1029/2004JA010815

Russell CT (1972) The configuration of the magnetosphere. In: Dyer R (ed) Critical problems of magnetospheric physics. Nat Acad Sci, Washington, DC, pp 1-16

Russell CT, Elphic RC (1978) Initial ISEE magnetometer results: magnetopause observations. Space Sci Rev 22:681-715

Russell CT, Elphic RC (1979) ISEE observations of flux transfer events at the dayside magnetopause. Geophys Res Lett 6:33-36

Sahr JD, Fejer BG (1996) Auroral electrojet plasma irregularity theory and experiment: a critical review of present understanding and future directions. J Geophys Res 101:26893-26909

StMaurice J-P, Prikryl P, Danskin DW, Hamza AM, Sofko GJ, Koehler JA, Kustov A, Chen J (1994) On the origin of narrow non-ion-acoustic coherent radar spectra in the high-latitude E region. J Geophys Res 99:6447-6474

Samson JC, Greenwald RA, Ruohoniemi JM, Baker KB (1989) High-frequency radar observations of atmospheric gravity waves in the high-latitude ionosphere. Geophys Res Lett 16:875-878

Samson JC, Greenwald RA, Ruohoniemi JM, Frey A, Baker KB (1990) Goose Bay radar observations of Earth-reflected gravity waves in the high-latitude ionosphere. J Geophys Res 95:7693-7709

Samson JC, Hughes TJ, Creutzberg F, Wallis DD, Greenwald RA, Ruohoniemi JM (1991) Observations of a detached, discrete arc in association with field line resonances. J Geophys Res 96:15683-15695

Sandholt PE, Deehr CS, Egeland A, Lybekk B, Viereck R, Romick GJ (1986) Signatures in the dayside aurora of plasma transfer from the magnetosheath. J Geophys Res 91:10063-10079

Sandholt PE, Moen J, Opsvik D (1992) Periodic auroral events at the midday polar cap boundary: implications for solar wind-magnetosphere coupling. Geophys Res Lett 19:1223-1226

Sandholt PE, Farrugia CJ, Moen J, Cowley SWH (1998a) Dayside auroral configurations: responses to southward and northward rotations of the interplanetary magnetic field. J Geophys Res 103:2027920295

Sandholt PE, Farrugia CJ, Moen J, Noraberg Ø, Lybekk B, Sten T, and Hansen T (1998b) A classification of dayside auroral forms and activities as a function of IMF orientation. J Geophys Res 103:23325-23346

Sandholt PE, Farrugia CJ (2001) Multipoint observations of substorm intensifications: the high-latitude aurora and electron injections in the inner equatorial plasmasheet. Geophys Res Lett 28:483-486

Sandholt PE, Farrugia CJ, Lester M, Cowley SWH, Milan S, Denig WF, Lybekk B, Trondsen E, Vorobjev V (2002) Multi-stage substorm expansion: auroral dynamics in relation to plasma sheet particle injection, precipitation, plasma convection. J Geophys Res 107:1342, doi:10.1029/2001JA900116

Saunders MA, Freeman MP, Southwood DJ, Cowley SWH, Lockwood M, Samson JC, Farrugia CJ, Hughes TJ (1992) Dayside ionospheric convection changes in response to long period IMF oscillations: determination of the ionospheric phase velocity. J Geophys Res 97:19373-19380

Schiffler A, Sofko G, Newell PT, Greenwald RA (1997) Mapping the outer LLBL with SuperDARN doublepeaked spectra. Geophys Res Lett 24:3149-3152

Senior C, Cerisier, J-C, Rich F, Lester M, Parks GK (2002) Strong sunward propagating flow bursts in the night sector during quiet solar wind conditions: SuperDARN and satellite observations. Ann Geophys 20:771-779

Shepherd SG, Greenwald RA, Ruohoniemi JM (1999) A possible explanation for rapid, large-scale ionospheric responses to southward turnings of the IMF. Geophys Res Lett 26:3197-3200 
Shepherd SG, Ruohoniemi J (2000) Electrostatic potential patterns in the high-latitude ionosphere constrained by SuperDARN measurements. J Geophys Res 105:23005-23014

Siscoe GL, Huang TS (1985) Polar cap inflation and deflation. J Geophys Res 90:543-547

Sofko GJ, Greenwald RA, Bristow W (1995) Direct determination of large-scale magnetospheric fieldaligned currents with SuperDARN. Geophys Res Lett 22:2041-2044

Sofko GJ, Huang C-S (2000) SuperDARN observations of medium-scale gravity wave pairs generated by Joule heating in the auroral zone. Geophys Res Lett 27:485-488

Southwood DJ (1976) A general approach to low-frequency instability in the ring current plasma. J Geophys Res 81:3340-3348

Southwood DJ, Dungey JW, Etherington RJ (1969) Bounce resonant interaction between pulsations and trapped particles. Planet Space Sci 17:349-362

Spiro RW, Heelis RA, Hanson WB (1979) Rapid subauroral ion drifts observed by Atmospheric Explorer C. Geophys Res Lett 6:660-663

Stephenson J A E, Walker ADM (2002) HF radar observations of Pc5 ULF pulsations driven by the solar wind. Geophys Res Lett 29:1297, doi:10.1029/2001GL014291

Stocker AJ, Arnold NF, Jones TB (2000) The synthesis of travelling ionospheric disturbance (TID) signatures in HF radar observations using ray tracing. Ann Geophys 18:56-64

Sutcliffe PR (1998) Observations of Pi2 pulsations in a near ground state magnetosphere. Geophys Res Lett 25:4067-4070

Taylor JR, Cowley SWH, Yeoman TK, Lester M, Jones TB, Greenwald RA, Sofko G, Villain J-P, Lepping RP, Hairston MR (1998) SuperDARN studies of the ionospheric convection response to a northward turning of the interplanetary magnetic field. Ann Geophys 16:549-565

Thorolfsson A, Cerisier J-C, Lockwood M, Sandholt PE, Senior C, Lester M (2000) Simultaneous optical and radar signatures of poleward-moving auroral forms. Ann Geophys 18:1054-1066

Thorolfsson A, Cerisier J-C, Pinnock M (2001) Flow transients in the postnoon ionosphere: the role of solar wind dynamic pressure. J Geophys Res 106:1887-1901

Todd H, Cowley SWH, Lockwood M, Willis DM, Luhr H (1988) Response time of the high latitude dayside ionosphere to sudden changes in the north-south component of the IMF. Planet Space Sci 36: 1415-1428

Trattner KJ, Fuselier SA, Yeoman TK, Korth A, Fraenz M, Mouikis C, Kucharek H, Kistler LM, Escoubet CP, Rème H, Dandouras I, Sauvaud JA, Bosqued JM, Klecker B, Carlson C, Phan T, McFadden JP, Amata E, Eliasson L (2003) Cusp structures: combining multi-spacecraft observations with groundbased observations. Ann Geophys 21:2031-2041

Trattner KJ, Fuselier SA, Petrinec SM (2004) Location of the reconnection line for northward interplanetary magnetic field. J Geophys Res 109:A03219, doi:10.1029/2003JA009975

Trattner KJ, Fuselier SA, Petrinec SM, Yeoman TK, Mouikis C, Kucharek H, Reme H (2005) Reconnection sites of spatial cusp structures. J Geophys Res 110:A04207, doi:10.1029/2004JA010722

Tsunoda RT (1988) High-latitude F-region irregularities: a review and synthesis. Rev Geophys 26:719-760

Uspensky MV, Koustov AV, Eglitis P, Huuskonen A, Milan SE, Pulkkinen T, Pirjola R (2001) CUTLASS HF radar observations of high-velocity E-region echoes. Ann Geophys 19:411-424

Uspensky MV, Kustov AV, Sofko GJ, Koehler JA, Villain J-P, Hanuise C, Ruohoniemi JM, Williams PJS (1994) Ionospheric refraction effects in slant range profiles or auroral HF coherent echoes. Radio Sci 29:503-517

Van Zandt TE (1982) A universal spectrum of buoyancy waves in the atmosphere. Geophys Res Lett 9: $575-578$

Villain J-P, Hanuise C, Caudal G (1985) A SAFARI-EISCAT comparison between the velocity of F region small-scale irregularities and the ion drift. J Geophys Res 90:8433-8443

Villain J-P, Greenwald RA, Baker KB, Ruohoniemi JM (1987) HF radar observations of E region plasma irregularities produced by oblique electron streaming. J Geophys Res 92:12327-12342

Villain J-P, Hanuise C, Greenwald RA, Baker KB, Ruohoniemi JM (1990) Obliquely propagating ion acoustic waves in the auroral $\mathrm{E}$ region: further evidence of irregularity production by field-aligned electron streaming. J Geophys Res 95:7833-7846

Villain J-P, André R, Hanuise C, Grésillon D (1996) Observation of the high latitude ionosphere by HF radars: interpretation in terms of collective wave scattering and characterization of turbulence. $\mathrm{J}$ Atmos Terr Phys 58:943-958

Villain J-P, André R, Pinnock M, Greenwald RA, Hanuise C (2002) A statistical study of the Doppler spectral width of high-latitude ionospheric F-region echoes recorded with SuperDARN coherent HF radars. Ann Geophys 20:1769-1781

Vontrat-Reberac A, Cerisier J-C, Sato N, Lester M (2002) Noon ionospheric signatures of a sudden commencement following a solar wind pressure pulse. Ann Geophys 20:639-645 
Voronkov I, Friedrich E, Samson JC (1999) Dynamics of the substorm growth phase as observed using CANOPUS and SuperDARN instruments. J Geophys Res 104:28491-28505

Walker ADM, Greenwald RA, Stuart WF, Green CA (1979) Stare auroral radar observations of Pc5 geomagnetic pulsations. J Geophys Res 84:3373-3388

Walker ADM, Ruohoniemi JM, Baker KB, Greenwald RA, Samson JC (1992) Spatial and temporal behaviour of ULF pulsations observed by the Goose Bay HF radar. J Geophys Res 97:12187-12202

Walker ADM, Pinnock M, Baker KB, Dudeney JR, Rash JPS (1998) Strong flow bursts in the nightside ionosphere during extremely quiet solar wind conditions. Geophys Res Lett 25:881-884

Walker ADM, Baker KB, Pinnock M, Dudeney JR, Rash JPS (2002) Radar observations of magnetospheric activity during extremely quiet solar wind conditions. J Geophys Res 107:1038 doi:10.1029/ 2001JA000063

Watanabe M, Pinnock M, Rodger AS, Sato N, Yamagishi H, Yukimatu AS, Greenwald RA, Villain J-P, Hairston MR (1998) Localized activation of the distant tail neutral line just prior to substorm onsets. J Geophys Res 103:17651-17669

Waters CL, Anderson BJ, Greenwald RA, Barnes RJ, Ruohoniemi JM (2004) High-latitude poynting flux from combined Iridium and SuperDARN data. Ann Geophys 22:2861-2875

Weimer DR (1995) Models of high-latitude electric potentials derived with a least error fit of spherical harmonic coefficients. J Geophys Res 100:19595-19608

Wild JA, Cowley SWH, Davies JA, Khan H, Lester M, Milan SE, Provan G, Yeoman TK, Balogh A, Dunlop MW, Fornacon K-H, Georgescu E (2001) First simultaneous observations of flux transfer events at the high-latitude magnetopause by the Cluster spacecraft and pulsed radar signatures in the conjugate ionosphere by the CUTLASS and EISCAT radars. Ann Geophys 19:1491-1508

Wild JA, Milan SE, Cowley SWH, Dunlop MW, Owen CJ, Bosqued JM, Taylor MGGT, Davies JA, Lester M, Sato N, Yukimatu AS, Fazakerley AN, Balogh A, Rème H (2003) Coordinated interhemispheric SuperDARN radar observations of the ionospheric response to flux transfer events observed by the Cluster spacecraft at the high-latitude magnetopause. Ann Geophys 21:1807-1826

Woodfield EE, Davies JA, Eglitis P, Lester M (2002a) A case study of HF radar spectral width in the post midnight magnetic local time sector and its relationship to the polar cap boundary. Ann Geophys 20:501-509

Woodfield EE, Davies JA, Lester M, Yeoman TK, Eglitis P, Lockwood M (2002b) Nightside studies of coherent HF radar spectral width behaviour. Ann Geophys 20:1399-1413

Woodfield EE, Hosokawa K, Milan SE, Sato N, Lester M (2002c) An inter-hemispheric, statistical study of nightside spectral width distributions from coherent HF scatter radars. Ann Geophys 20:1921-1934

Wright DM, Yeoman TK (1999) High resolution bistatic radar observations of ULF waves in artificially generated backscatter. Geophys Res Lett 26:2825-2828

Wright DM, Davies JA, Robinson TR, Chapman PJ, Yeoman TK, Thomas EC, Lester M, Cowley SWH, Stocker AJ, Horne RB, Honary F (2000) Space Plasma Exploration by Active Radar (SPEAR): an overview of a future radar facility. Ann Geophys 18:1248-1255

Wright DM, Yeoman TK, Baddeley LJ, Davies JA, Dhillon R, Lester M, Milan SE, Woodfield EE (2004) High resolution observations of spectral width features associated with ULF wave signatures in artificial HF radar backscatter. Ann Geophys 22:169-182

Xu L, Koustov AV, Thayer J, McCready MA (2001) SuperDARN convection and Sondrestrom plasma drift. Ann Geophys 19:749-759

Yeoman TK, Lühr H (1997) CUTLASS/IMAGE observations of high-latitude convection features during substorms. Ann Geophys 15:692-702

Yeoman TK, Lester M, Cowley SWH, Milan SE, Moen J, Sandholt PE (1997a) Simultaneous observations of the cusp in optical, DMSP and HF radar data. Geophys Res Lett 24:2251-2254

Yeoman TK, Wright DM, Robinson TR, Davies JA, Rietveld MT (1997b) High spatial and temporal resolution observations of an impulse-driven field line resonance in radar backscatter artificially generated with the Troms $\varnothing$ heater. Ann Geophys 15:634-644

Yeoman TK, Lewis RV, Milan SE, Watanabe M (1999) An interhemispheric study of the ground magnetic and ionospheric electric fields during the substorm growth phase and expansion phase onset. J Geophys Res 104:14867-14877

Yeoman TK, Davies JA, Wade NM, Provan G, Milan SE (2000) Combined CUTLASS, EISCAT and ESR observations of ionospheric plasma flows at the onset of an isolated substorm. Ann Geophys 18: 1073-1087

Yeoman TK and Wright DM (2001) ULF waves with drift resonance and drift-bounce resonance energy sources as observed in artificially-induced HF radar backscatter. Ann Geophys 19:159-170 